\title{
Infrared Spectra of Sugar Acetates in Solution
}

\author{
Horace S. Isbell, Francis A. Smith, E. Carroll Creitz, Harriet L. Frush, Joseph D. Moyer, \\ and James E. Stewart
}

\begin{abstract}
Infrared absorption spectra are reported for a group of structurally and configurationally related carbohydrate derivatives. The conformation of the pyranose ring and other structural features of the compounds are discussed in relation to the spectra. Most of the absorption that is characteristic of the cyclic carbohydrate structure occurs in the region of 8.4 to $15 \mu$. Although the spectra are complex and difficult to interpret, they show features from which a number of provisional conclusions have been drawn.

It was found that fully acetylated monosaccharides with an axial glycosidic acetate group give a moderately strong absorption band at $8.63 \pm 0.04 \mu$, and at most a weak band at $8.87 \pm 0.06 \mu$; whereas compounds having an equatorial glycosidic acetate group absorb weakly at $8.63 \mu$, and give a moderately strong band at $8.87 \mu$. The spectra for the acetates having the gulo-, ido-, or talo-configurations appear to indicate the presence of the $\mathrm{C}^{\prime} 2$, or less common chair conformation, or a mixture of conformations.

Acetylated methyl glycosides with the methoxyl group in the axial position give characteristic absorption at $8.33 \pm 0.02 \mu$ and at $8.80 \pm 0.05 \mu$; none of the compounds with the methoxyl group in the equatorial position shows absorption in these regions. Absorption at $8.80 \mu$ is enhanced further by the presence of axial acetyl groups on the ring. On the basis of this generalization, an acetylated methyl glycoside with the $\beta$-gulo structure gives evidence for the presence of the $\mathrm{C}^{\prime} 2$ conformation.

Overlapping bands in the region of 8.0 to $8.2 \mu$ arise from acetyl groups of diverse character, with the result that spectra in this region show characteristic features for some compounds. Thus the pyranose acetates of the pentoses and of rhamnose give a sharp, well-defined band at $8.0 \mu$, but the acetates of the hexoses and higher sugars give a poorly defined band that seems to include an overlapping component with a maximum at higher wavelength. This characteristic may serve to distinguish acetates that do, or do not, have a primary acetyl group.
\end{abstract}

\section{Scope and Purpose of the Project}

This project was undertaken with the object of providing infrared spectrograms of an extensive group of carbohydrates and carbohydrate derivatives, for the purpose of discovering correlations that might be of value in structural analysis. It was particularly desired to obtain information concerning the conformation of the pyranose ring. For this reason, the study has included some rare configurations that might exist in unusual conformations.

Spectrograms of crystalline materials suspended in mineral oil, or in a pellet of an alkali metal halide, differ from spectrograms of the same material dissolved in a solvent, or cast in an amorphous film. The differences arise from the presence or absence of intercrystalline forces, hydrogen bridging, intermolecular combinations, intramolecular steric effects, and other factors. By a study of the infrared absorption of materials both in the crystalline state and in solution, changes in ring conformation, hydrogen bridging, and other properties can be detected [1]. ${ }^{2}$ Infrared absorption spectra are reported in this paper for compounds dissolved in suitable solvents, whereas absorption spectra for the same compounds and many others in pellets of an alkali metal halide will be reported separately. ${ }^{3}$

1 This paper is based on work supported by the Chemistry Branch of the Office of Naval Research, done under contract No. NR055208.

2 Figures in brackets indicate the literature references at the end of this paper. The references for table 2 are given at the end of the table.

While the work was in progress, several papers appeared that presented infrared absorption spectra of some of the carbohydrate derivatives reported here $[2$ to 6$]$. However, none of the compounds was studied under the conditions of the present project.
Comparison of these ultimately will be used to detect possible changes in conformation with change in state.

The use of infrared absorption spectra for structural studies depends on absorption bands that can be correlated either directly or indirectly with definite structures. The presence or absence of the characteristic absorption, in an unknown subtance, is then taken as evidence for the presence or absence of the structure in question. The position and intensity of the absorption bands produced by each atomic linkage vary somewhat with structure. Hence the spectra of many compounds of known structure must be mapped before the method can be used to study unknown structures. The reliability of the structural assignments increases with the accumulation of spectra for substances of known structure that confirm the assignment $[7,8]$.

\section{Ring Conformation}

Interpretation of the infrared spectra of the carbohydrates requires consideration not only of structure and configuration but also of ring conformation, or shape. The presence of large groups in axial positions, bridged groups, fused rings, eclipsed atoms, and other types of steric hindrance make some conformations less stable than others. Ordinarily, large groups tend to take equatorial positions and thus greatly influence ring conformation [9]. In most cases, the pyranose ring assumes 1 of 2 chair conformations in which carbons $1,2,4$, and 5 lie in one plane, and carbon 3 and the ring oxygen lie outside of the plane in the trans position [10]. 
The two conformations differ in that carbon 3 and the ring oxygen are trans to each other in the opposite sense. This difference causes the axial groups of one conformation to be the equatorial groups of the other, and vice versa. In order to facilitate comparison of the spectra of carbohydrate derivatives, a system of classification has been devised in which these conformations are designated $\mathrm{C}^{\prime} 1$ and $\mathrm{C}^{\prime} 2$ [11]. The normal, or $\mathrm{C}^{\prime} 1$, conformation has the reference group ${ }^{4}$ at carbon 5 in the equatorial position, and the $\mathrm{C}^{\prime} 2$ conformation has this group in the axial position. ${ }^{5}$ The positions of the reference groups in the two conformations are listed in table 1. In contrast to the classification of Reeves [10], this svstem has the advantage of classifying in the same group, in both $\mathrm{D}$ and $\mathrm{L}$ series, that conformation having the same equatorial and axial arrangement of groups. The relationship to the Reeves classification is:

\begin{tabular}{ccc} 
Isbell nomenclature & \multicolumn{2}{c}{ Reeves nomenclature } \\
D- or L-hexose & D-hexose & L-hexose \\
$\mathrm{C}^{\prime} 1$ & $\mathrm{C} 1$ & $1 \mathrm{C}$ \\
$\mathrm{C}^{\prime} 2$ & $1 \mathrm{C}$ & $\mathrm{C} 1$
\end{tabular}

TABLE 1. Positions of reference groups in pyranose structures a

\begin{tabular}{|c|c|c|c|c|c|}
\hline \multirow[b]{2}{*}{ Code } & \multicolumn{2}{|c|}{$\mathrm{C}^{\prime} 1$ conformation } & \multirow[b]{2}{*}{ Code } & \multicolumn{2}{|c|}{$\mathrm{C}^{\prime} 2$ conformation } \\
\hline & Configuration & $\begin{array}{c}\text { Position of } \\
\text { reference } \\
\text { groups }\end{array}$ & & Configuration & $\begin{array}{c}\text { Position o } \\
\text { reference } \\
\text { groups }\end{array}$ \\
\hline . -11 & $\alpha-g l u c o$ & a e e e & .-53 & $\beta$-ido & a e e e a \\
\hline .12 & $\beta$-gluco & e e e e &.-54 & $\alpha$-ido & e e e a \\
\hline.-21 & $\alpha$-manno & a a e e & -63 & $\boldsymbol{\beta}$-gulo & a a e e a \\
\hline.-22 & $\beta$-manno & e a e e &.-64 & $\alpha$-gulo & e a e a \\
\hline.-31 & $\alpha$-galacto & a e e a e & . -73 & $\beta$-altro & $\mathrm{a}$ e e a a \\
\hline . -32 & $\beta$-galacto & e e e a e &.-74 & $\alpha$-altro & e e a a \\
\hline . -41 & $\alpha$-talo & a a e a &.-83 & $\beta$-allo & a a e a a \\
\hline . -42 & $\beta$-talo & e a e e & -84 & $\alpha$-allo & e a e a a \\
\hline .-51 & $\alpha$-ido & a a a a $\mathrm{e}$ & .13 & $\beta$-gluco & a a a a \\
\hline .52 & $\beta$-ido & ea a a &.-14 & $\alpha-g l u c o$ & e a a a a \\
\hline-61 & $\alpha$-gulo & a e a a e &.-23 & $\beta$-manno & a e a a a \\
\hline.-62 & $\boldsymbol{\beta}$-gulo & e e a e &.-24 & $\alpha$-manno & e e a a \\
\hline .71 & & a a a e e & .-33 & $\beta$-galacto & a a a e a \\
\hline.-72 & $\beta$-altro & e a a e e & .34 & $\alpha$-galacto & e a a e a \\
\hline $\begin{array}{l}.-81 \\
.-82\end{array}$ & $\underset{\beta \text {-allo }}{\alpha}$ & $\begin{array}{l}\text { a e a e e } \\
\text { e e a e }\end{array}$ & $\begin{array}{r}-43 \\
-44\end{array}$ & $\begin{array}{l}\beta \text {-talo } \\
\alpha \text {-talo }\end{array}$ & $\begin{array}{l}\text { ae a e a } \\
\text { eеае a }\end{array}$ \\
\hline & & & & & \\
\hline
\end{tabular}

\& Axial and equatorial positions for reference groups of the ring are shown consecutively, with increasing carbon number from left to right. Hydrogen atoms occupy the remaining positions.

Table 1 shows that the positions of the reference groups and hydrogen atoms with respect to the ring depend on both configuration and ring conformation. For example, $\alpha$-gulose $\mathrm{C}^{\prime} 1$ (aeaae) differs at all carbons from $\alpha$-gulose $\mathrm{C}^{\prime} 2$ (eaeea), whereas $\alpha$-gulose

\footnotetext{
${ }^{4}$ A reference group is defined as any group, other than hydrogen, that is at tached to the ring structure. Inasmuch as the pentoses and ketohexoses do not have a reference group at carbon 5, this rule is not applicable. However, on the basis of similarities in properties, the pentoses and ketohexoses are classified with the aldohexoses, in both the $\mathrm{C} 1$ and $\mathrm{C} 2$ conformations, as follows: xylose and sorbose with glucose, lyxose and tagatose with mannose, arabinose and fructose with galactose, and ribose and psicose with talose

${ }_{5}^{5}$ The symbols $\mathrm{C} 1$ and $1 \mathrm{C}$ have been used extensively to represent the two chair conformations of the pyranose ring. Reeves defines the symbols on the basis of formulas given in his publication [10]. The arrangement of the ringforming atoms in the two conformations are related as object and mirror image, and consequently the conformation designated C1 in the D-pyranose series is 1C in the L-pyranose series. To facilitate comparison of structurally related substances in the D- and L-series, Isbell used the $\mathrm{C} 1$ term in a slightly different sense. Inasmuch as use of the same symbol with different meaning may lead to confusion, hereafter the conformations defined by Isbell [11] will be designated $\mathrm{C}^{\prime} 1$ and $\mathrm{C}^{\prime} 2$.
}

$\mathrm{C}^{\prime} 1$ and $\beta$-mannose $\mathrm{C}^{\prime} 2$ (aeaa) have like axial and equatorial arrangements at all carbons except carbon 5. Furthermore, in the $\mathrm{C}^{\prime} 1$ conformation, the glycosidic group of an alpha hexose or higher sugar is axial, but in the $\mathrm{C}^{\prime} 2$ conformation it is equatorial. Therefore, with regard to the axial and equatorial positions of the glycosidic group only, this relationship makes the alpha $\mathrm{C}^{\prime} 1$ comparable to the beta $\mathrm{C}^{\prime} 2$ derivatives, ${ }^{6}$ and the beta $\mathrm{C}^{\prime} 1$ comparable to the alpha $\mathrm{C}^{\prime} 2$ derivatives. It follows that the axial and equatorial positions of the glycosidic carbon are not definitive of alpha and beta configuration except in a given conformation. These examples show that in rationalizing the reactions and properties of carbohydrate derivatives, configuration and conformation must be considered to be mutually dependent. Because all of the axial groups of one chair conformation are the equatorial groups of the other, then for a substance having a known configuration and a chair conformation, the axial or equatorial position of any specific atom. or group attached to the ring will define the conformation of a pyranose structure.

Classification of the pyranose derivatives only in the $\mathrm{C}^{\prime} 1$ and $\mathrm{C}^{\prime} 2$ groups involves oversimplification. Some of the compounds may exist in mixtures even including boat forms. To interpret the infrared spectra, definite conformations must be assumed. As a working hypothesis, the $\mathrm{C}^{\prime} 1$ conformation is considered as a first choice, the $\mathrm{C}^{\prime} 2$ conformation as a second. Finally, the possibility of various boat conformations must be considered. With provisional assignments, attempts can be made to rationalize the experimental results with the postulated conformations. The method is one of trial and error, but should ultimately lead to the recognition of absorption bands characteristic of the structure of the compounds.

To facilitate comparison, code numbers have been assigned to compounds listed in table 2 by means of the scheme previously published [11]; the codes are suitable for classifying and separating the data by punched-card techniques. Generic classification is obtained by means of only one or two of the digits in the code number, and a more specific classification by use of a sequence of digits following a decimal point. For example, all aldohexose derivatives are characterized by 2 to the right of the decimal point, and all substances having the $\alpha$-glucopyranosyl structure and the $\mathrm{C}^{\prime} 1$ conformation by the sequence .211. For reference purposes, the code numbers are based on a postulated $\mathrm{C}^{\prime} 1$ ring conformation. The usefulness of the system. for study of infrared spectra arises from the ease with which carbohydrate derivatives can be sorted and correlated according to structure, configuration, and ring conformation. A complete analysis of the spectrograms would be beyond the scope of the present report, but certain aspects of the work will be considered briefly in sections 4 and 5 .

${ }^{6}$ The alpha $\mathrm{C}^{\prime} 1$ and the beta $\left\{\mathrm{C}^{\prime} 2\right.$ derivatives of a given pyranose have the glycosidic group in the axial position on the opposites sides of the plane of carbons $1,2,4$, and 5 . 
TABLE 2. Compounds measured and index to spectrograms

\begin{tabular}{|c|c|c|c|c|c|c|c|c|}
\hline \multirow[b]{2}{*}{ Code } & \multirow[b]{2}{*}{ Compound } & \multicolumn{3}{|c|}{ Constants reported } & \multicolumn{3}{|c|}{ Constants found } & \multirow[b]{2}{*}{$\begin{array}{l}\text { Spectro- } \\
\text { gram }\end{array}$} \\
\hline & & $\mathrm{mp}$ & $\begin{array}{l}\text { Specific } \\
\text { rotation a } \\
{[\alpha]_{D}^{20}}\end{array}$ & $\begin{array}{c}\text { Refer- } \\
\text { ence }\end{array}$ & $\mathrm{mp}$ & $\begin{array}{l}\text { Specific } \\
\text { rotation a } \\
{[\alpha]_{D}^{20}}\end{array}$ & $\begin{array}{l}\text { Solubil- } \\
\text { ity in } \\
\mathrm{CCl}_{4}\end{array}$ & \\
\hline \multicolumn{9}{|c|}{ FULLY ACETYLATED MONOSACCHARIDES } \\
\hline $\begin{array}{l}12.11121 \\
12.11221 \\
12.12121 \\
12.13221\end{array}$ & $\begin{array}{l}\text { Tetra- } O \text {-acetyl- } \alpha \text {-D-xylopyranose } \\
\text { Tetra- } O \text {-acetyl- } \beta \text {-D-xylopyranose } \\
\text { Tetra } O \text {-acetyl- } \alpha \text {-D-lyxopyranose } \\
\text { Tetra- } O \text {-acetyl- } \alpha \text {-L-arabinopyranose }\end{array}$ & $\begin{array}{c}{ }^{\circ} C \\
59 \\
128 \\
93 \text { to } 94 \\
97\end{array}$ & $\begin{array}{l}+89.3 \\
-25.1 \\
+25 \\
+42.5\end{array}$ & $\begin{array}{l}1 \\
1 \\
2 \\
3\end{array}$ & $\begin{array}{c}{ }^{\circ} \mathrm{C} \\
59 \text { to } 60 \\
126 \text { to } 127 \\
94 \text { to } 95 \\
96 \text { to } 97\end{array}$ & $\begin{array}{l}+89.8 \\
-25.3 \\
+24.4 \\
+43.1\end{array}$ & $\begin{array}{l}g / 100 \mathrm{ml} \\
\text { v. } \mathrm{s} . \\
\text { 1. } 8 \\
3.4 \\
4.2\end{array}$ & $\begin{array}{l}1 \\
2 \\
3 \\
4\end{array}$ \\
\hline $\begin{array}{l}12.21121 \\
12.21221 \\
12.22121 \\
12.22221 \\
12.23121 \\
12.23221 \\
12.23621 \\
12.26121 \\
12.71121\end{array}$ & 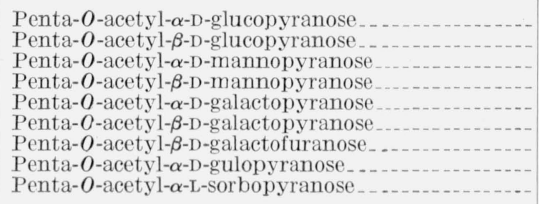 & $\begin{array}{c}114 \\
132 \\
64 \\
117 \text { to } 118 \\
96 \\
142 \\
98 \\
105 \text { to } 106 \\
97\end{array}$ & $\begin{array}{r}+101.2 \\
+3.9 \\
+55.0 \\
-25.2 \\
+106.7 \\
+25 \\
+41.6 \\
+86.2 \\
+56.5\end{array}$ & $\begin{array}{r}4 \\
5 \\
6 \\
7 \\
8 \\
8 \\
9 \\
10 \\
11\end{array}$ & $\begin{array}{l}113 \text { to } 114 \\
132 \text { to } 133 \\
73 \text { to } 74 \\
116 \text { to } 117 \\
96 \text { to } 97 \\
144 \text { to } 145 \\
98 \text { to } 99 \\
105 \text { to } 106 \\
95\end{array}$ & $\begin{array}{r}+101.3 \\
+3.9 \\
+55.0 \\
-25.1 \\
+106.8 \\
+23.3 \\
-42.6 \\
+86.3 \\
-57.3\end{array}$ & $\begin{array}{r}2.5 \\
1.9 \\
21.6 \\
4.7 \\
5.4 \\
0.8 \\
1.9 \\
2.9 \\
2.2\end{array}$ & $\begin{array}{r}5 \\
6 \\
7 \\
8 \\
9 \\
10 \\
11 \\
12 \\
13\end{array}$ \\
\hline $\begin{array}{l}12.33221 \\
12.35221 \\
12.36121 \\
12.36221 \\
12.42121\end{array}$ & $\begin{array}{l}\text { Hexa- } O \text {-acetyl-D-glycero- } \beta \text {-D-gala-heptopyranose } \\
\text { Hexa- } O \text {-acetyl-D-glycero- } \beta \text {-D-ido-heptopyranose- } \\
\text { Hexa- } O \text {-acetyl-D-glycero- } \alpha \text {-D-gulo-heptopyranose--- } \\
\text { Hexa- } O \text {-acetyl-D-glycero- } \beta \text { - }- \text {-gulo-heptopyranose } \\
\text { Hexa- } O \text {-acetyl-D-glycero- } \alpha \text {-L-manno-heptopyranose-- }\end{array}$ & $\begin{array}{l}107 \\
136 \\
164 \\
135\end{array}$ & $\begin{array}{r}+34.1 \\
-9.1 \\
+87.0 \\
+4.8 \\
\end{array}$ & $\begin{array}{l}12 \\
10 \\
13 \\
13 \\
14\end{array}$ & $\begin{array}{l}106 \text { to } 107 \\
135 \text { to } 136 \\
171 \text { to } 172 \\
134 \text { to } 135 \\
132 \text { to } 133\end{array}$ & $\begin{array}{r}+33.8 \\
-8.9 \\
+94.9 \\
+4.4 \\
-25.8\end{array}$ & $\begin{array}{l}3.8 \\
3.5 \\
0.4 \\
6.3 \\
2.9\end{array}$ & $\begin{array}{l}14 \\
15 \\
16 \\
17 \\
18\end{array}$ \\
\hline \multicolumn{9}{|c|}{ FULLY ACETYLATED METHYL GLYCOSIDES } \\
\hline $\begin{array}{l}12.11111 \\
12.11211 \\
12.12111 \\
12.13111\end{array}$ & $\begin{array}{l}\text { Methyl tri- } O \text {-acetyl- } \alpha \text {-D-xylopyranoside } \\
\text { Methyl tri- } O \text {-acetyl- } \beta \text {-D-xylopyranoside- } \\
\text { Methyl tri- } O \text {-acetyl- } \alpha \text {-D-lyxopyranoside } \\
\text { Methyl tri- } O \text {-acetyl- } \beta \text {-L-arabinopyranoside }\end{array}$ & $\begin{array}{r}86 \\
115 \\
96 \\
85\end{array}$ & $\begin{array}{r}+119.6 \\
-60.8 \\
+30.1 \\
+182.0\end{array}$ & $\begin{array}{r}15 \\
16 \\
17 \\
3\end{array}$ & $\begin{array}{c}85 \text { to } 86 \\
115 \text { to } 116 \\
96 \\
85 \text { to } 86\end{array}$ & $\begin{array}{r}+119.5 \\
-61.0 \\
+30.4 \\
+182.1\end{array}$ & $\begin{array}{r}23.3 \\
3.0 \\
20.1 \\
34.7\end{array}$ & $\begin{array}{l}19 \\
20 \\
21 \\
22\end{array}$ \\
\hline $\begin{array}{l}12.21111 \\
12.21211 \\
12.22111 \\
12.22111(6) 80 \\
12.22211 \\
12.22211(6) 80 \\
12.23111 \\
12.23211\end{array}$ & 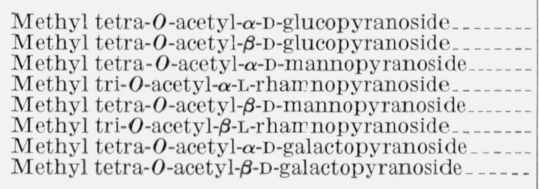 & $\begin{array}{l}100 \text { to } 101 \\
104 \text { to } 105 \\
65 \\
86 \text { to } 87 \\
161 \\
151 \text { to } 152 \\
87 \\
93 \text { to } 94\end{array}$ & $\begin{array}{r}+130.5 \\
-18.2 \\
+49.1 \\
-53.7 \\
-50.4 \\
+45.7 \\
+133.0 \\
-14.0\end{array}$ & $\begin{array}{r}5 \\
5 \\
18 \\
19 \\
20 \\
19 \\
21 \\
21,22\end{array}$ & $\begin{array}{l}102 \text { to } 103 \\
104 \text { to } 105 \\
64 \text { to } 65 \\
88 \text { to } 89 \\
160 \text { to } 161 \\
152 \text { to } 153 \\
86 \text { to } 87 \\
95 \text { to } 96\end{array}$ & $\begin{array}{r}+129.6 \\
-18.2 \\
+48.8 \\
-60.1 \\
-49.4 \\
+45.5 \\
+132.6 \\
-13.9\end{array}$ & $\begin{array}{r}32.7 \\
2.7 \\
53.8 \\
4.5 \\
0.3 \\
-20.7 \\
6.2\end{array}$ & $\begin{array}{l}23 \\
24 \\
25 \\
26 \\
27 \\
28 \\
29 \\
30\end{array}$ \\
\hline 12.36211 & $\begin{array}{l}\text { Methyl penta- } O \text {-acetyl-D-glycero- } \beta \text {-D-gulo-heptopy- } \\
\text { ranoside. }\end{array}$ & 150 & -16.0 & 23 & 153 to 154 & -20.8 & 2.2 & 31 \\
\hline \multicolumn{9}{|c|}{ ACETYLATED METHYL ORTHOACETATES } \\
\hline 12.22263 & $\begin{array}{l}\text { 1,2[3,4,6-Tri- } O \text {-acetyl-D-mannopyranose }] \text { methyl } \\
\text { orthoacetate. }\end{array}$ & 105 & -26.6 & 24 & 105 to 106 & -26.8 & $-\cdots-$ & 32 \\
\hline $12.22263(6) 80$ & $\begin{array}{l}\text { 1,2[3,4-Di- } O \text {-acetyl-L-rhamnopyranose }] \text { methyl } \\
\text { orthoacetate. }\end{array}$ & 83 & +35 & 25 & 86 to 57 & +33.9 & -....- & 33 \\
\hline \multicolumn{9}{|c|}{ ACETYLATED SUGARS WITH FREE GLYCOSIDIC HYDROXYL } \\
\hline $\begin{array}{l}12.2120 \\
12.2210 \\
12.7110\end{array}$ & $\begin{array}{l}\text { 2,3,4,6-Tetra- } O \text {-acetyl- } \beta \text {-D-glucopyranose } \\
2,3,4,6 \text {-Tetra- } O \text {-acetyl- } \alpha \text {-D-mannopyranose } \\
1,3,4,5 \text {-Tetra- } O \text {-acetyl- } \alpha \text {-L-sorbopyranose }\end{array}$ & $\begin{array}{r}138 \\
93 \\
101\end{array}$ & $\begin{array}{r}-3.0 \\
+26.3 \\
-21.3\end{array}$ & $\begin{array}{l}26 \\
27 \\
11\end{array}$ & $\begin{array}{l}137 \text { to } 139 \\
95 \text { to } 96 \\
101 \text { to } 102\end{array}$ & $\begin{array}{r}-1.9 \\
+24.1 \\
-19.8\end{array}$ & $\begin{array}{l}0.05 \\
.2 \\
.7\end{array}$ & $\begin{array}{l}34 \\
35 \\
36\end{array}$ \\
\hline 12.8110 & $1,3,4,5,7$-Penta- $O$-acetyl- $\alpha$-D-glucoheptulopyranose & 114 to 115 & +45.9 & 10 & 114 to 115 & +46.0 & .3 & 37 \\
\hline \multicolumn{9}{|c|}{ ACETYLATED OXO-DERIVATIVES } \\
\hline 12.1360 & Tetra- $O$-acetyl-aldehydo-L-arabinose-_-.- & 113 to 115 & -65.4 & 28 & 113 to 115 & $-\ldots$ & 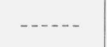 & 38 \\
\hline $\begin{array}{l}12.2360 \\
12.23618\end{array}$ & $\begin{array}{l}\text { Penta- } O \text {-acetyl-aldeh } y d o \text {-D-galactose } \\
\text { Penta- } O \text {-acetyl-aldeh } y d o \text {-D-galactose aldehydrol..-- }\end{array}$ & $\begin{array}{l}120 \text { to } 121 \\
124 \text { to } 126\end{array}$ & $\begin{array}{l}-25 \\
+19.5\end{array}$ & $\begin{array}{r}29 \\
29\end{array}$ & $\begin{array}{l}118 \text { to } 120 \\
126 \text { to } 127\end{array}$ & - n-1-1 & 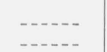 & $\begin{array}{l}39 \\
40\end{array}$ \\
\hline 12.23617 & $\begin{array}{l}\text { Penta-O-acetyl-aldehydo-D-galactose ethyl hemi- } \\
\text { acetal. }\end{array}$ & 133 to 134 & -0.5 & 29 & 134 to 135 & & & 41 \\
\hline $\begin{array}{l}12.7160 \\
12.13645\end{array}$ & $\begin{array}{l}\text { Penta- } O \text {-acetyl-keto-L-sorbose } \\
\text { Tetra- } 0 \text {-acetyl-aldehydo-L-arabinose ethyl mer- } \\
\text { captal. }\end{array}$ & $\begin{array}{c}99 \\
79 \text { to } 80\end{array}$ & $\begin{array}{r}+2.9 \\
-29.9\end{array}$ & $\begin{array}{l}30 \\
28\end{array}$ & $\begin{array}{l}99 \text { to } 100 \\
78 \text { to } 79\end{array}$ & $\begin{array}{r}+2.2 \\
-27.9\end{array}$ & 0.3 & $\begin{array}{l}42 \\
43\end{array}$ \\
\hline 12.23645 & $\begin{array}{l}\text { Penta- } O \text {-acetyl-aldehydo-D-galactose ethyl mer- } \\
\text { captal. }\end{array}$ & 78 & +9.7 & 29 & 80 to 81 & +11.2 & $-\cdots$ & 44 \\
\hline \multicolumn{9}{|c|}{ ACETYLATED POLYOLS } \\
\hline $\begin{array}{l}12.22521 \\
12.25521\end{array}$ & Hexa- $O$-acetyl-D mannitol $\ldots$ & 123 to 124 & $\begin{array}{r}+25.0 \\
+25.3\end{array}$ & 31 & 123 to 124 & +25.0 & 2.1 & 45 \\
\hline $\begin{array}{l}12.25521 \\
12.99821\end{array}$ & $\begin{array}{l}\text { Hexa- } O \text {-acetyl-D-iditol } \\
\text { Hexa-O-acetyl-inositol. }\end{array}$ & $\begin{array}{l}121 \text { to } 122 \\
216\end{array}$ & $\begin{array}{l}+25.3 \\
\text { Inactive }\end{array}$ & $\begin{array}{l}31 \\
32\end{array}$ & $\begin{array}{l}121 \text { to } 122 \\
216 \text { to } 217\end{array}$ & $\begin{array}{l}+25.7 \\
\text { Inactive }\end{array}$ & $\begin{array}{r}0.6 \\
.14\end{array}$ & $\begin{array}{l}46 \\
47\end{array}$ \\
\hline
\end{tabular}


TABLE 2. Compounds measured and index to spectrograms-Continued

\begin{tabular}{|c|c|c|c|c|c|c|c|c|}
\hline \multirow{2}{*}{ Code } & \multirow{2}{*}{ Compound } & \multicolumn{3}{|c|}{ Constants reported } & \multicolumn{3}{|c|}{ Constants found } & \multirow[b]{2}{*}{$\begin{array}{l}\text { Spectro- } \\
\text { gram }\end{array}$} \\
\hline & & $\mathrm{mp}$ & $\begin{array}{l}\text { Specific } \\
\text { rotation a } \\
{[\alpha]_{D}^{20}}\end{array}$ & $\begin{array}{l}\text { Refer- } \\
\text { ence }\end{array}$ & $\mathrm{mp}$ & $\begin{array}{l}\text { Specific } \\
\text { rotation a } \\
\qquad[\alpha]_{D}^{20}\end{array}$ & $\begin{array}{l}\text { Solubil- } \\
\text { ity in } \\
\mathrm{CCl}_{4}\end{array}$ & \\
\hline \multicolumn{9}{|c|}{ FULLY ACETYLATED DISACCHARIDES } \\
\hline $22.211^{*}(1-4) .21221$ & $\begin{array}{l}\text { Octa- } O \text {-acetyl- } \beta \text {-maltose } \\
\text { [Octa- } O \text {-acetyl- } \alpha \text {-D-glucopyranosyl- }(1 \rightarrow 4)-\beta \text {-D- } \\
\text { glucopyranose }\end{array}$ & 159 to 160 & +62.6 & 33 & 161 to 162 & +62.5 & 2.9 & 48 \\
\hline $22.211^{*}(1-1) .211^{*}$ & $\begin{array}{l}\text { Octa- } O \text {-acetyl-trehalose } \\
\text { [Octa- } O \text {-acetyl- } \alpha \text {-D-glucopyranosyl- }(1 \rightarrow 1)-\alpha-\mathrm{D}- \\
\text { glucopyranoside]. }\end{array}$ & 96 to 98 & +162.3 & 1 & 99 to 101 & +162.1 & $-\ldots$ & 49 \\
\hline $22.212^{*}(1-4) .21121$ & $\begin{array}{l}\text { Octa-C }- \text {-acetyl- } \alpha \text {-cellobiose } \\
\text { [Octa- } O \text {-acetyl- } \beta \text {-D-glucopyranosyl- }(1 \rightarrow 4)-\alpha \text {-D- } \\
\text { glucopyranose]. }\end{array}$ & 229 & +41 & 33 & 227 to 228 & +41.7 & 0.03 & 50 \\
\hline $22.212^{*}(1-6) .21221$ & $\begin{array}{l}\text { Octa- } O \text {-acetyl- } \beta \text {-gentiobiose } \\
\text { [Octa- } O \text {-acetyl- } \alpha \text {-D-glucopyranosyl- }(1 \rightarrow 6)-\beta \text {-D- } \\
\text { glucopyranose]. }\end{array}$ & 192 to 193 & -5.3 & 34 & 194 to 195 & -6.0 & .06 & 51 \\
\hline $22.231^{*}(1-6) .21221$ & $\begin{array}{l}\text { Octa- } O \text {-acetyl- } \beta \text {-melibiose } \\
\text { [Octa- } O \text {-acetyl- } \alpha \text {-D-galactopyranosyl- }(1 \rightarrow 6)-\boldsymbol{\beta} \text {-D- } \\
\text { glucopyranose }] \text {. }\end{array}$ & 177 & +102.5 & 35 & 179 to 180 & +102.6 & .14 & 52 \\
\hline $22.232^{*}(1-4) .21121$ & $\begin{array}{l}\text { Octa- } O \text {-acetyl- } \alpha \text {-lactose } \\
\text { [Octa- } O \text {-acetyl- } \beta \text {-D-galactopyranosyl- }(1 \rightarrow 4)-\alpha-\mathrm{D}- \\
\text { glucopyranose]. }\end{array}$ & 152 & +53.6 & 36 & 155 to 156 & +53.4 & 2.9 & 53 \\
\hline $22.232^{*}(1-4) .21221$ & $\begin{array}{l}\text { Octa- } O \text {-acetyl- } \beta \text {-lactose } \\
\text { [Octa- } O \text {-acetyl- } \beta \text {-D-galactopyranosyl- }(1 \rightarrow 4)-\beta \text {-D- } \\
\text { glucopyranose }]\end{array}$ & 90 & -4.7 & 36 & 91 to 93 & -4.8 & 1.4 & 54 \\
\hline $22.232^{*}(1-4) .73521$ & $\begin{array}{l}\text { Octa- } O \text {-acetyl-lactulose } \\
\text { [Octa- } O \text {-acetyl- } \beta \text {-D-galactopyranosyl- }(1 \rightarrow 4)-\beta-\mathrm{D}- \\
\text { fructofuranose]. }\end{array}$ & 138 & -6.6 & 10 & 138 to 139 & -6.5 & 0.2 & 55 \\
\hline $22.211^{*}(1-2) .735^{*}$ & $\begin{array}{l}\text { Octa- } O \text {-acetyl-sucrose } \\
\text { [Octa- } O \text {-acetyl- } \alpha \text {-D-glucopyranosyl- }(1 \rightarrow 2)-\beta \text {-D- } \\
\text { fructofuranoside]. }\end{array}$ & 89 & +59.7 & 37 & 89 to 90 & +60.3 & 3.9 & 56 \\
\hline
\end{tabular}

a In a few cases the temperature reported in the literature differed from that employed at the Bureau. The original literature should be consulted. b Strueture uncertain.

\section{REFERENCES}

1. C. S. Hudson and J. M. Johnson, J. Am. Chem. Soc. 37, 2748 (1915).

2. P. A. Levene and M. L. Wolfrom, J. Biol. Chem. 78, 525 (1928).

3. C. S. Hudson and J. K. Dale, J. Am. Chem. Soc. 40, 992 (1918).

4. A. Georg, Helv. Chim. Acta. 12, 261 (1929).

5. C. S. Hudson and J. K. Dale, J. Am. Chem. Soc. 37, 1264 (1915).

6. C. S. Hudson and J. K. Dale, J. Am. Chem. Soc. 37, 1280 (1915)

7. D. H. Brauns, J. Research NBS $\boldsymbol{\gamma}, 573$ (1931) RP358.

8. C. S. Hudson and H. O. Parker, J. Am. Chem. Soc. 37, 1589 (1915)

9. C. S. Hudson, J. Am. Chem. Soc. 37, 1591 (1915).

10. H. L. Frush and H. S. Isbell, J. Research NBS 35, 111 (1945) RP1663.

11. H. H. Schlubach and G. Graefe, Liebigs Ann. Chem. 532, 211 (1937)

12. E. Montgomery and C. S. Hudson, J. Am. Chem. Soc. 56, 2463 (1934)

13. C. S. Hudson and E. Yanovsky, J. Am. Chem. Soc. 38, 1575 (1916).

14. H. S. Isbell and H. L. Frush, unpublished.

15. C. S. Hudson and J. K. Dale, J. Am. Chem. Soc. 40, 997 (1918).

16. J. K. Dale, J. Am. Chem, Soc, 37, 2745 (1915).

17. F. P. Phelps and C. S. Hudson, J. Am. Chem. Soc. 50, 2049 (1928).

18. $\mathrm{K}$. Dale, J Am. Chem. Soc, 46, 1046 (1924).

19. E. Fischer, M. Bergmann, and A. Rabe, Ber, deut. chem. Ges. 53, 2362

(1920).
20. T. L. Harris, E. L. Hirst, and C. E. Wood, J. Chem. Soc 1932, 2108. 21. J. K. Dale and C. S. Hudson, J. Am. Chem. Soc. 52, 2534 (1930).

22. W. Koenigs and E. Knorr, Ber, deut. chem. Ges. 34, 957 (1901).

23. W. N. Haworth, E. L. Hirst, and M. Stacey, J. Chem. Soc. 1931, 2864. 24. J. K. Dale, J. Am. Chem. Soc, 46, 1046 (1924)

25. W. N. Haworth, E. L. Hirst, and E. J. Miller, J. Chem. Soc 1929, 2469. 26. S. B. Hendricks, O. R. Wulf, and U. Liddel, J. Am. Chem. Soc. 58, 1997 (1936).

27. P. A. Levene and R. S. Tipson, J. Biol. Chem. 90, 89 (1931)

28. M. L. Wolfrom and M. R. Newlin, J. Am. Chem. Soc. 52, 3619 (1930)

29. M. L. Wolfrom, J. Am. Chem. Soc. 52, 2464 (1930)

30. G. Arragon, Compt. rend. 196, 1733 (1933); H. Schlubach and J. Vorwerk Ber. deut, chem. Ges. 66, 1251 (1933).

31. R. M. Hann and C. S. Hudson, J. Am. Chem. Soc. 64, 925 (1942).

32. E. G Griffin and J M Nelson, J Am. Chem. Soc, 37, 1552 (1915).

33. C. S. Hudson and J. M. Johnson, J. Am. Chem. Soc. 37, 1276 (1915)

34 C. S Hudson and J M Johnson, J Am Chem Soc 39, 1272 (1917)

34. C. S. Hudson and J. Johnson, J. Am. Chem. Soc. 39, 1272 (1917)

35. C. S. Hudson and J. M. Johnson, J. Am. Chem. Soc. 37, 2752 (1915)

37. R. P. Linstead, A. Rutenberg, W. G. Dauben, and W. L. Evans, J. Am. Chem. Soc. 62, $3260(1940)$

\section{Experimental Procedures}

\subsection{Preparation and Purification of the Compounds}

The compounds listed in table 2 were prepared by the methods given in the references cited. Each substance was recrystallized from a suitable solvent until further crystallization caused no change in either melting point or optical rotation. In most cases the melting point and optical rotation agree with values found in the literature. Some discrepancies can be seen, but because the purifications were conducted with great care, it is believed that the values reported here are correct.

\subsection{Solubility of Compounds in Carbon Tetrachloride}

The approximate solubilities of the materials in carbon tetrachloride were determined in order to facilitate preparation of solutions, and not as a criterion of purity. The values were obtained in the following manner: A sufficient quantity of the compound was added to $10 \mathrm{ml}$ of carbon tetrachloride to provide a saturated solution at $20^{\circ} \mathrm{C}$. After 24 hours, during which the mixture was occasionally shaken, $5 \mathrm{ml}$ of the solution was drawn through a cotton filter into a pipet and transferred to a tared dish; the solvent was evaporated and the weight of the residue determined.

\subsection{Solvents Used for Spectrograms}

The choice of solvents used in these measurements was determined by their suitability for use in cells with rock salt windows, by their transparency in the range of wavelengths studied, and by their effectiveness in dissolving the samples.

The following solvents were used in this work:

Carbon tetrachloride - This solvent was purified by 
efficient fractional distillation; purity was checked by refractive index.

Carbon disulfide - $\mathrm{A}$ commercial analytical reagent was used; purity was checked by determination of boiling point and residue.

Chloroform - This solvent was purified in small quantities at frequent intervals (every 2 to 3 days). U. S. P. chloroform was washed several times with concentrated sulfuric acid, with water, with a solution of sodium bicarbonate, and finally with water. It was then dried with anhydrous calcium sulfate, filtered, and stored in the dark over silica gel.

Dioxane-Peroxides present in commercial dioxane were removed by treatment of the solvent with solid potassium iodide. The dioxane was decanted from the iodide, and the free iodine and most of the water were removed by shaking the material with an excess of solid potassium hydroxide. The dioxane was decanted, and treated with sodium to remove traces of water and iodine. After 24 hours the product was distilled, and then stored in the dark.

\subsection{Measurement of Spectrograms}

The spectrograms ${ }^{7}$ of the substances listed in table 2 were made with a model $12 \mathrm{~B}$ Perkin-Elmer spectrometer with the auxiliary equipment and working conditions described by Creitz and Smith [12]. The observed transmission in percentage, corrected for solvent, was plotted with respect to wavelength and wave number. The resulting spectrograms are presented in the figures at the end of this paper, in which the solid lines represent absorption in carbon tetrachloride solutions, and the broken lines, absorption in chloroform, dioxane, or carbon disulfide solutions, as shown by the key. When solubility of the compounds permitted, measurements were made in carbon tetrachloride; in the region in which carbon tetrachloride is opaque, either carbon disulfide or dioxane was used. For some compounds of low solubility, it was necessary to use chloroform solutions. In a few cases, measurements are given at more than one concentration and in cells of different length.

\subsection{Estimation of the Molar Absorbancy Indices}

Molar absorbancy indices were calculated by means of the Beer-Lambert law in the form

$$
-\log _{10} T_{\mathrm{s}}=-\log _{10}\left(T_{\text {soln. }} / T_{\text {solv }} .\right)=a_{M} b c,
$$

where $T_{\mathrm{s}}$ is the transmittancy of the sample, $T_{\mathrm{soln}}$. and $T_{\text {solv }}$ are the transmittances of the cell containing solution and solvent, respectively, $b$ is the cell length in centimeters, $c$ is the concentration in moles per liter, and $a_{M}$ is the molar absorbancy index [13]. The integrated molar absorbancy index equals $\int a_{M}(\nu) d \nu$, where $\nu$ is a measure of the frequency expressed in wave numbers (reciprocal centimeters)

${ }^{7}$ The spectrograms were given in an NBS unpublished report to the Office of Naval Research dated December 31,1951 . The report was distributed to numerous research workers, and the data for some of the compounds have been included in a review article [3]. and the limits of integration are selected to cover the area enclosed by the bands. When $-\log _{10} T_{\mathrm{s}}$ is plotted against wave number, the area beneath a given absorption band is proportional to the integrated molar absorbancy index. In a few cases, integrated molar absorbancy indices were compared by cutting out and weighing the area of paper enclosed. The results were reduced to a comparable basis by dividing the weight of the clipping by the product of the molar concentration of the substance and the cell length. In the study of absorbancy due to the acetyl carbonyl group, the molar absorbancy index was divided by the number of these groups $(n)$ per molecule. The resulting value $\left(a_{M} / n\right)$ is termed the "group absorbancy index" (see table 5).

\section{Assignment of Ring Conformation From Infrared Absorption}

One of the main objects of the present investigation was to obtain information concerning the conformation of the pyranose ring. Although the structure and configuration of most carbohydrates are known, there is comparatively little information concerning ring conformation. Assignments of ring conformation based on the formation of copper complexes $[10,14]$ and other products may be open to question because of changes under the influence of the reagent; assignments based on reaction rates [15] require the interpretation of mechanisms that may not always be correct. Ultimately, the study of infrared absorption spectra may provide a more satisfactory means for the assignment of ring conformation. Some progress in this direction has already been made. Thus, Jones, Ramsay, Herling, and Dobriner [16] have found that the carbonyl stretching vibration of $\alpha$-bromo-ketosteroids is displaced in a characteristic manner according to whether the bromine atom has an axial or equatorial position in the cyclohexanone ring; Cole, Jones, and Dobriner $[17,18]$ have shown that an axial or equatorial position of an acetate group on the A ring of steroids is characterized by different band patterns, as well as by a shift of the stretching vibration of the acetyl carbonyl. Also, Barker, Bourne, Stacey, and Whiffen [4] have made the suggestion that certain absorption bands for pyranose derivatives may be characteristic of the axial or equatorial position of the hydrogen of carbon 1 (see also [5]).

The results of the present study show clearly that infrared absorption provides the basis for a promising method of studying the ring conformation of carbohydrates. A few of the bands that seem characteristic of certain structures or conformations will be discussed here; others will be considered in future publications.

Table 3 lists certain bands for the fully acetylated monosaccharides that seem. to vary with the axial or equatorial positions of the glycosidic acetate groups. Interpretation of the absorption spectra in terms of structure requires knowledge of the ring conformation of at least some of the members of the group. Rates of oxidation with bromine [15], indicate that 
TABLE 3. Absorption bands at 8.64 and $8.87 \mu$ for fully acetylated monosaccharides

\begin{tabular}{|c|c|c|c|c|c|c|c|c|c|}
\hline \multirow{2}{*}{ Compound } & \multirow{2}{*}{$\begin{array}{l}\text { Configura- } \\
\text { tion }\end{array}$} & \multirow{2}{*}{$\begin{array}{l}\text { Probable } \\
\text { conform- } \\
\text { ation }\end{array}$} & \multirow{2}{*}{$\begin{array}{l}\text { Position of } \\
\text { reference } \\
\text { groups }\end{array}$} & \multirow{2}{*}{$\begin{array}{l}\text { Hypothet- } \\
\text { ical a-pyra- } \\
\text { nose band a } \\
8.63 \pm 0.04 \mu\end{array}$} & \multirow{2}{*}{$\begin{array}{l}\text { Hypothet- } \\
\text { ical e-pyra- } \\
\text { nose band } \mathrm{s} \\
8.87 \pm 0.06 \mu\end{array}$} & \multicolumn{3}{|c|}{ Molar absorbancy indices } & \multirow{2}{*}{ Spectrum } \\
\hline & & & & & & $\begin{array}{l}a_{M} \text { at } \\
8.64 \mu\end{array}$ & $\begin{array}{l}a_{M} \text { at } \\
8.87 \mu\end{array}$ & Difference & \\
\hline Tetra- $O$-acetyl- $\alpha$-D-xylopyranose & $\alpha-g l u c o$ & $\mathrm{C}^{\prime} 1$ & a e e e - & $8.61 \mathrm{~s}$ & $8.83 \mathrm{w}$ & 300 & 173 & +127 & 1 \\
\hline Penta-O-acetyl- $\alpha$-D-glucopyranose . & $\alpha-g l u c o$ & $\mathrm{C}^{\prime} 1$ & a e e e & $8.63 \mathrm{~s}$ & $8.85 \mathrm{w}$ & 382 & 160 & +222 & 5 \\
\hline Tetra- $O$-acetyl- $\alpha$-D-lyxcpyranose & $\alpha-$ manno & $\mathrm{C}^{\prime} 1$ & a a e e- & $8.67 \mathrm{~s}$ & $8.84 \mathrm{~W}$ & 390 & 77 & +313 & 3 \\
\hline Penta- $O$-acetyl- $\alpha$-D-mannopyranose & $\alpha-\operatorname{manno}$ & $\mathrm{C}^{\prime} 1$ & a a e e & $8.65 \mathrm{~s}$ & $8.92(\mathrm{tr})$ & 593 & 98 & +495 & 7 \\
\hline Hexa-O-acetyl-D-glycero- $\alpha$-L-manno-heptopyranose - & $\alpha-\operatorname{manno}$ & $\mathrm{C}^{\prime} 1$ & a a e e & $8.65 \mathrm{~m}$ & $8.92(\mathrm{tr})$ & 444 & 223 & +221 & 18 \\
\hline Penta- $O$-acetyl- $\alpha$-D-galactopyranose & $\alpha-g a l a$ & $\mathrm{C}^{\prime} 1$ & a e e a e & $8.61 \mathrm{~m}$ & $8.84(\operatorname{tr})$ & 366 & 158 & +208 & 9 \\
\hline Tetra- $O$-acetyl- $\beta$-D-xylopyranose & $\beta$-gluco & $\mathrm{C}^{\prime} 1$ & e e e e- & $8.62(\mathrm{tr})$ & $8.89 \mathrm{~m}$ & 71 & 223 & -152 & 2 \\
\hline Penta- $O$-acetyl- $\beta$-D-glucopyranose_ & B-gluco & $\mathrm{C}^{\prime} 1$ & e e e e & (c) & $8.92 \mathrm{~m}$ & $(118)$ & 233 & $(-115)$ & 6 \\
\hline Penta- $O$-acetyl- $\beta$-D-mannopyranose & $\beta$-manno & $\mathrm{C}^{\prime} 1$ & e a e e & $8.67(\mathrm{tr})$ & $8.89 \mathrm{~m}$ & 107 & 161 & -54 & 8 \\
\hline Tetra- $O$-acetyl- $\alpha$-L-arabinopyranose & B-gala & $\mathrm{C}^{\prime} 1$ & e e e a - & (c) & $8.86 \mathrm{~m}$ & (90) & 232 & $(-142)$ & 4 \\
\hline Penta- $O$-acetyl- $\beta$-D-galactopyranose & $\beta$-gala & $\mathrm{C}^{\prime} 1$ & e e e a e & (c) & $8.86 \mathrm{~m}$ & (92) & 233 & $(-141)$ & 10 \\
\hline Hexa- $O$-acetyl-D-glycero- $\beta$-D-gala-heptopyranose & $\beta-g a l a$ & $\mathrm{C}^{\prime} 1$ & e e a e & $8.62 \mathrm{~W}$ & $8.83 \mathrm{~m}$ & 139 & $\begin{array}{r}282 \\
\end{array}$ & -143 & 14 \\
\hline Penta- $O$-acetyl- $\alpha$-D-gulopyrancse & $\alpha-g u l o$ & $\mathrm{C}^{\prime} 2 \mathrm{~b}$ & e a e e a & (c) & $8.83 \mathrm{~m}$ & $(95)$ & $\left\{\begin{array}{l}342 \\
312\end{array}\right.$ & $(-247)$ & 12 \\
\hline Hexa-O-acetyl-D-glycero- $\alpha$-D-gulo-heptopyranose & $\alpha-g u l 0$ & $\mathrm{C}^{\prime} 2 \mathrm{~b}$ & e a e e a & $8.59 \mathrm{~m}$ & $8.86 \mathrm{~m}$ & 206 & $\left\{\begin{array}{l}312 \\
294 \\
309\end{array}\right.$ & $\begin{array}{r}(-217) \\
-88\end{array}$ & 16 \\
\hline Hexa- $O$-acetyl-D-glycero- $\beta$-D-gulo-heptopyranose & $\beta-g u l o$ & $\mathrm{C}^{\prime} 2 \mathrm{~b}$ & a a e e a & $8.60 \mathrm{~m}$ & $8.91(\mathrm{tr})$ & 199 & $\begin{array}{r}509 \\
172\end{array}$ & $\begin{array}{r}-100 \\
+27\end{array}$ & 17 \\
\hline Hexa- $O$-acetyl-D-alycero- $\beta$-D-ido-heptopyranose... & $\beta$-ido & $\mathrm{C}^{\prime} 2 \mathrm{~b}$ & a e e a & $8.65 \mathrm{w}$ & $8.83(\mathrm{tr})$ & 222 & 207 & +15 & 15 \\
\hline Penta- $O$-acetyl- $\alpha$-D-talopyranose & $\alpha$-talo & $\mathrm{C}^{\prime} 2 \mathrm{~b}$ & e e a e a & $\ldots$ & $8.90 \mathrm{~s}$ & (d) & (d) & neg. & (d) \\
\hline
\end{tabular}

a s, m, and w indicate strong, moderately strong, and weak bands, respectively; (tr) indicates the weakest observable absorption.

b Although the spectra indicate the presence of the $\mathrm{C}^{\prime} 2$ conformation, the data are not conclusive, and both conformations may be present.

c No absorption band was evident. For purposes of comparison only, $a_{M}$ at $8.63 \mu$ was calculated and deducted from that at $8.87 \mu$ to give the difference cited in parentheses.

the free pyranose sugars having the gluco-, manno-, and galacto-configurations ordinarily exist in the $\mathrm{C}^{\prime} 1$ conformation. If the $\mathrm{C}^{\prime} 1$ conformation is postulated for all of the fully acetylated monosaccharides having these three configurations, it is found that the modifications having an axial glycosidic acetate group give a moderately strong absorption band near 8.63 $\mu$ and at most a weak band near $8.87 \mu$; whereas, the modifications having an equatorial glycosidic acetate group absorb weakly near $8.63 \mu$ but give a moderately strong band near $8.87 \mu$. Thus, strong absorption near $8.63 \mu$ appears to be characteristic of a structure having an axial glycosidic acetyl group; similarly, strong absorption near $8.87 \mu$ appears to be characteristic of a structure having an equatorial glycosidic group. The differences between the molar absorbancy indices in the two regions for all of the acetates having the gluco-, manno-, and galactoconfigurations (table 3) are in agreement with this generalization. At present, little is known concerning conformation in the gulo-, ido-, and talo-configurations. If the above generalization is applied to these three configurations, it indicates the presence of the a-pyranose $\mathrm{C}^{\prime} 2$ conformation in hexa-Oacetyl-D-glycero- $\beta$-D-ido-heptose (fig. 15 ) and hexa$O$-acetyl-D-glycero- $\beta$-D-gulo-heptose (fig. 17), and the e-pyranose $\mathrm{C}^{\prime} 2$ conformation in penta- $O$-acetyl- $\alpha$-Dgulose (fig. 12), hexa-O-acetyl-D-glycero- $\alpha$-D-guloheptose (fig. 16) and penta- $O$-acetyl- $\alpha$-D-talose. ${ }^{8}$

However, the spectra for these compounds show that the situation is not entirely clear, and it seems possible that both conformations may be present. Consideration of stereomeric factors seems to indicate that some of the compounds in this group should exist in the $\mathrm{C}^{\prime} 1$ form. Both the $\beta$-gulo- and the $\beta$-talostructures have three equatorial reference groups

8 The numbers of the spectra are given in parentheses. Because of lack of material, the spectrum of penta- $O$-acetyl- $\alpha$-D-talose, previously measured by the potassium chloride pellet technique [19], was not measured in solution. d The spectrogram, previously published [19], was made by the potassium chloride pellet technique. Hence values for $a_{M}$ comparable to those reported the absorption in the region of $8.63 \mu$ was less than that in the region of $8.87 \mu$.

when in the $\mathrm{C}^{\prime} 1$ conformation, and two when in the $\mathrm{C}^{\prime} 2$ conformation. The reverse distribution is present in the alpha forms (see table 1). In view of the tendency of large groups to take equatorial, rather than axial positions, the $\mathrm{C}^{\prime} 1$ conformation would seem to be the more probable for the $\beta$-gulo- and $\beta$-talo- structures, and the $\mathrm{C}^{\prime} 2$ conformation for the corresponding alpha modifications. One of the two modifications of the talose configuration is not available for comparison, but the distinction suggested is not apparent from the absorption bands for the alpha and beta modifications of hexa- $O$ acetyl-D-glycero-D-gulo-heptose (figs. 16, 17).

Table 4 gives a summary of absorption bands for the acetylated methyl glycosides in the regions of 8.33 and $8.80 \mu$. These regions seem particularly promising for study of the conformation of the ring in the acteylated methyl pyranosides. All of the acetylated methyl pyranosides in the gluco-, manno-, and galacto-configuration that have been assigned the a-pyranose $\mathrm{C}^{\prime} 1$ conformation show absorption bands at 8.30 to $8.35 \mu\left(1,205\right.$ to $\left.1,198 \mathrm{~cm}^{-1}\right)$ with the possible exception of methyl tri- $O$-acetyl- $\alpha$-Dlyxoside (fig. 21), the spectrogram of which shows a slight inflection. None of the corresponding compounds having the e-pyranose $\mathrm{C}^{\prime} 1$ conformation gives a band in this region. Table 4 shows that the a-pyranose acetylglycosides absorb more strongly than the e-pyranose acetylglycosides in the region of $8.80 \mu$. Methyl penta-O-acetyl-D-glycero- $\beta$-D-guloheptoside (fig. 31), the conformation of which is unknown, shows no distinctive band near $8.33 \mu$, but a fairly strong one at $8.83 \mu$. Classification of the compound is therefore uncertain, but it seems possible that it has both the $\mathrm{C}^{\prime} 1$ and $\mathrm{C}^{\prime} 2$ ring conformations.

The absorption in the region of $8.80 \mu$ appears to depend not only on the axial and equatorial positions 
TABLE 4. Absorption bands at 8.33 and $8.80 \mu$ for acetylated methyl glycosides

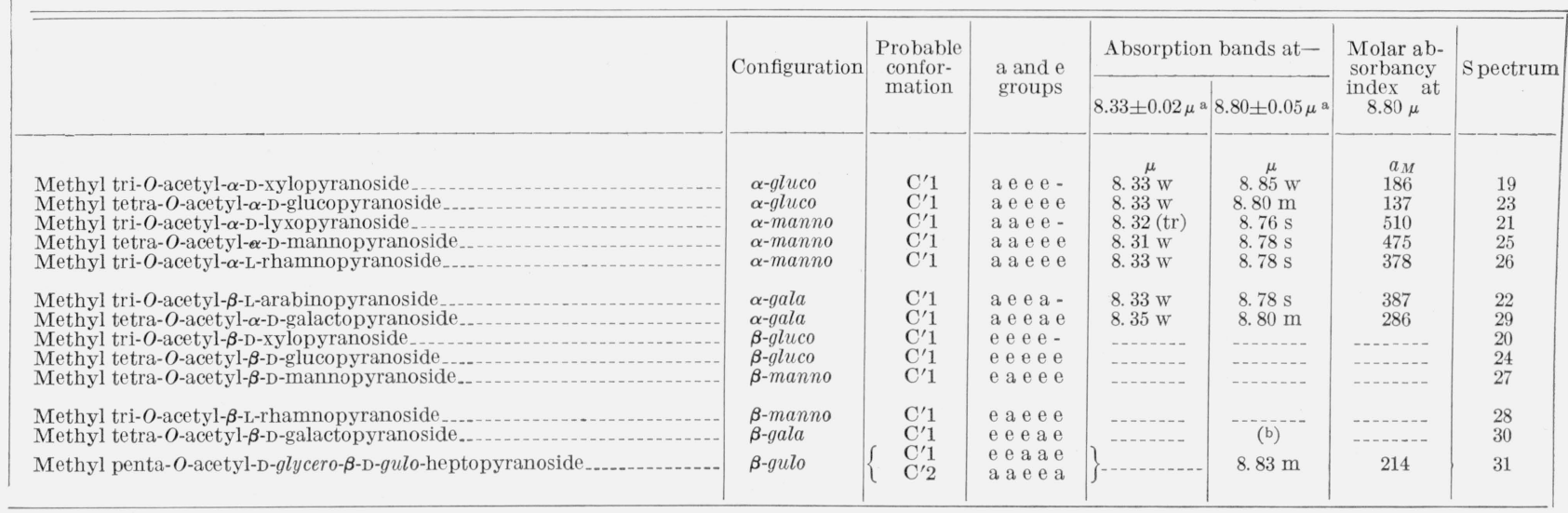

${ }^{a} \mathrm{~s}, \mathrm{~m}$, and $\mathrm{w}$ indicate strong, moderately strong, and weak bands, respectively; (tr) indicates the weakest observable absorption. ${ }^{\mathrm{b}} \mathrm{A}$ weak band at $8.73 \mu$ appear to be outside the region to be considered.

at the glycosidic carbon but also on those positions at other carbons of the ring. Table 4 shows that those glycosides having the a-pyranose structure with no axial acetyl group have an average molar absorbancy index of 162 , and those with one axial acetyl group have an average index of 407 . It thus appears that absorbancy at $8.80 \mu$ is enhanced by the presence of axial acetate groups.

The examples given clearly show the usefulness of infrared spectra for the study of the structure of carbohydrate derivatives. Most of the bands characteristic of the cyclic carbohydrate structure occur in the region of 8.4 to $15 \mu$. The spectra are complex and difficult to interpret because there are many variables, and in some cases the bands are weak and poorly resolved. Part of the difficulty arises from lack of solubility of the compounds, and opacity of the solvents, especially in the range of 10 to $15 \mu$. More satisfactory spectra were obtained in this range with solid substances in potassium chloride pellets. However, comparison of spectra for configurationally related substances in the solid state will be deferred to a later paper, and the remainder of the discussion restricted to a less comprehensive treatment of the absorption found in the range 2.5 to $8.3 \mu$.

\section{Miscellaneous Ábsorption Bands}

\subsection{The O-H Stretching Vibrations (2.5 to $3.2 \mu$, or 4,000 to $3,125 \mathrm{~cm}^{-1}$ )}

The infrared absorption in the region of 2.5 to $3.2 \mu$ arises from $\mathrm{O}-\mathrm{H}$ stretching vibrations. The absorption corresponding to vibration of free hydroxyl groups lies in the region of about $2.75 \mu$. The absorption band for the free hydroxyl is sharp, and is given by most hydroxyl-containing substances in dilute solution in nonpolar solvents, or in the form of vapor. It is also given by substances in which steric hindrance prevents association [20]. The hydroxyl group normally associates with groups of atoms having polar attraction. The resulting hydrogen bridges vary from weak to strong according to the character of the bridged atoms and the stereomeric conditions. Two types of bridges are generally recognized: Intermolecular bridges linking two or more molecules, and intramolecular bridges. Intermolecular (polymeric) bridges give rise to broad absorption bands between 2.9 and $3.1 \mu$. Intramolecular bridges are similar to the intermolecular bridges but differ in that they are not broken by dilution with a nonpolar solvent. Bands due to intramolecular bridges vary considerably, but are generally broad.

Spectrograms 34, 35, 36, 37, 40, and 41 are of compounds containing hydroxyl groups. The shape and intensity of the $\mathrm{O}-\mathrm{H}$ absorption bands in the range 2.7 to $3.2 \mu$ provide information as to the state of the hydroxyl groups in the molecules. At this time, a detailed analysis of the spectra for most substances in this region is not feasible but a brief structural analysis will be presented for penta-O-acetyl -aldehydo-D-galactose aldehydrol (fig. 40) and penta$O$-acetyl-aldehydo-D-galactose hemiacetal (fig. 41). The absorption bands under consideration show two maxima, caused by the presence of free and of hydrogen-bridged hydroxyls. With the aldehydrol, the maximum absorption for the free hydroxyl $(2.78 \mu)$ is greater than that for the bridged hydroxyl (2.87 $\mu)$, but with the hemiacetal, the reverse is true. Thus, a larger proportion of the hydroxyl groups seems to be free in the aldehydrol than in the hemiacetal. A plausible explanation is that some of the hydroxyl groups in both compounds are bridged to the oxygen of the neighboring acetyl groups. The structure for the aldehydrol and hemiacetyl with a bridged hydroxyl would be as follows:

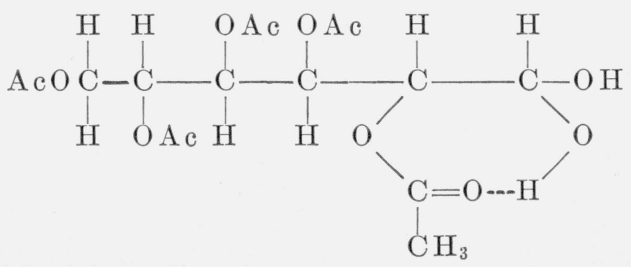

Penta-O-acetyl-aldehydo-D-galactose aldehydrol (40) 


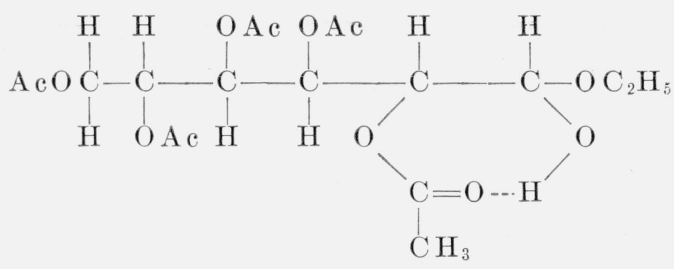

Penta-O-acetyl-aldehydo-D-galactose ethyl hemiacetal

$(41)$

Comparisons of the maxima at 2.78 and $2.87 \mu$ for curves 1,2, and 3 of figure 41 show that there is little variation in the proportions of the free and bridged hydroxyls with dilution, in agreement with the proposed intramolecular linkage. The product from the aldehydrol would have one bridged and one free hydroxyl; that from the hemiacetal would have only the bridged hydroxyl. Thus, with an equal amount of hydrogen bridging, the aldehydrol would be expected to show a higher proportion of free hydroxyl groups, in agreement with the bands found in the spectra of the two compounds. In this connection, it is recognized that the intensities of bands arising from the same functional group in different environments are not necessarily invariant, but the differences found appear to be too large to be ascribed to minor variations in absorbancies.

A comparison of the total absorption for the hydroxyl groups can be used to confirm the existence of two hydroxyls in the aldehydrol and one in the hemiacetal. When measured by the method described on page 45 , the integrated molar absorbancy indices for the aldehydrol and the hemiacetal in the region between 3,300 and $3,800 \mathrm{~cm}^{-1}$ (3.03 and 2.63 $\mu)$ had a ratio of 1.88 . It is known that hydrogenbridged hydroxyls absorb more strongly than free hydroxyls $[20,21]$. Hence absorbancy for the bridged and free bydroxyls should not be weighted equally, and the ratio of integrated absorbancy indices must be somewhat larger than 1.88 , in substantial agreement with the existence of twice as many hydroxyls in the aldehydrol as in the hemiacetal.

\subsection{The $\mathrm{C}-\mathrm{H}$ Stretching Vibrations ( 3.2 to $3.5 \mu$, or 3,125 to $2,857 \mathrm{~cm}^{-1}$ )}

The sugar acetates in carbon tetrachloride ${ }^{9}$ were found to give absorption in the region of 3.3 to $3.5 \mu$. The absorption seems to be composed of at least five overlapping bands. The intensity of the bands, or of the components of a broad band, varies for different materials, and gives rise to characteristic shapes for the spectrograms in this region. Presumably the absorption arises from $\mathrm{C}-\mathrm{H}$ bands of diverse type, such as those of the acetyl $\mathrm{CH}_{3}$ groups, the terminal $\mathrm{CH}_{2} \mathrm{OR}$ groups, and the pyranose ring. It would be desirable, if possible, to obtain independent evidence for the orientation of the ring

${ }^{9}$ Because of its absorption in this region, chloroform is not satisfactory for use as a solvent. hydrogens, and detailed study of absorption in this region with a high-dispersion prism or grating might possibly shed light on this important question.

\subsection{The Spectral Range 3.5 to $5.5 \mu$, or 2,857 to $1,818 \mathrm{~cm}^{-1}$}

The few weak bands observed in this region, like the bands often encountered at wavelengths shorter than those of the $\mathrm{O}-\mathrm{H}$ region, are overtones and combination bands. It might be of interest to observe this region at higher concentrations, and attempt to assign the bands in terms of fundamental frequencies.

\subsection{The $\mathrm{C}=\mathrm{O}$ Stretching Vibration (5.5 to $6.0 \mu$, or 1,818 to $1,667 \mathrm{~cm}^{-1}$ )}

All of the compounds, as expected, show strong absorption bands in the regions characteristic of the carbonyl group. To explore the effect of solvent and structure on the position and intensity of the $\mathrm{C}=\mathrm{O}$ stretching band at 5.6 to $5.8 \mu$ the maximum absorbancy index, $a_{M}$, was determined for each spectrum. The results, summarized in table 5 , show that the group absorbancy indices, $a_{M} / n$, of the substances are considerably lower in chloroform than in carbon tetrachloride solution. The difference may be caused by bridging between the hydrogen of the chloroform, and the oxygen of the acetyl carbonyl groups, resulting in a broadening of the carbonyl absorption band, and hence a lowering of the absorption maximum. Furthermore, the absorption peak for the carbonyl band seems to be at a slightly longer wavelength in chloroform than in carbon tetrachloride solution. However, it is unnecessary to postulate hydrogen bridging in order to explain the reduced absorption in chloroform solution. Electrostatic dispersion forces in condensed phases are apparently sufficient to produce this effect [22].

TABLE 5. Group absorbancy indices for the carbonyl stretching band at 5.65 to $5.8 \mu$

\begin{tabular}{|c|c|c|c|c|c|c|}
\hline \multirow[b]{2}{*}{ Type } & \multicolumn{3}{|c|}{ Carbon tetrachloride } & \multicolumn{3}{|c|}{ Chloroform } \\
\hline & $\begin{array}{l}\text { Num- } \\
\text { ber of } \\
\text { spectra }\end{array}$ & $\begin{array}{l}\text { A ver- } \\
\text { age } \\
a_{M} / n\end{array}$ & $\begin{array}{l}\text { Stand- } \\
\text { ard de- } \\
\text { viation }\end{array}$ & $\begin{array}{l}\text { Num- } \\
\text { ber of } \\
\text { spectra }\end{array}$ & $\begin{array}{l}\text { Aver- } \\
\text { age } \\
a_{M} / n\end{array}$ & $\begin{array}{l}\text { Stand- } \\
\text { ard a } \\
\text { devi- } \\
\text { ation }\end{array}$ \\
\hline Fully acetylated sugars. & 21 & 380 & \pm 24 & 6 & 330 & \pm 16 \\
\hline $\begin{array}{l}\text { Acetylated metnyiglyco- } \\
\text { sides }\end{array}$ & 11 & 444 & \pm 36 & 2 & 367 & \pm 9 \\
\hline $\begin{array}{l}\text { Acetylated sugars with a } \\
\text { free hydroxyl group b. }\end{array}$ & & & & 6 & 337 & \pm 19 \\
\hline $\begin{array}{l}\text { Acetylated open-chain } \\
\text { derivatives. }\end{array}$ & 3 & 398 & \pm 26 & 4 & 348 & \pm 7 \\
\hline All types ${ }^{\circ} \ldots . . .$. & 35 & 402 & \pm 42 & 18 & 341 & \pm 19 \\
\hline
\end{tabular}

\& $\sigma=\sqrt{\frac{\overline{\Sigma(x-\bar{x})^{2}}}{N}}$

b Penta-O-acetyl-aldehydo-D-galactose aldehydrol (40) and penta-O-acetylaldehydo-D-galactose ethyl hemiacetal (41) are included with the type characterized by a free hydroxyl group rather than with the open-chain derivatives.

c 1,2 [3,4,6-Tri-O-acetyl-D-mannopyranose] methyl orthoacetate $(32), 1,2$ [3,4di-O-acetyl-L-rhamnopyranose] methyl orthoacetate (33), and hexa-O-acety inositol (47) are special types and are not included in the treatment represented by this table. 
The compounds of the present study vary with respect to the number and character of the $O$-acetyl groups. Table 5 shows that there are small but significant differences for the average group absorbancy indices obtained for the fully acetylated sugars, acetylated methyl glycosides, acetylated sugars with free glycosidic hydroxyls, and acetylated open-chain derivatives. These differences could arise from intramolecular forces between the groups attached to the glycosidic carbon, and the neighboring acetyl groups. However, because the carbonyl absorptions of the various acetate groups do not necessarily coincide, it is to be expected that the band will be broader and the maximum group absorbancy index somewhat lower for those compounds with the greatest number of acetate groups.

The acetyl derivatives of the aldehyde and ketone forms of the sugars have generally been considered to be true aldehydes and ketones. However, penta-Oacetyl-aldehydo-D-galactose forms a hydrate and an alcoholate for which Wolfrom has proposed an aldehydrol and a hemiacetal structure respectively [23]. The results of the present study, already discussed, are in agreement with these structures. ${ }^{10}$ If the carbonyl groups of the anhydrous aldehydo sugar acetates are free, these compounds should show a strong aldehydo carbonyl band in a range of somewhat longer wavelength than that occupied by the acetate carbonyl band. However, no strong absorption in this range was found for anhydrous tetra- $O$-acetylaldehydo-L-arabinose (fig. 38), penta-O-acetyl-aldehydo-D-galactose (fig. 39), and penta-O-acetyl-keto-Lsorbose (fig. 42). Faint absorption bands at 5.95 and $6.05 \mu$ were found in the spectrum of penta- $O$-acetylketo-L-sorbose, but these are too weak to support a free carbonyl structure, and the latter band is at too long a wavelength. A polymeric structure analogous to that of paraldehyde seemed possible, but a molecular-weight determination for penta- $O$-acetyl-aldehydo-D-galactose showed that this substance is truly a monomer. ${ }^{11}$ The data, then, appear to indicate that several monomeric aldehydo sugar acetates fail to show absorption in a range considered to be characteristic of the aldehydo carbonyl group. There remains the possibility that an aldehydo carbonyl might absorb at so nearly the same place as the acetate carbonyl that absorption due to the former would be obscured.

\subsection{The Spectral Range 6.0 to $6.7 \mu$, or 1,667 to $1,493 \mathrm{~cm}^{-1}$}

Absorption in the range of 6.0 to $6.7 \mu$ was found to be too weak for accurate determination, with the concentrations used in most of the measurements. Some of the spectra show almost complete absence of absorption; others show weak bands, principally be-

\footnotetext{
${ }^{10}$ Absorption spectra studies by Rowen, Forziati, and Reeves [24] show that the aldehyde groups in periodate-oxidized cellulose are also hydrated, and the material contains few, if any, free aldehyde groups.

${ }_{11}$ The semicarbazones of aldehydo-D-galactose pentaacetate and of aldehydo-Larabinose tetraacetate are reported to have normal molecular weight $[23,25]$. However, the structure of these products does not establish the structure of the parent acetates. In this investigation, aldehydo-D-galactose pentaacetate was found to be a monomer by means of a cryoscopic determination of molecular weight in benzene.
}

tween 6.0 and $6.25 \mu$. It is interesting that penta- $O$ acetyl-aldehydo-D-galactose aldehydrol (fig. 40) shows a weak but definite absorption at $6.25 \mu$ that is not observed for the anhydrous form, penta- $O$ acetyl-aldehydo-D-galactose (fig. 39), or for penta$O$-acetyl-aldehydo-D-galactose hemiacetal (fig. 41).

\subsection{The $\mathrm{CH}_{3}$ Vibrations (6.7 to $7.5 \mu$, or 1,493 to $\left.1,333 \mathrm{~cm}^{-1}\right)$}

All of the spectrograms show absorption bands at approximately 7.0 and $7.3 \mu$, presumably caused by deformation of the $\mathrm{CH}_{3}$ groups. The $7.0-\mu$ band is broad and rather weak, whereas the $7.3-\mu$ band is sharp and strong. In most cases the $7.3-\mu$ band is symmetrical, but in the methyl orthoacetates and a few other compounds it appears as a doublet, or with irregularities at 7.2 and $7.3 \mu$. The absorption at $7.3 \mu$ may be attributed to the deformation vibration of the $\mathrm{CH}_{3}$ group of the normal acetate; the absorption at $7.2 \mu$ may arise in the methyl orthoacetates from the deformation vibration of the $\mathrm{CH}_{3}$ group of the orthoacetate ring structure. Tetra- $O$-acetyl- $\beta$ $\mathrm{D}$-glucose (fig. 34) and penta- $O$-acetyl- $\alpha$-D-glucoheptulose (fig. 37) show marked absorption at $7.25 \mu$ in addition to the normal absorption at $7.3 \mu$. Slight irregularities are found in the same region in the spectrograms of a few of the remaining compounds.

The acetylated methyl glycosides show a weak band at $6.9 \mu$ that overlaps the band due to the $\mathrm{CH}_{3}$ symmetrical deformation vibration. This absorption seems to be in accord with the wavelength previously ascribed to the vibration of the $\mathrm{CH}_{3}$ group of methanol $(6.87 \mu)$ and dimethyl ether $(6.83 \mu)$ [1, p. 24], although it may be analogous to the 6.89 $\mu$ band of tetrahydropyran [26].

\subsection{The Acetate Bands at 8.0 and $8.2 \mu(1,250$ and $1,220 \mathrm{~cm}^{-1}$ )}

All of the spectra included in the present study show a strong absorption band at $8.2 \mu$ and a weak to moderately strong band at $8.0 \mu$. Presumably these bands arise from the stretching vibrations of the $\mathrm{C}-\mathrm{O}$ bonds in the acetyl groups, and are analogous to bands shown in the same regions by other acetates. In most cases the $8.2-\mu$ band is broad, with several shoulders or inflections indicative of three or more components. The complex character of the bands may arise from axial or equatorial effects such as those described for the cis and trans 3 -acetosteroids [17, 18]. It seems significant that the $8.0-\mu$ band is particularly sharp for the acetates of the pentoses and of rhamnose, compounds that lack an acetyl-substituted primary alcoholic group. In the absence of this group, and if its absorption falls between 8.0 and $8.2 \mu$, the absorption at $8.0 \mu$ would appear sharper. Because furanose derivatives of the pentoses, unlike the pyranose derivatives, have a primary alcoholic group, the presence or absence of a sharp band at $8.0 \mu$ may serve to distinguish the two types of rings in the acetates of the pentoses. In accord with this possible distinction is the fact that 
penta- $O$-acetyl- $\alpha$-L-sorbopyranose (fig. 13 ), having a pyranose ring similar to that of $\mathrm{L}$-xylose but an acetylated primary alcoholic group at carbon 1 , fails, like the acetates of the aldohexopyranoses, to give a sharp band at $8.0 \mu$.

\section{References}

[1] L. J. Bellamy, The infra-red spectra of complex molecules (Methuen \& Co., Ltd., London; John Wiley \& Sons, Inc., New York, N. Y., 1954).

[2] L. P. Kumm, Anal. Chem. 22, 276 (1950).

["] R. L. Whistler and L. R. House, Anal. Chem. 25, 1463 (1953).

[4] S. A. Barker, E. J. Bourne, M. Stacey, and D. H ; ] Whiffen, J. Chem. Soc. 1954, 171.

[5] S. A. Barker, E. J. Bourne, R. Stephens, and D. H. Whiffen, J. Chem. Soc. 1954, 3468

[6] S. A. Barker, E. J. Bourne, M. Stacey, and D. H. Whiffen, Chem. and Ind. 1953, 196.

[7] R. B. Barnes, R. C. Gore, U. Liddel, and V. Z. Williams, Infrared spectroscopy: Industrial applications and bibliography (Reinhold Publishing Corp., New York, N. Y., 1944).

[8] H. M. Randall, R. G. Fowler, N. Fuson, and J. R. Dangl, Infrared determination of organic structures (D. Van Nostrand, Inc., New York, N. Y., 1949).

[9] O. Hassel and B. Ottar, Acta. Chem. Scand. 1, 929 (1947).
[10] R. E. Reeves, Advances in Carbohydrate Chem. 6, 107 (1951).

[11] H. S. Isbell, J. Research NBS 5\%, 171 (1956) RP2707.

[12] E. C. Creitz and F. A. Smith, J. Research NBS 43, 365 (1949) RP2031.

[13] K. S. Gibson, Spectrophotometry, NBS Circ. 484 (1949).

[14] R. E. Reeves, J. Am. Chem. Soc. \%1, 212, 215, 1737, 2116 (1949); $\boldsymbol{7}$, 1499 (1950).

[15] H. S. Isbell and W. W. Pigman, J. Org. Chem. 1, 505 (1937).

[16] R. N. Jones, D. A. Ramsay, F. Herling, and K. Dobriner, J. Am. Chem. Soc. 74,2828 (1952).

[17] A. R. H. Cole, R. N. Jones, and K. Dobriner, J. Am. Chem. Soc. 74, 5571 (1952).

[18] R. N. Jones, P. Humphries, F. Herling, and K. Dobriner, $J$ Am. Chem. Soc. 73, 3215 (1951).

[19 H. S. Isbell, J. E. Stewart, H. L. Frush, J. D. Moyer, and F. A. Smith, J. Research NBS 5\%, 179 (1956) RP2708.

[20] F. A. Smith and E. C. Creitz, J. Research NBS 46, 145 (1951) RP2187.

[21] H. Tsubomura, J. Chem. Phys. 24, 927 (1956).

[22] E. Ferguson, J. Chem. Phys. In press.

[23] M. L. Wolfrom, J. Am. Chem. Soc. 52, 2464 (1930).

[24] J. W. Rowen, F. H. Forziati, and R. E. Reeves, J. Am. Chem. Soc. 73, 4454 (1951).

[25] M. L. Wolfrom and M. R. Newlin, J. Am. Chem. Soc. 52, 3619 (1930).

[26] S. C. Burket and R. M. Badger, J. Am. Chem. Soc. $7 \boldsymbol{q}$, 4397 (1950).

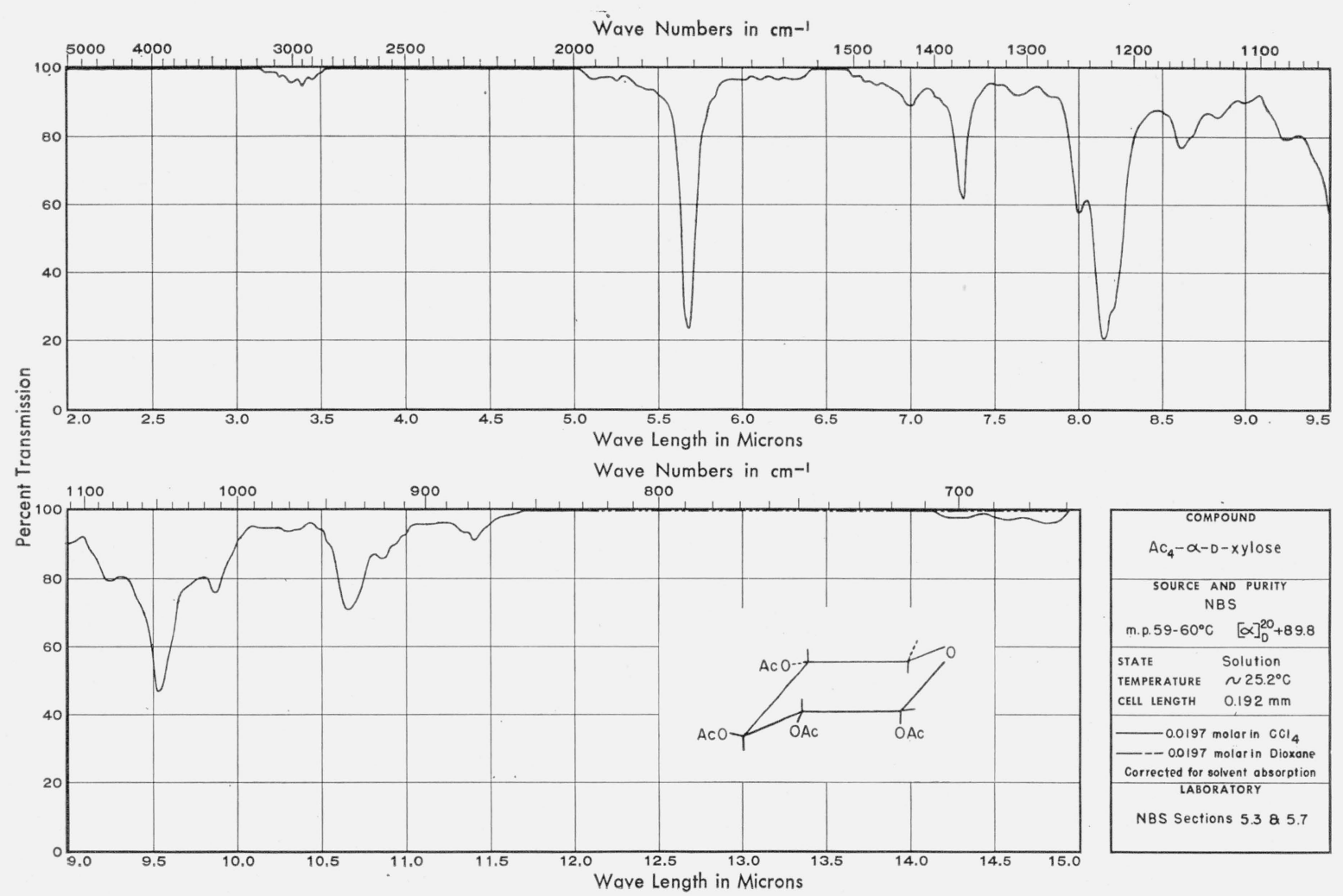

Figure 1. 


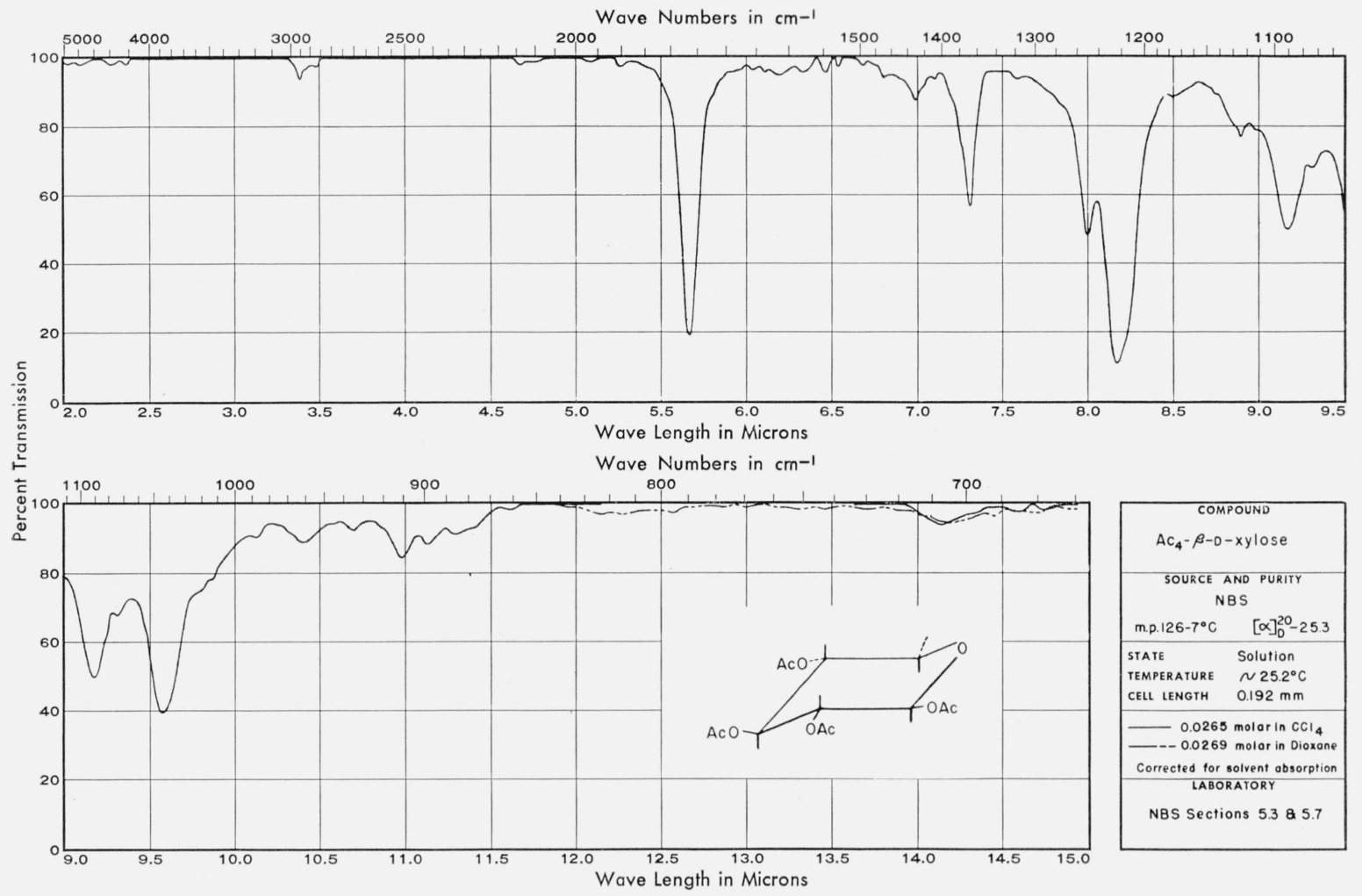

Figure 2.

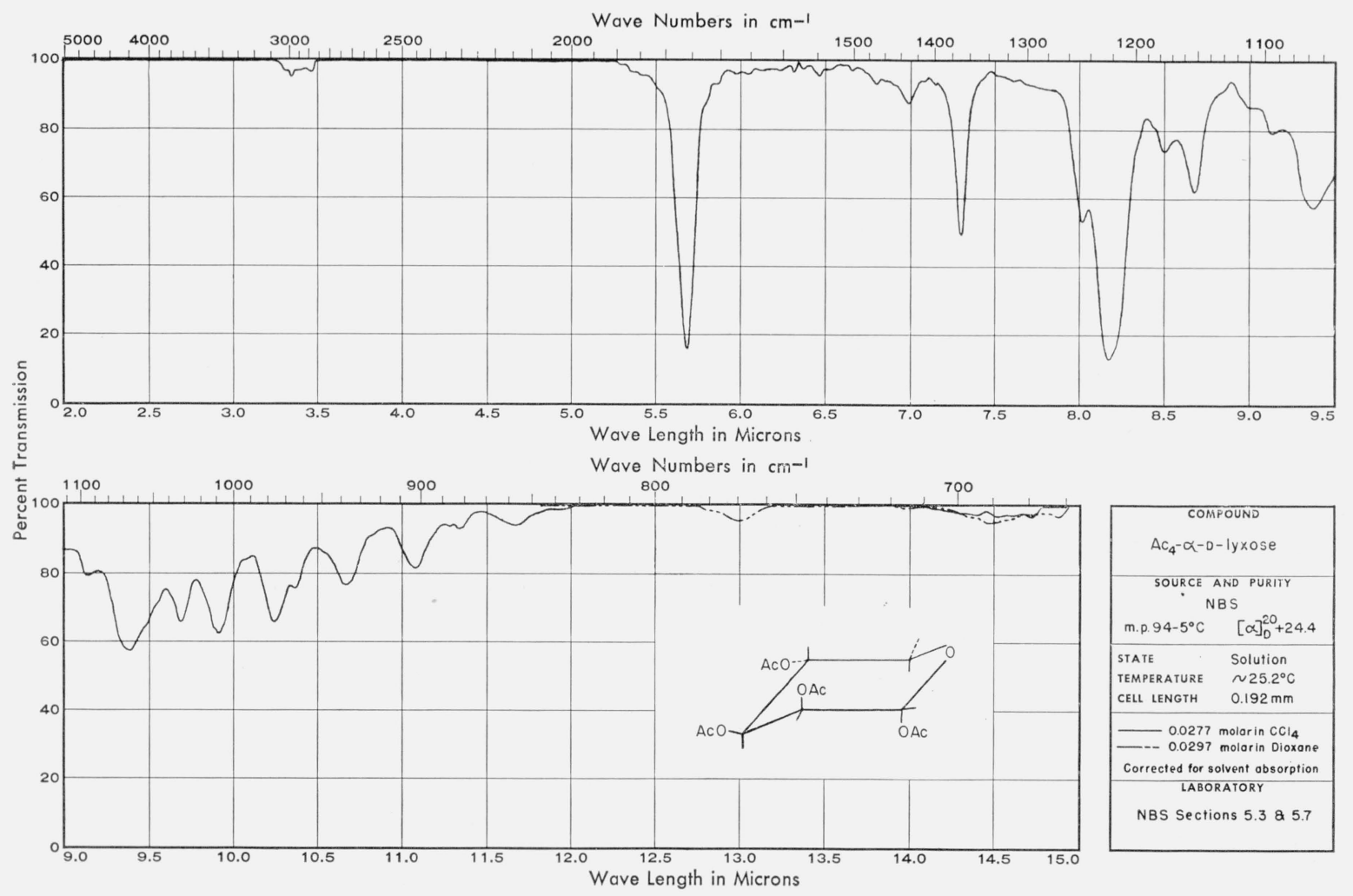

Figure 3. 


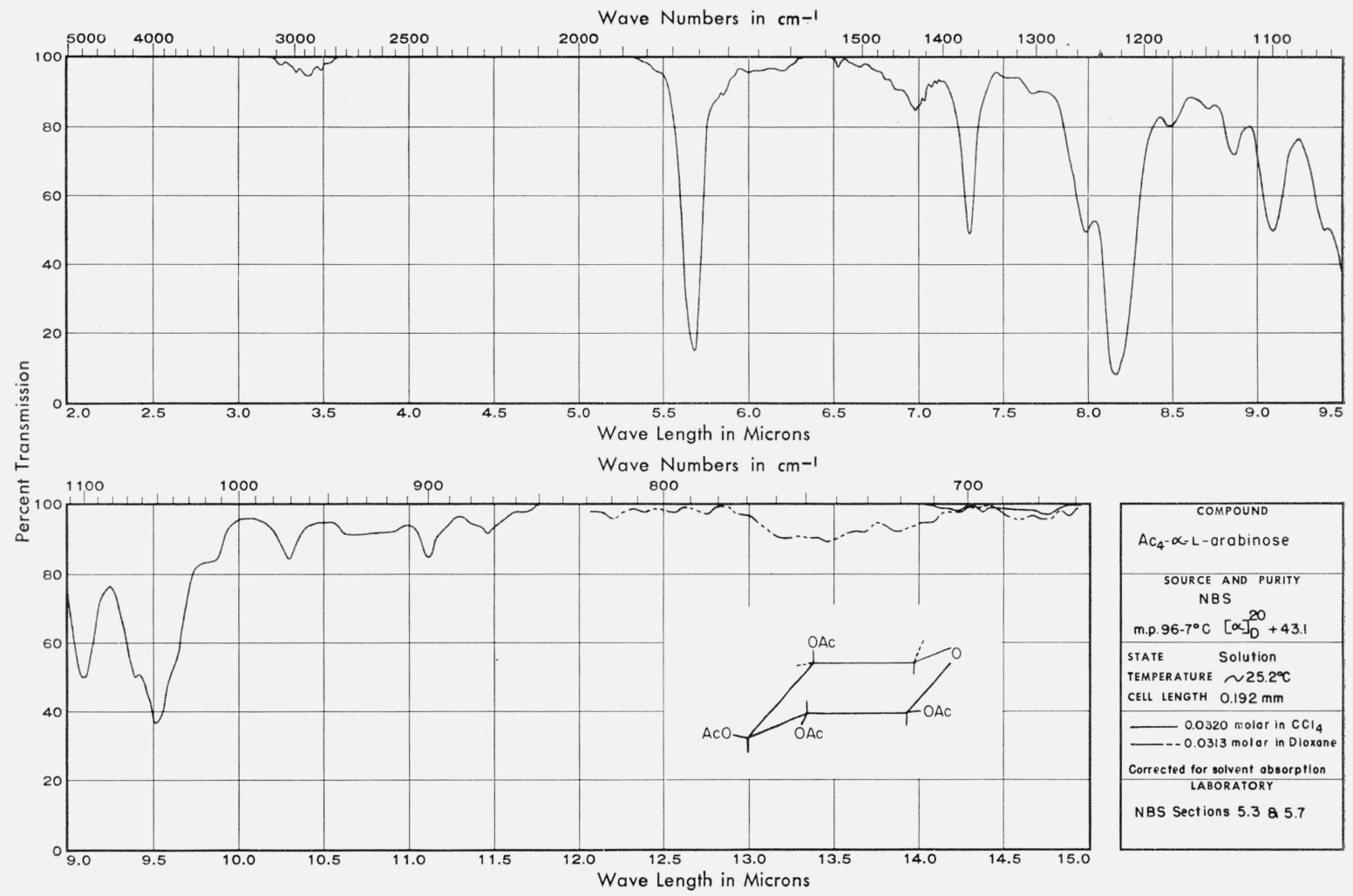

Figure 4.
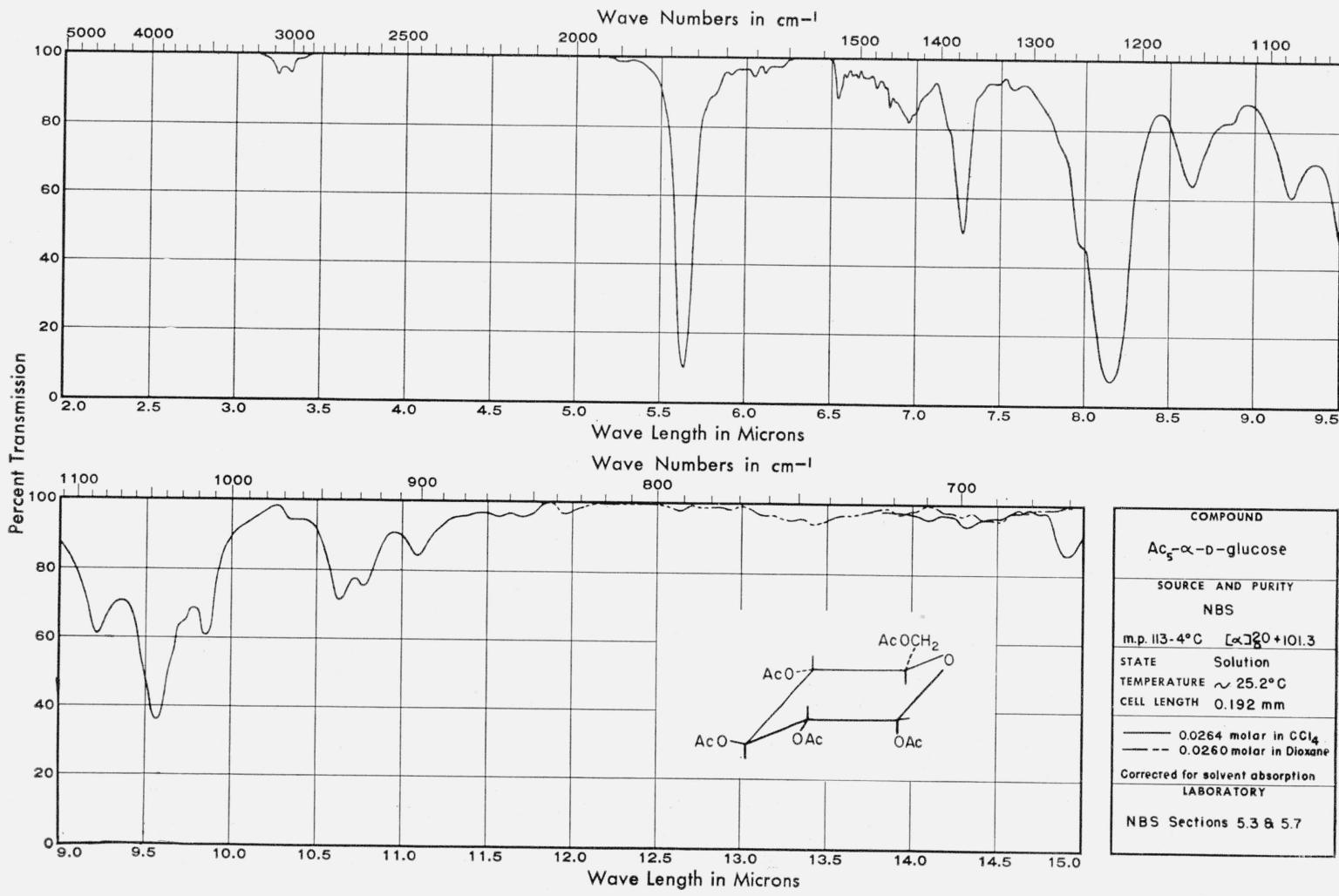

Figure 5. 


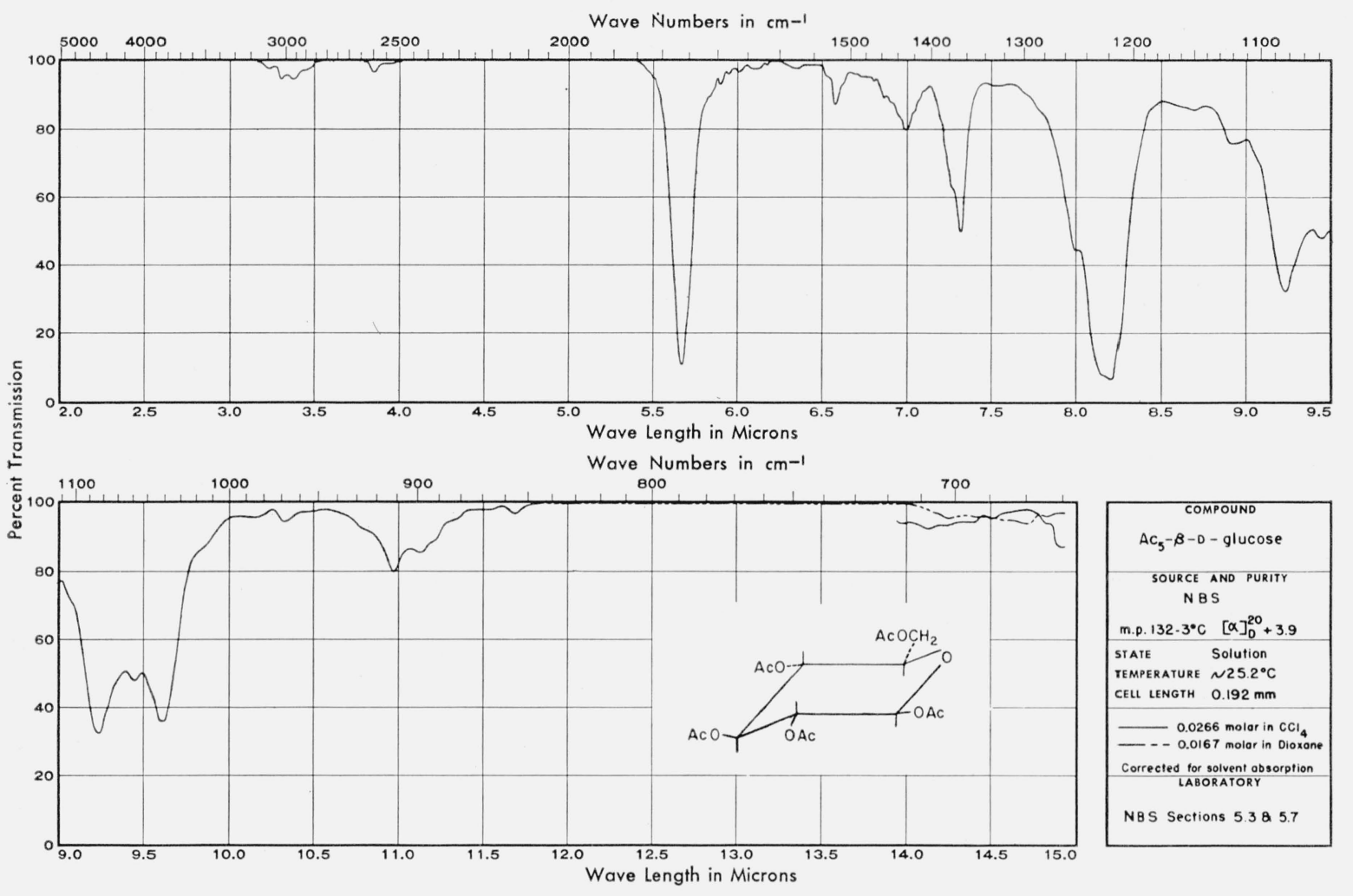

Figure 6.

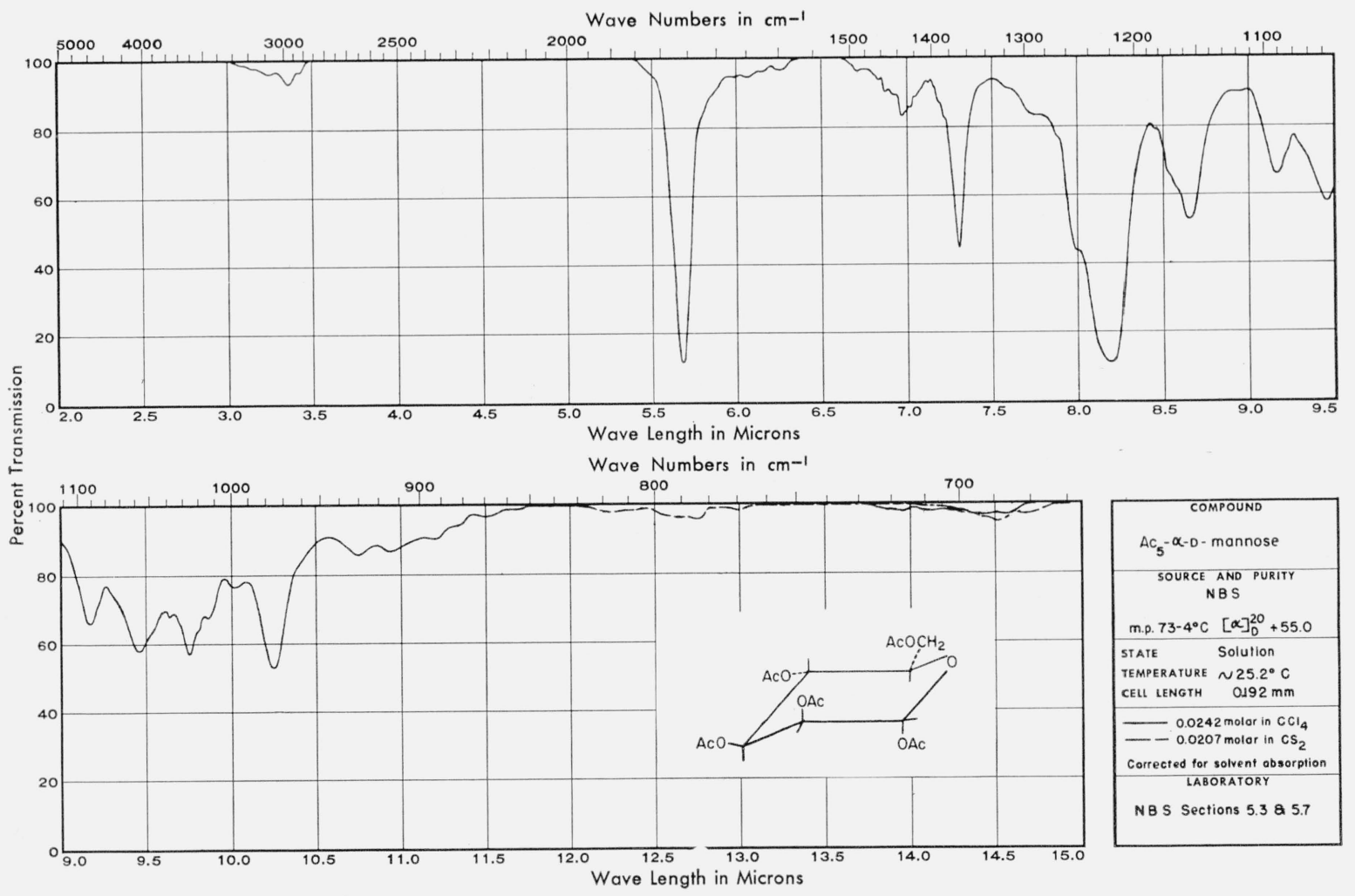

Figure 7. 


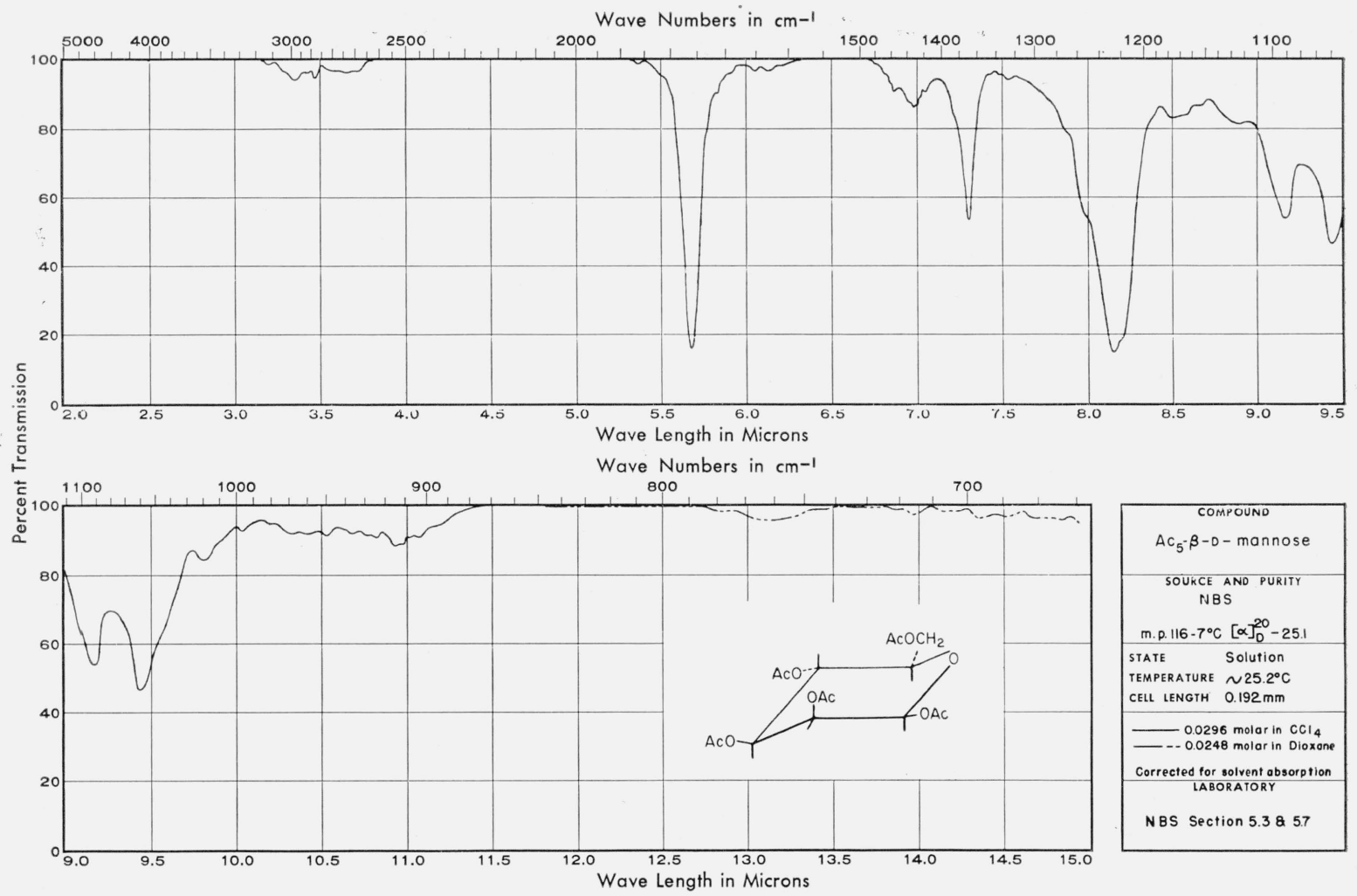

Figure 8.
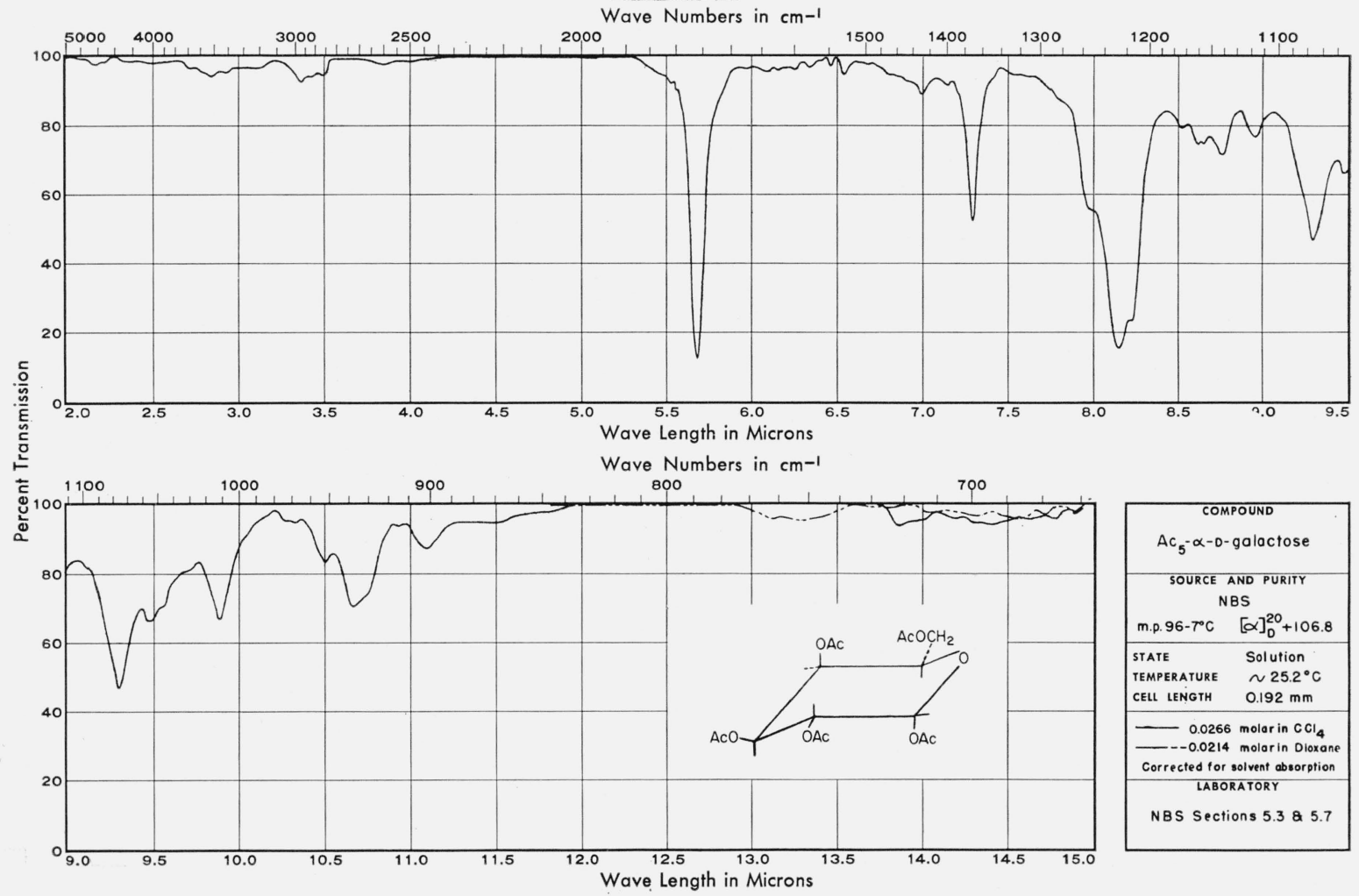

Figure 9. 

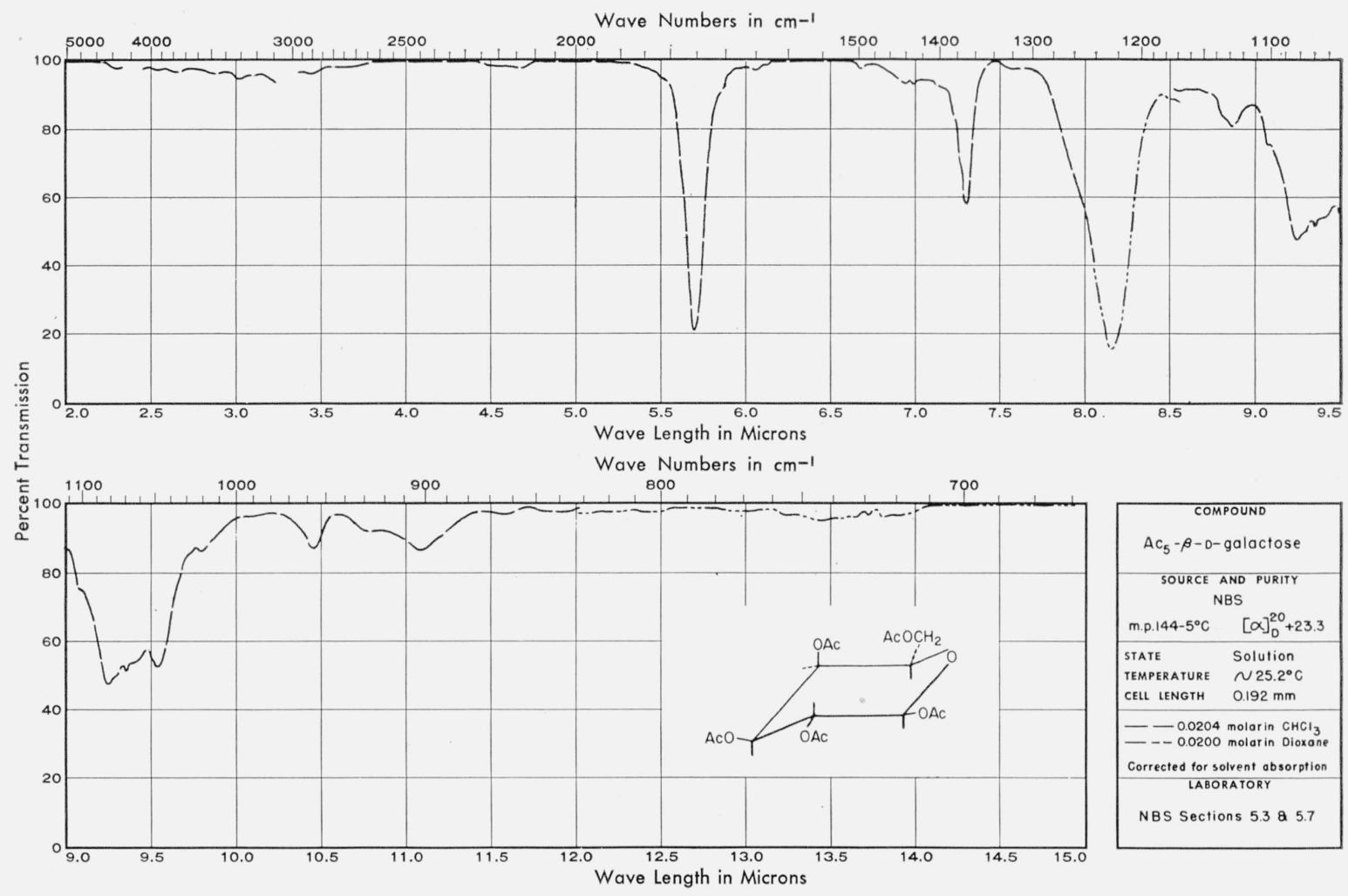

Figure 10.





Figure 11. 


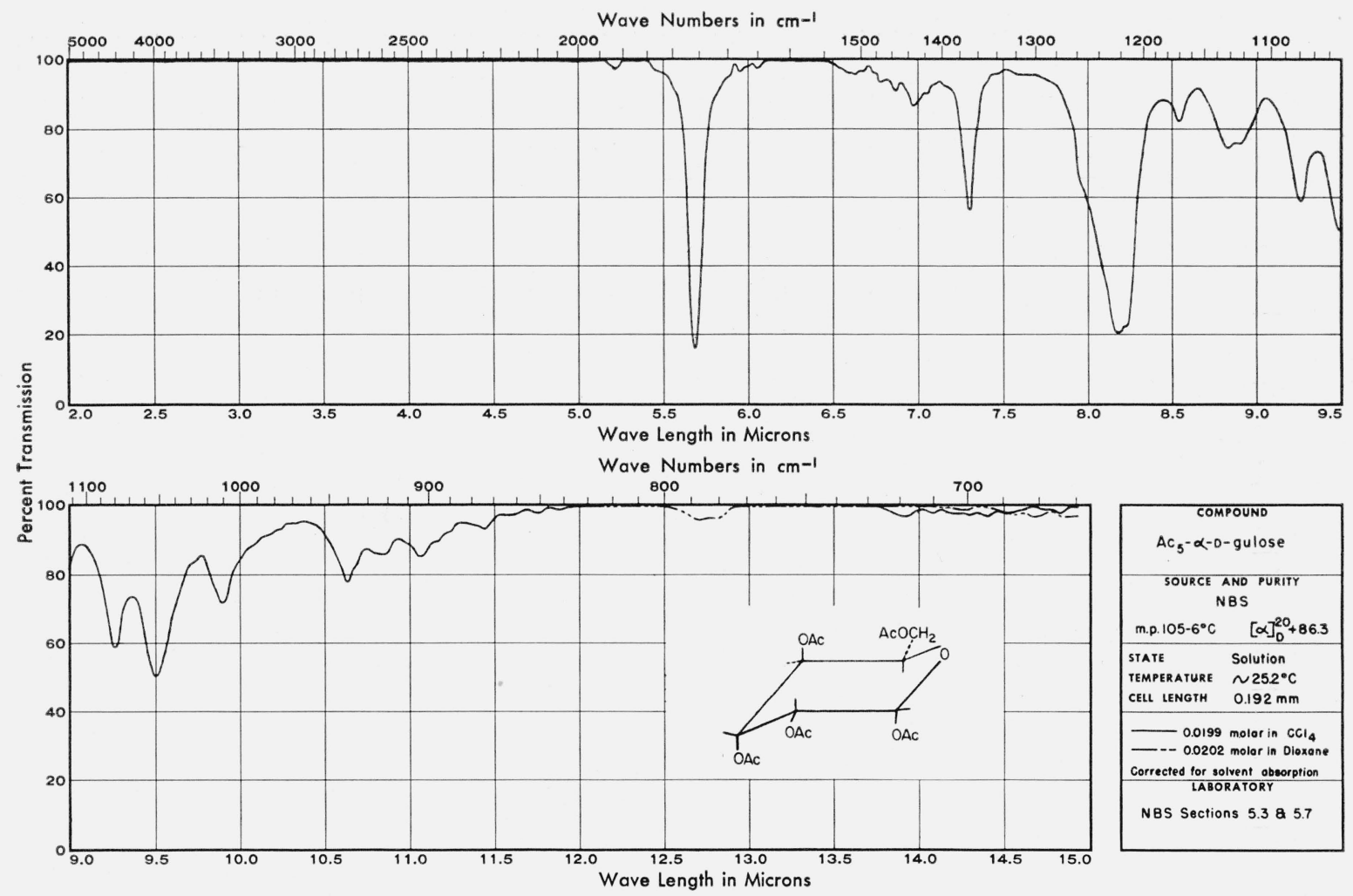

Figure 12.

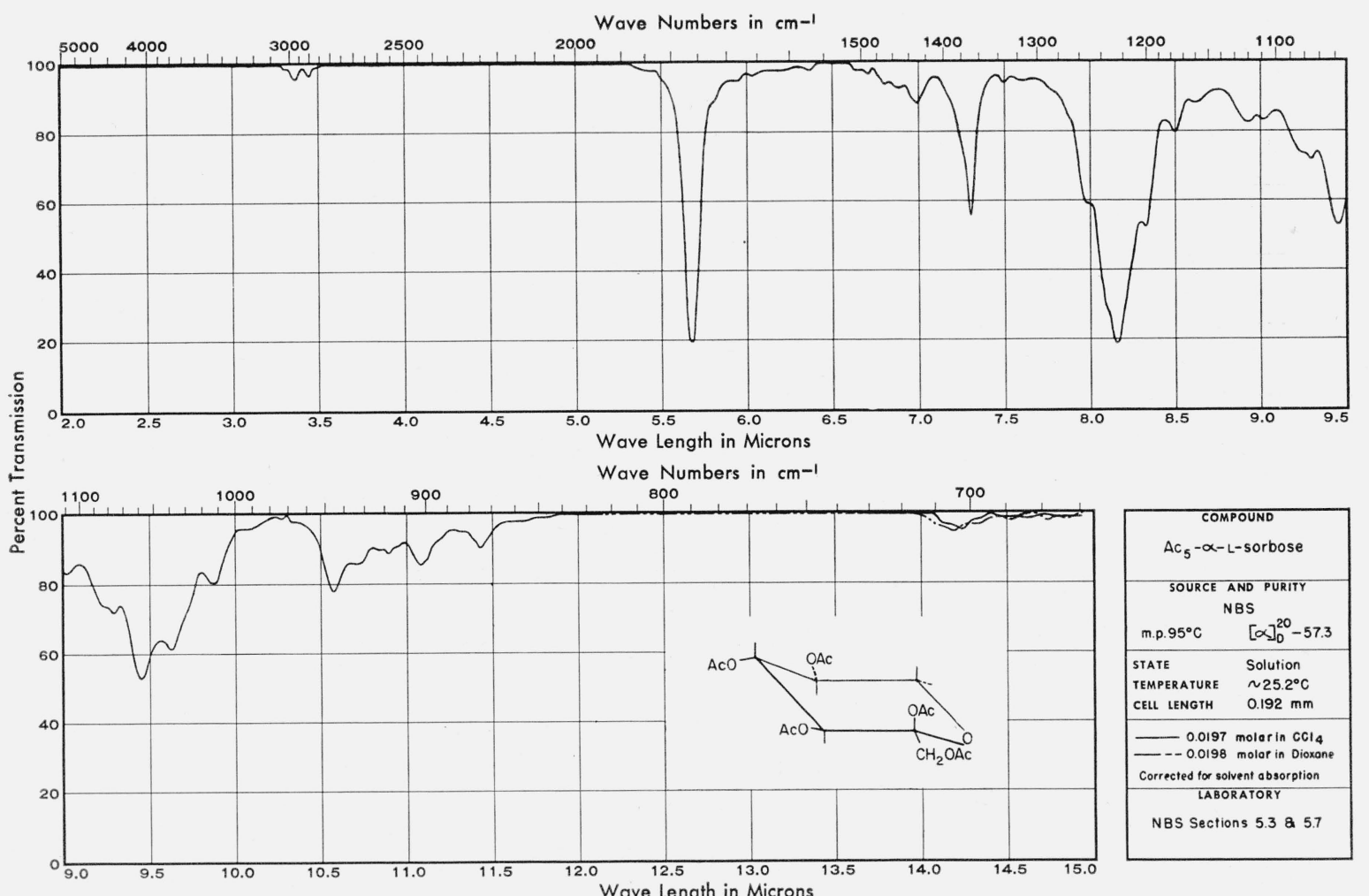

Figure 13. 


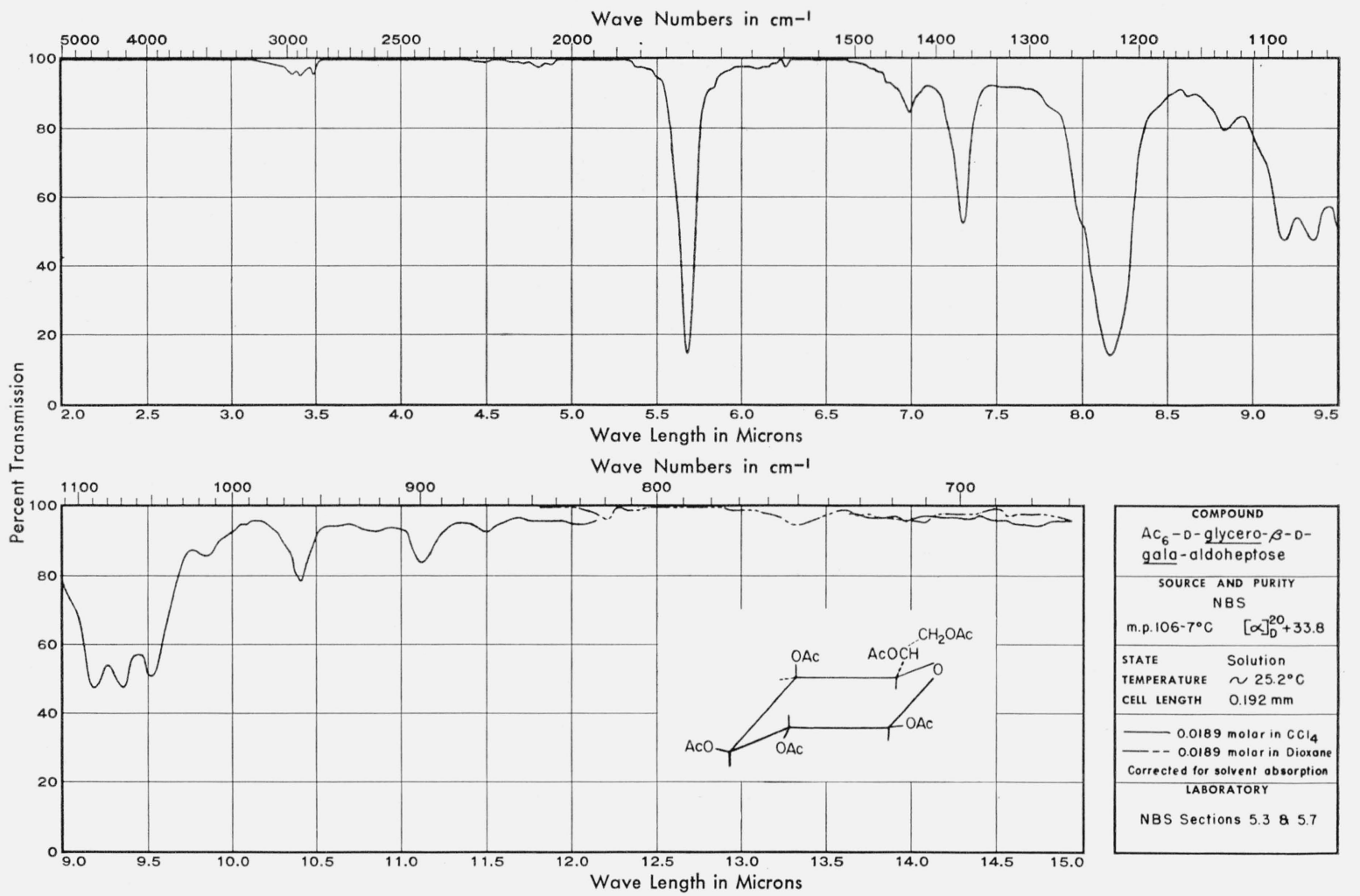

Figure 14.

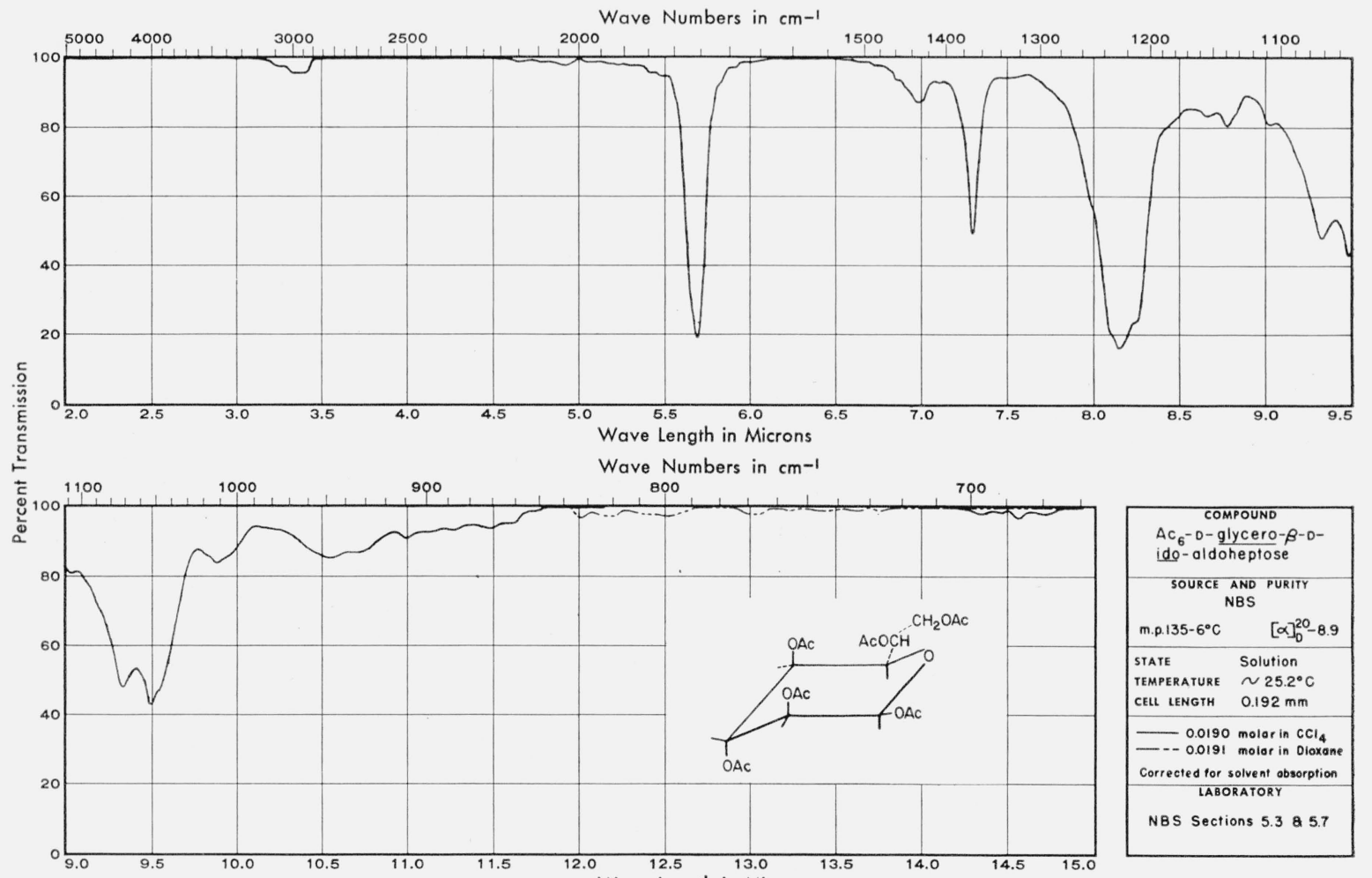

Figure 15. 


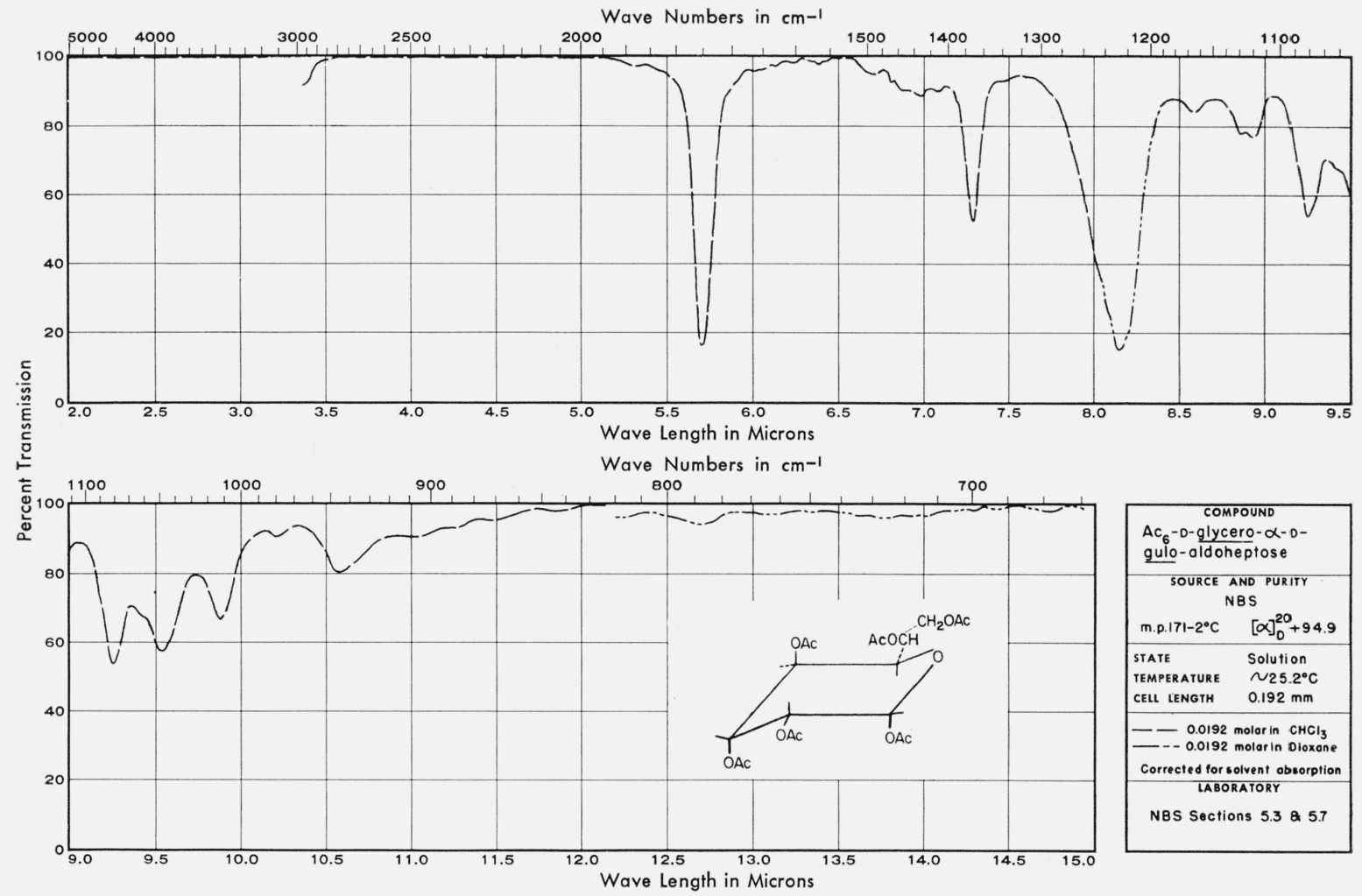

FiguRe 16.

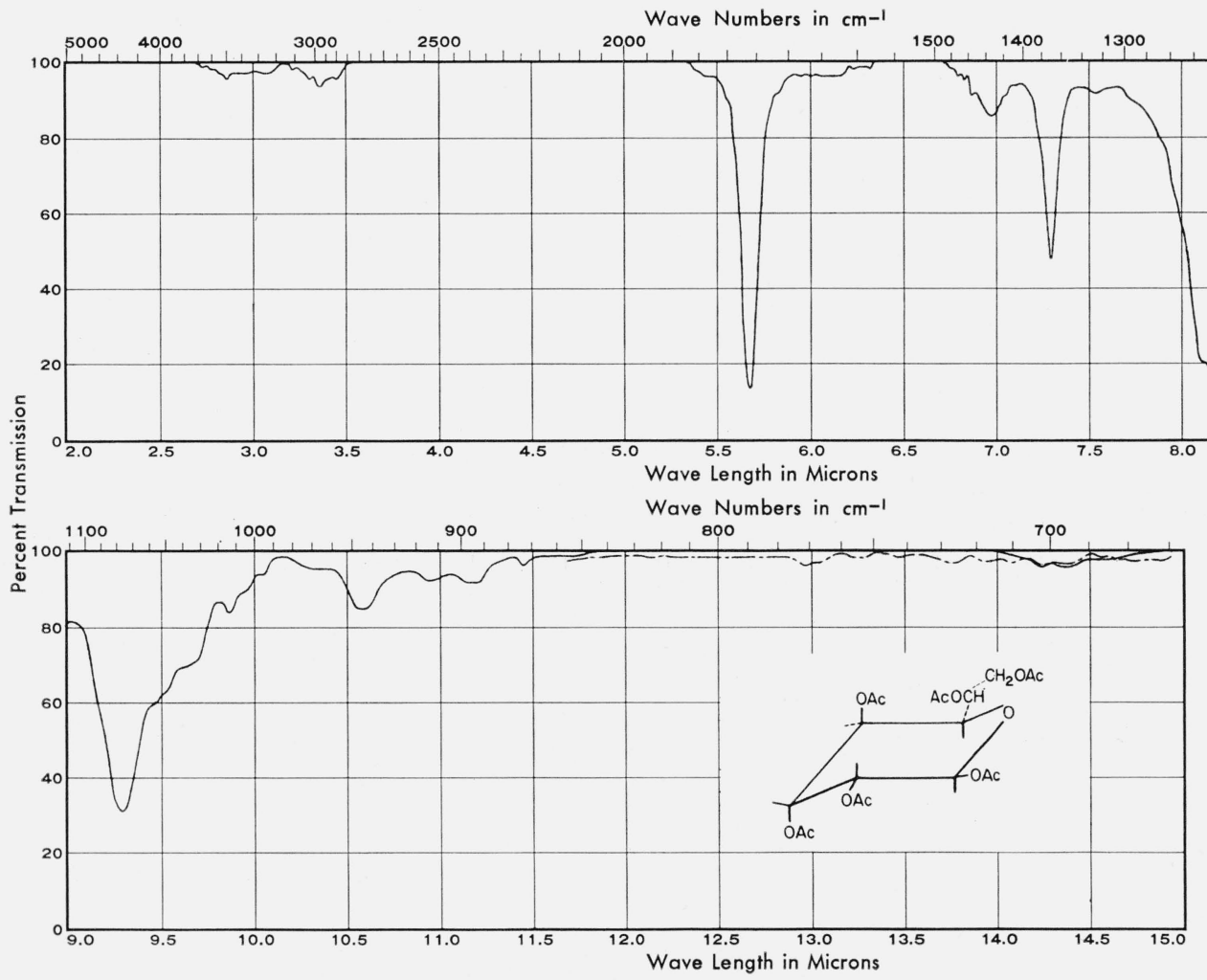

$\begin{array}{r}1200 \quad 1100 \\ \hline\end{array}$ 




Figure 18.


Figure 19. 


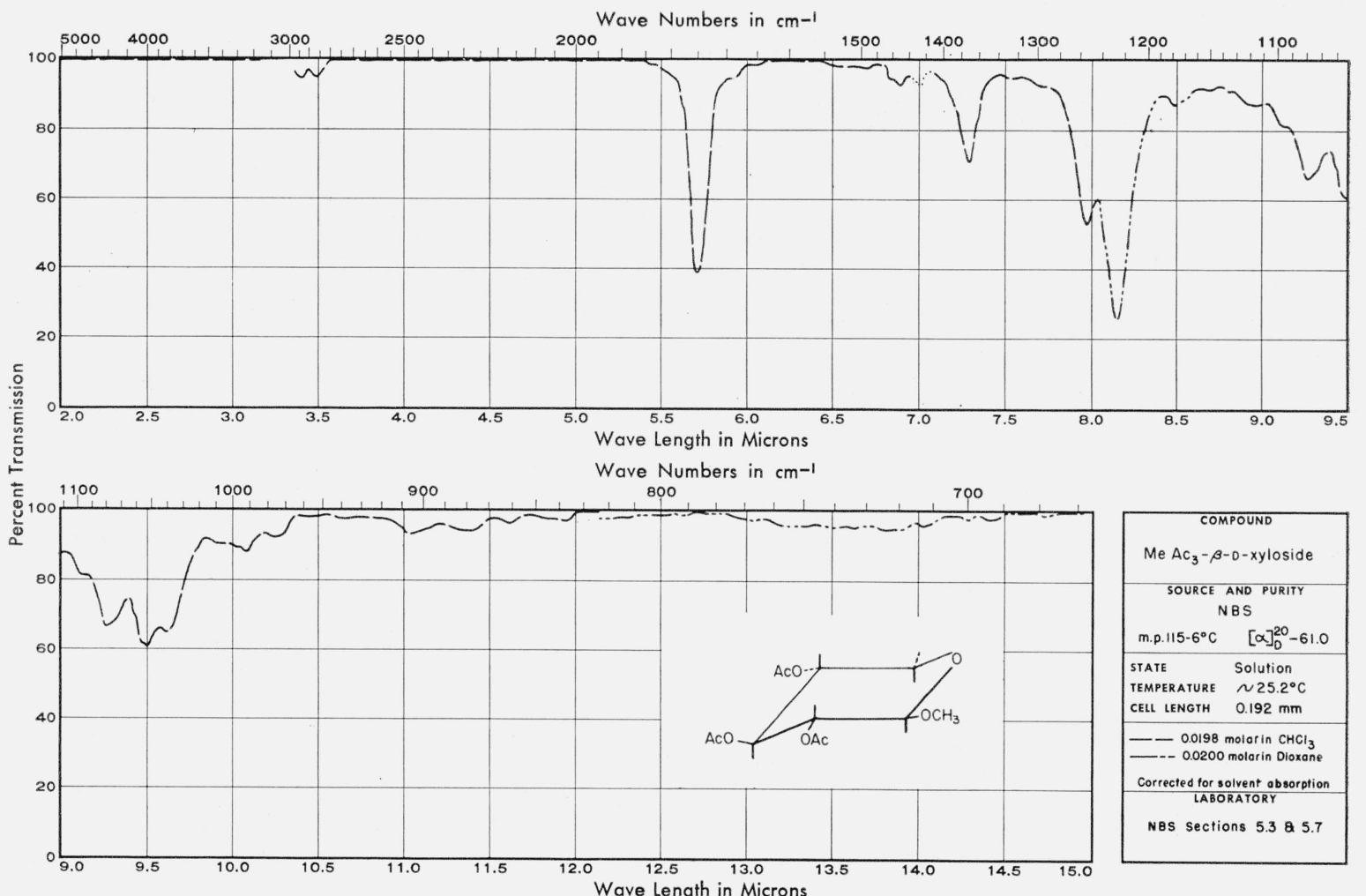

Figure 20.

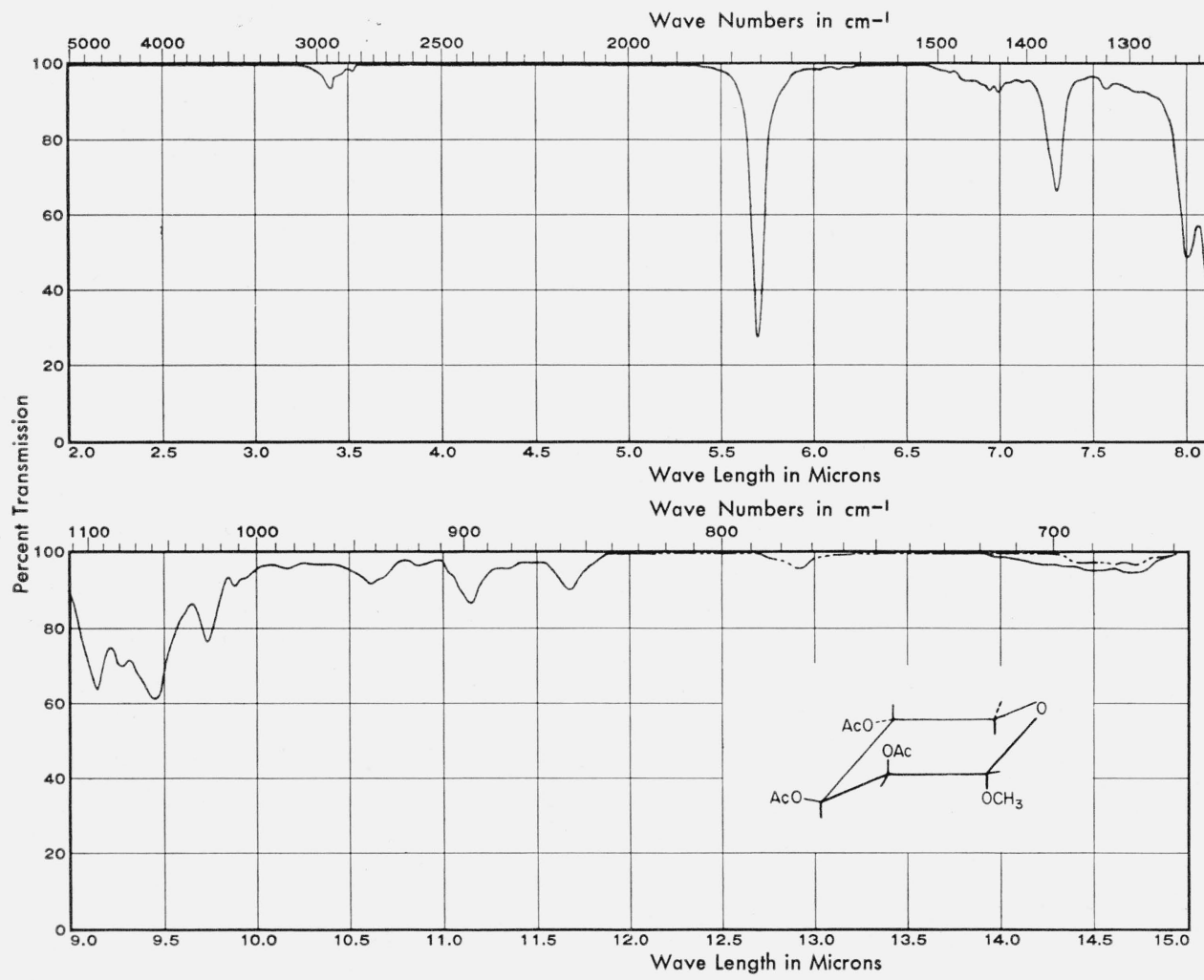

\begin{tabular}{|c|c|}
\hline $\begin{array}{l}\mathrm{COM} \\
\mathrm{Me} \mathrm{Ac}_{3}-\alpha\end{array}$ & $\begin{array}{l}\text { POUND } \\
\text { D-lyxoside }\end{array}$ \\
\hline SOURCE & $\begin{array}{l}\text { AND PURITY } \\
\text { BS }\end{array}$ \\
\hline m.p. $96^{\circ} \mathrm{C}$ & {$[\alpha]_{0}^{20}+30.4$} \\
\hline $\begin{array}{l}\text { STATE } \\
\text { TEMPERATURE } \\
\text { CELI LENGTH }\end{array}$ & $\begin{array}{l}\text { Solution } \\
\sim 25.2^{\circ} \mathrm{C} \\
0.192 \mathrm{~mm}\end{array}$ \\
\hline $\begin{array}{r}-0.0198 \\
--0.0199\end{array}$ & $\begin{array}{l}\text { molar in } \mathrm{CCl}_{4} \\
\text { molar in Dioxane }\end{array}$ \\
\hline $\begin{array}{r}\text { Corrected for } 8 \\
\text { LABO }\end{array}$ & $\begin{array}{l}\text { olvent absorption } \\
\text { RATORY }\end{array}$ \\
\hline NBS Secti & ons $5.3 \& 5.7$ \\
\hline
\end{tabular}

Figure 21. 




Figure 22.

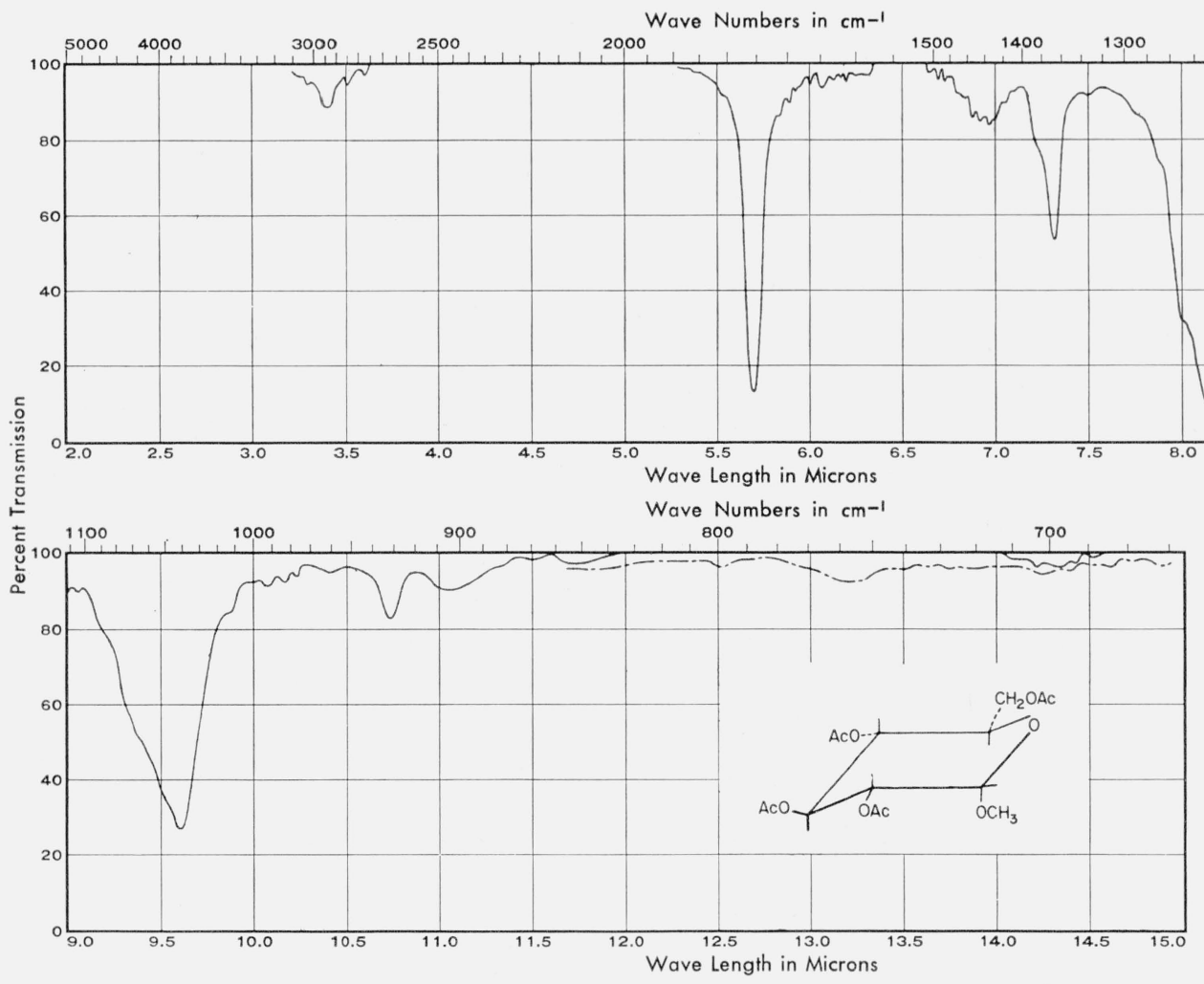

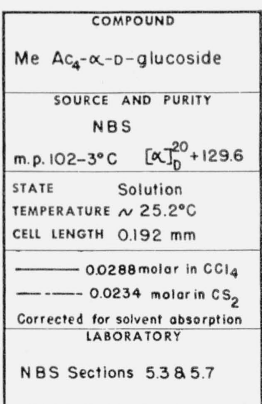

Figure 23. 


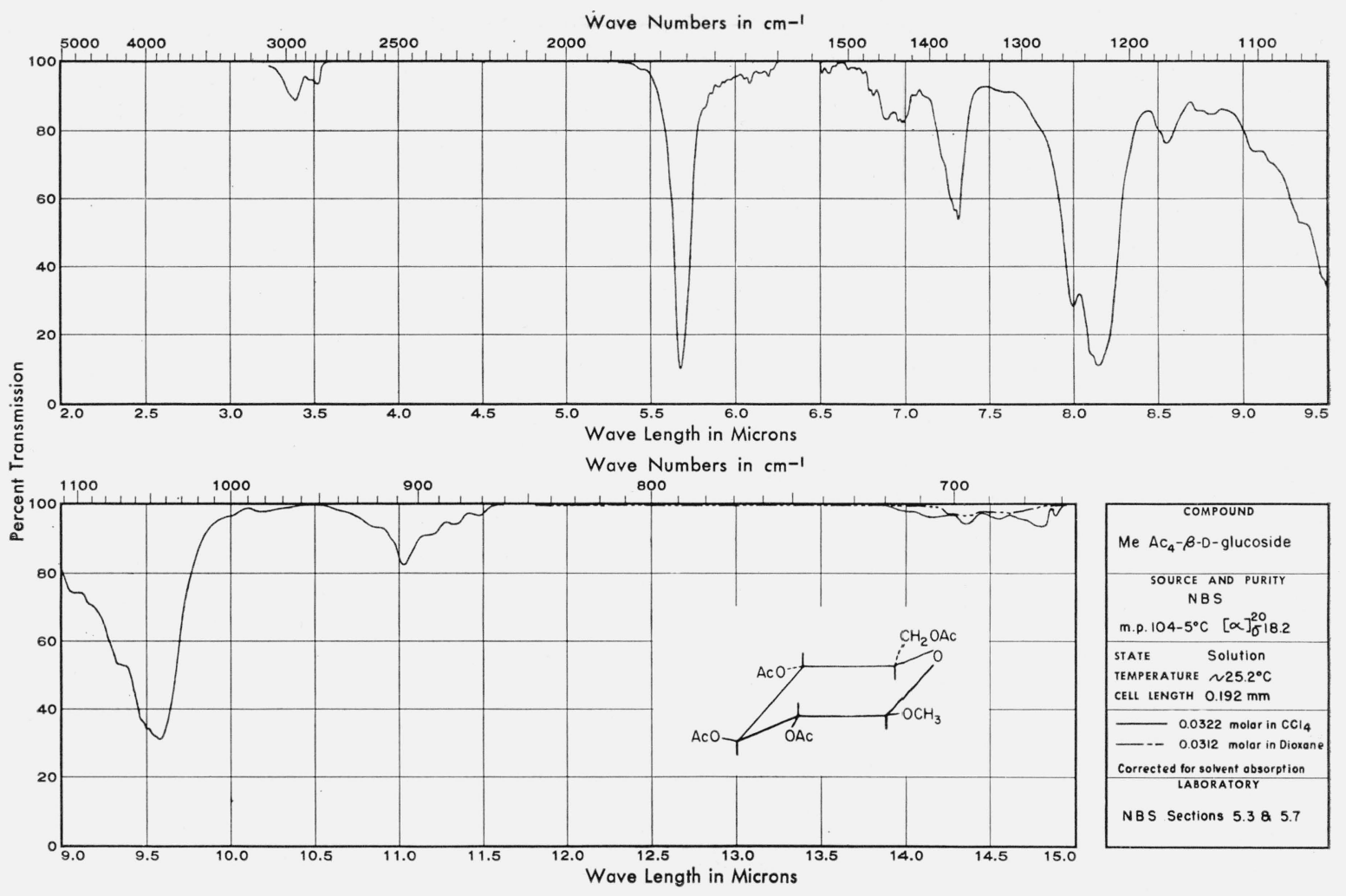

Figure 24.
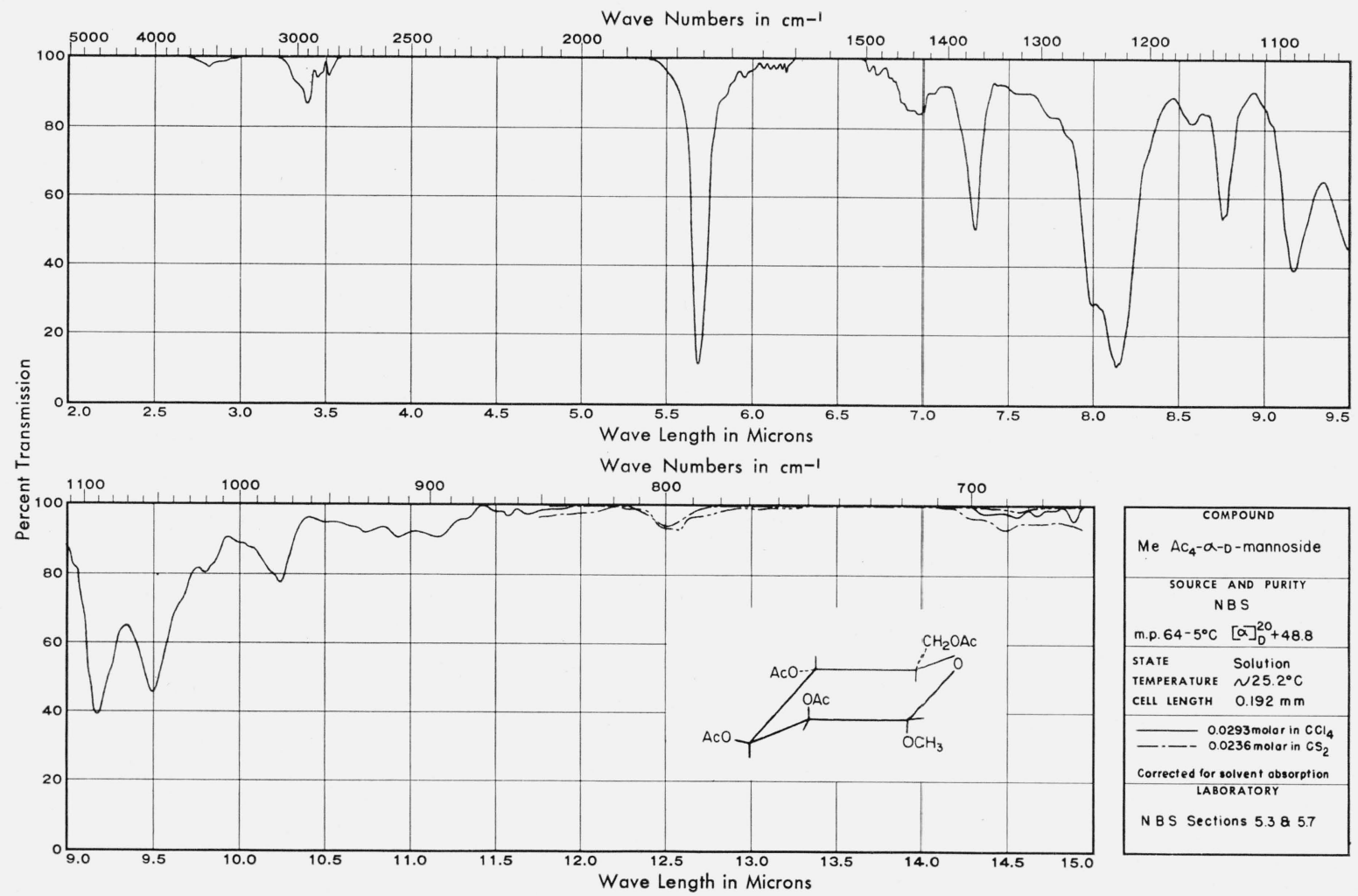

Figure 25. 




Figure 26.

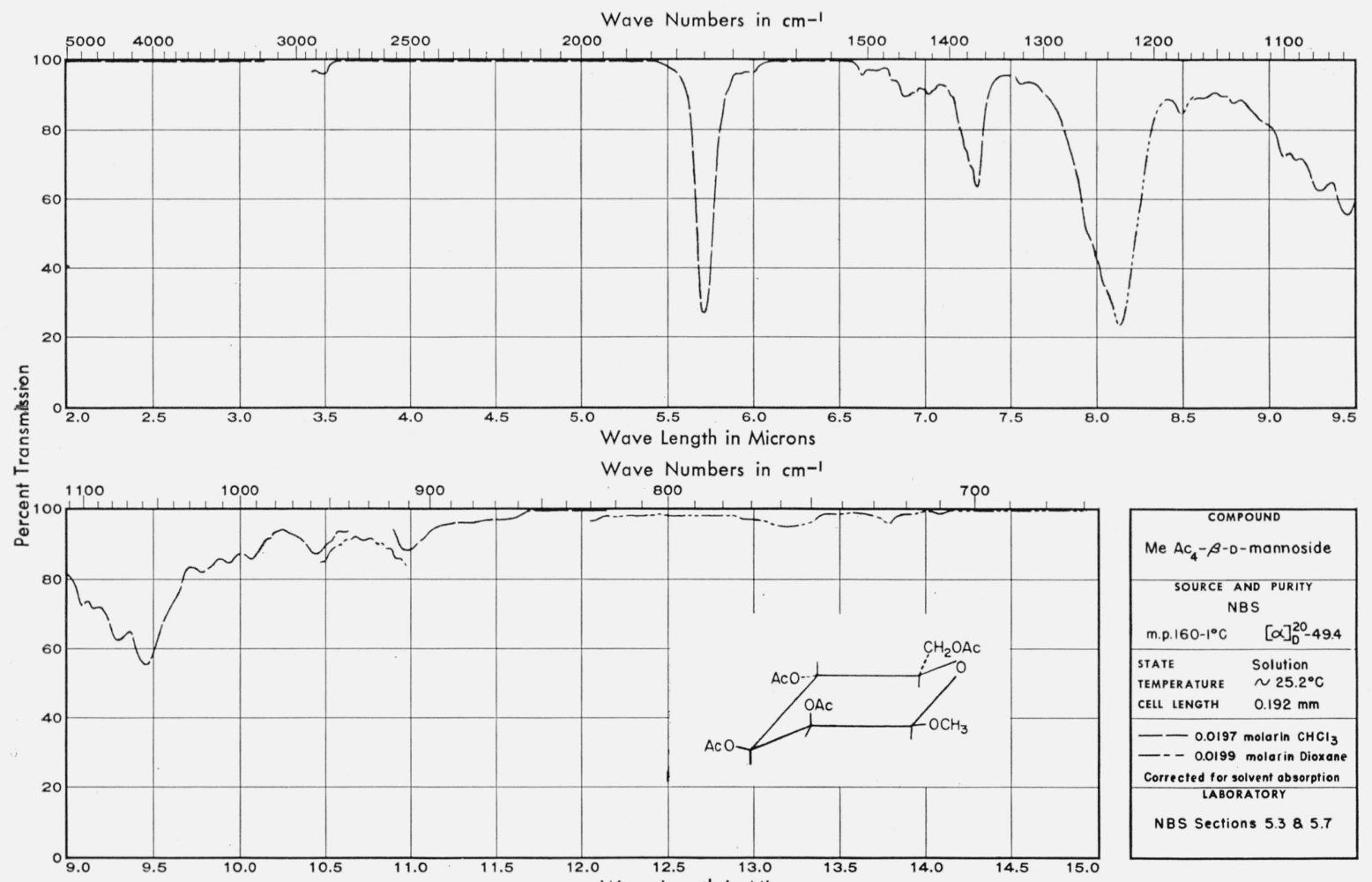

Figdre 27. 


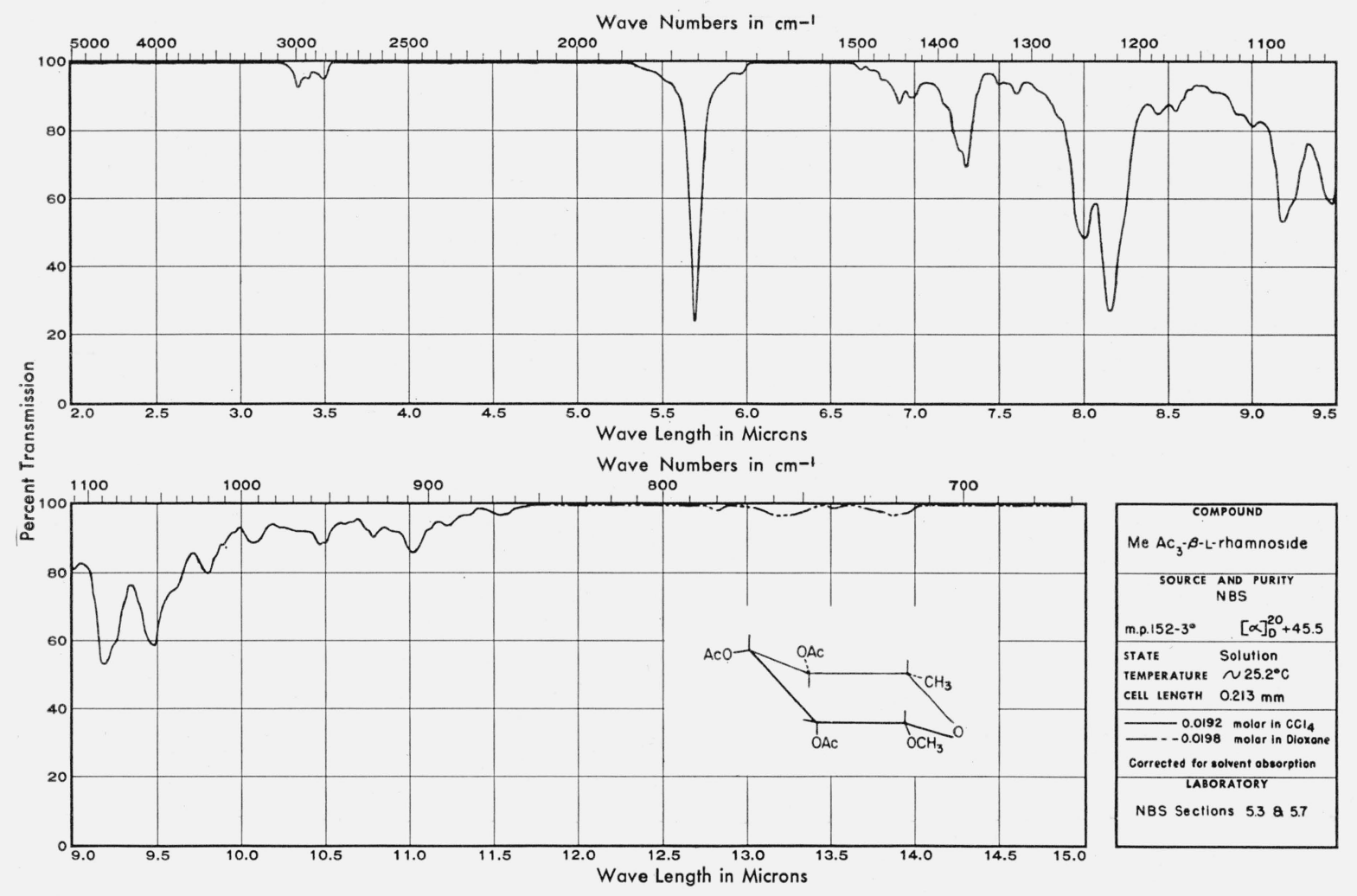

FigURE 28.

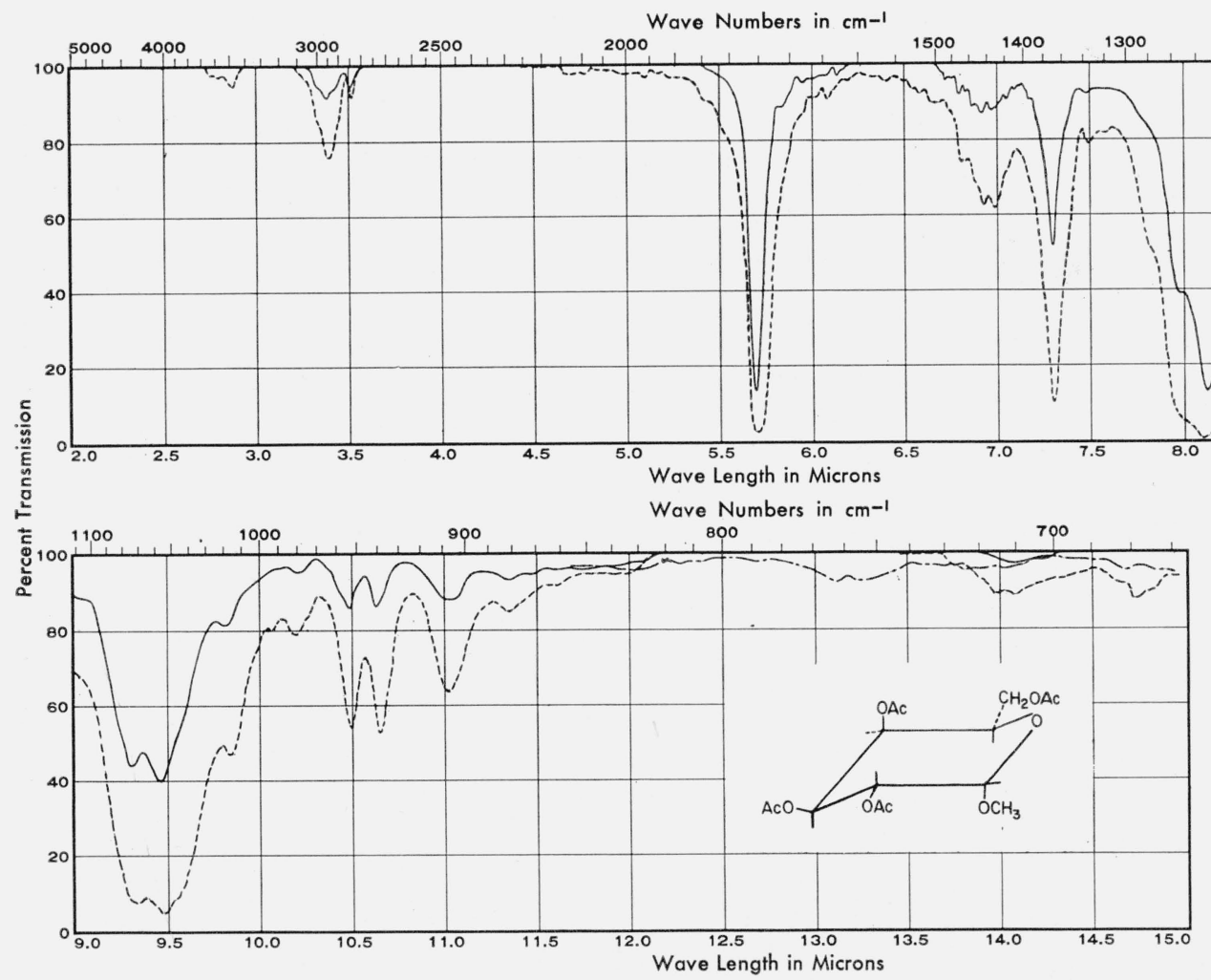

$1200 \quad 1100$

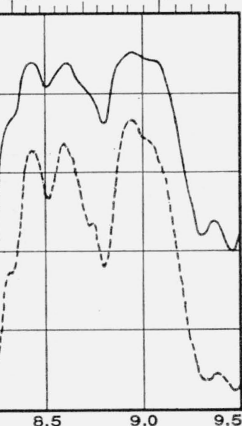

Figure 29. 



Figure 30.

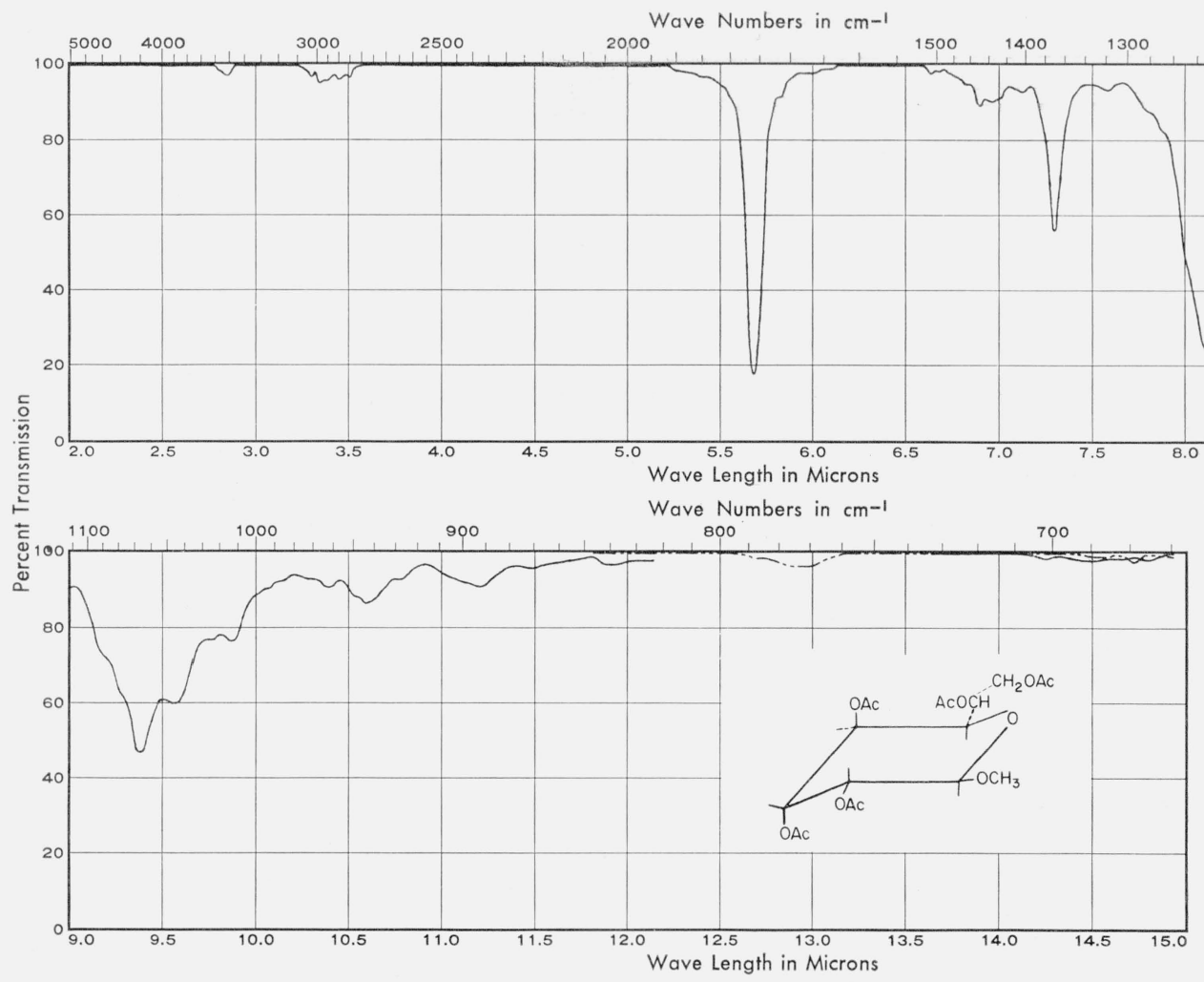

COMPOUND

$M e \mathrm{AC}_{5}-0$-glycero- $\beta$ - 0 -

gulo-aldoheptoside

SOURCE AND PURITY

SOURCE AND
NBS

m.p. $153-4^{\circ} \mathrm{C}[\alpha]_{0}^{20}-20.8$

STATE Solution

TEMPERATURE $\sim 25.2^{\circ} \mathrm{C}$

CELL LENGTH $0.192 \mathrm{~mm}$

0.0197 molor in $\mathrm{CCl}_{4}$

- 0.0182 moiar in Dioxane

Corrected for solvent obsorption

LABORATORY

NBS Sections $5.3 \& 5.7$

Figure 31. 


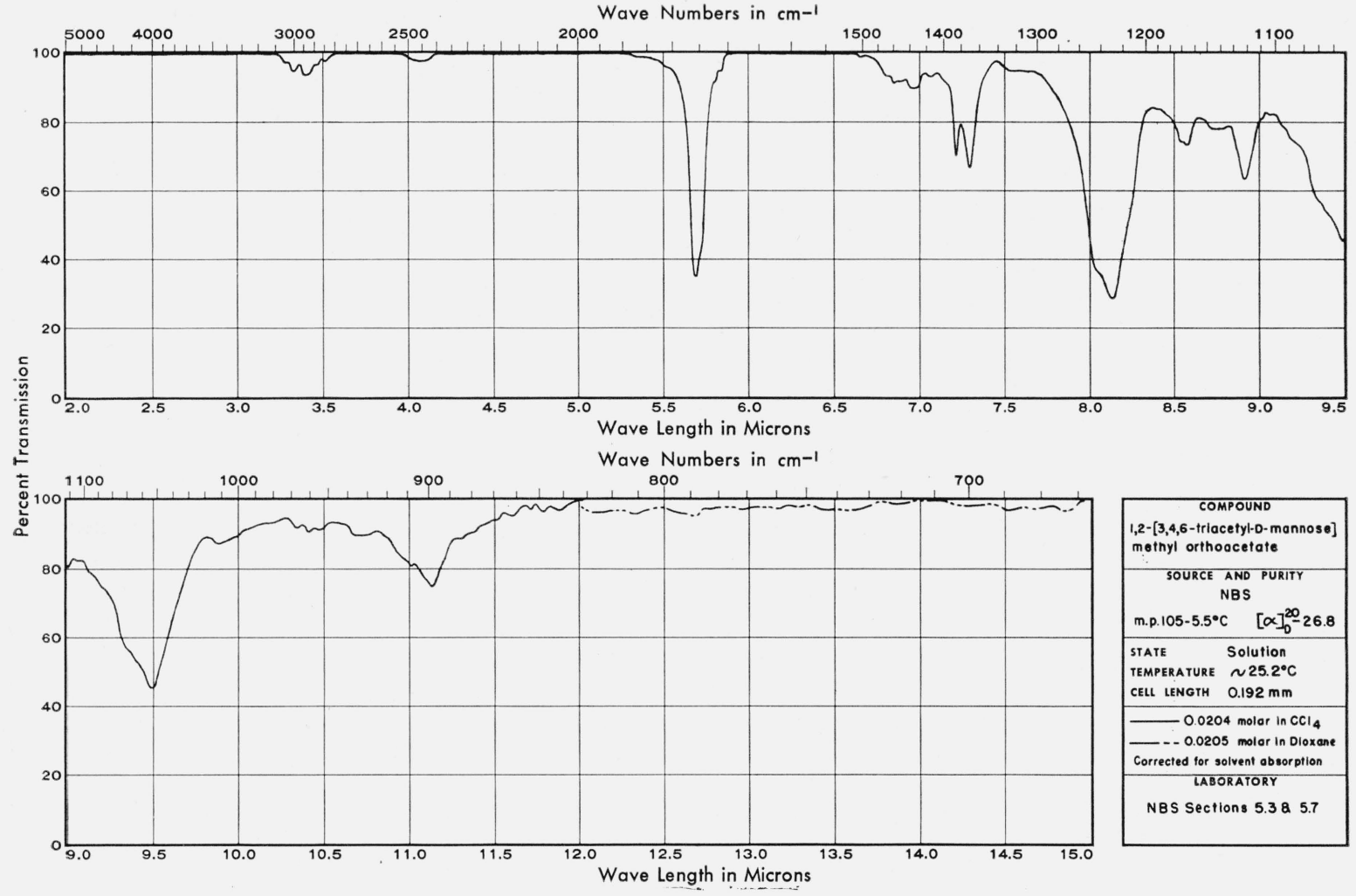

Figure 32

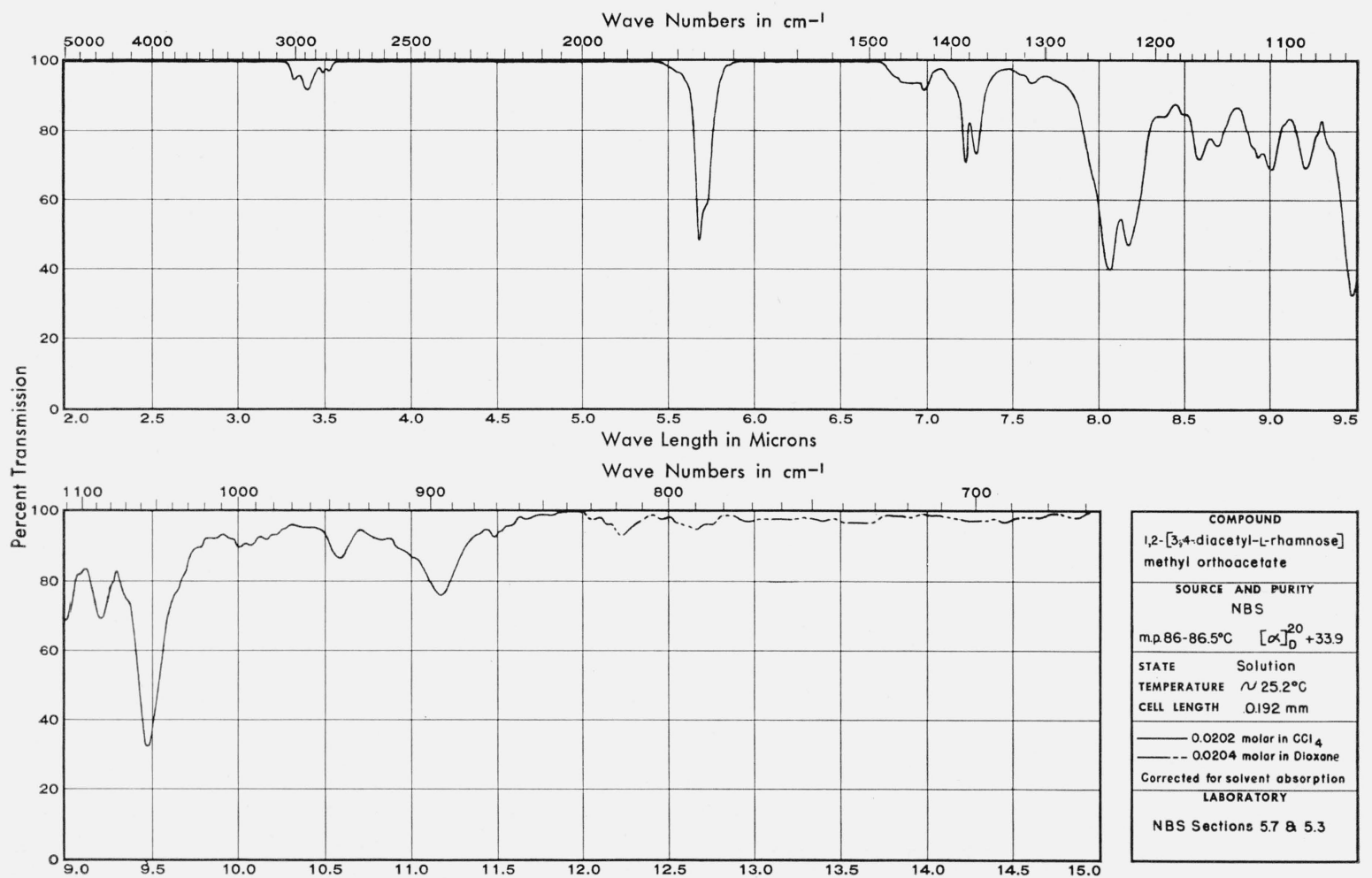

Figure 33. 




Figure 34 .

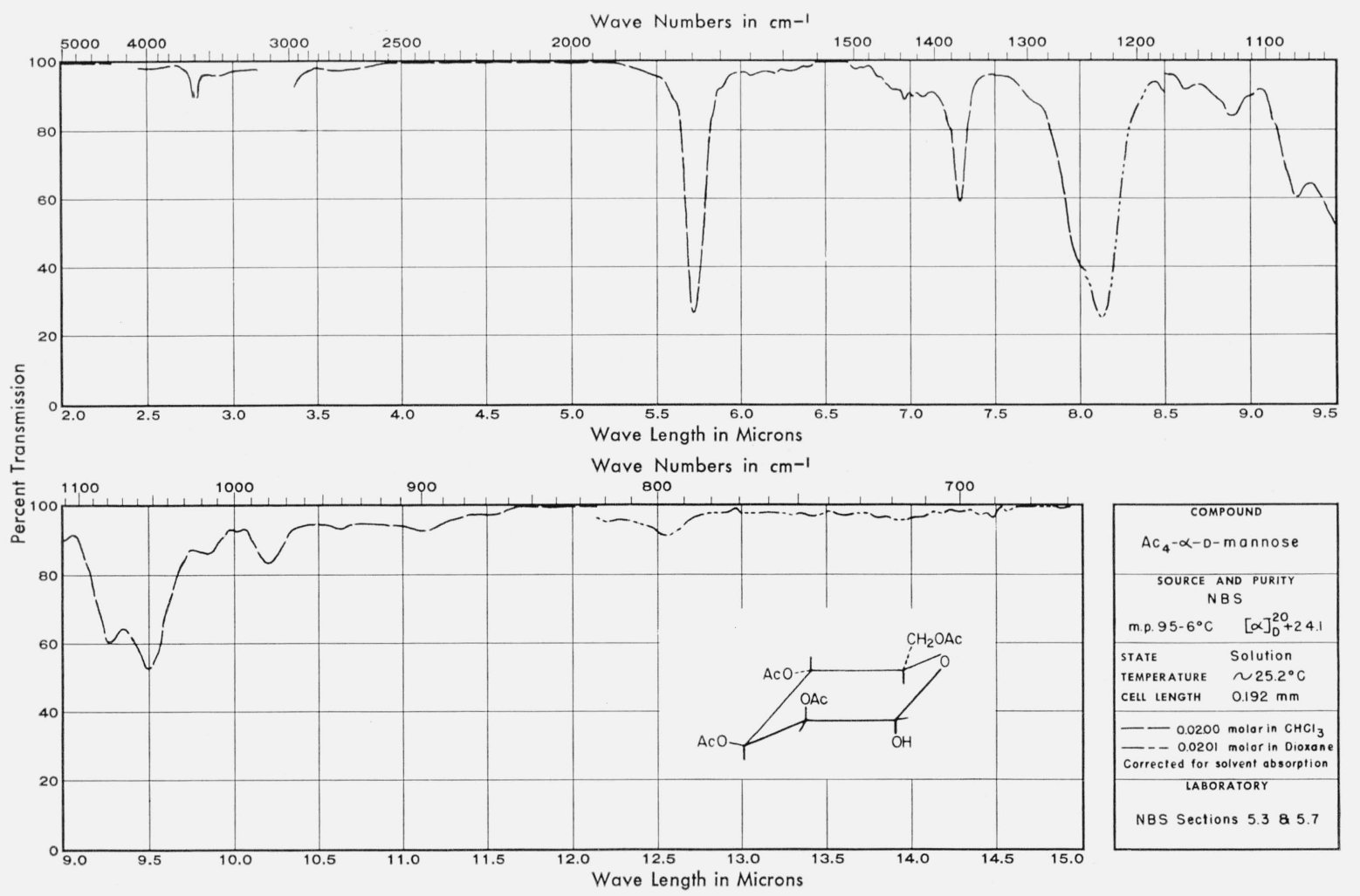

Figure 35. 

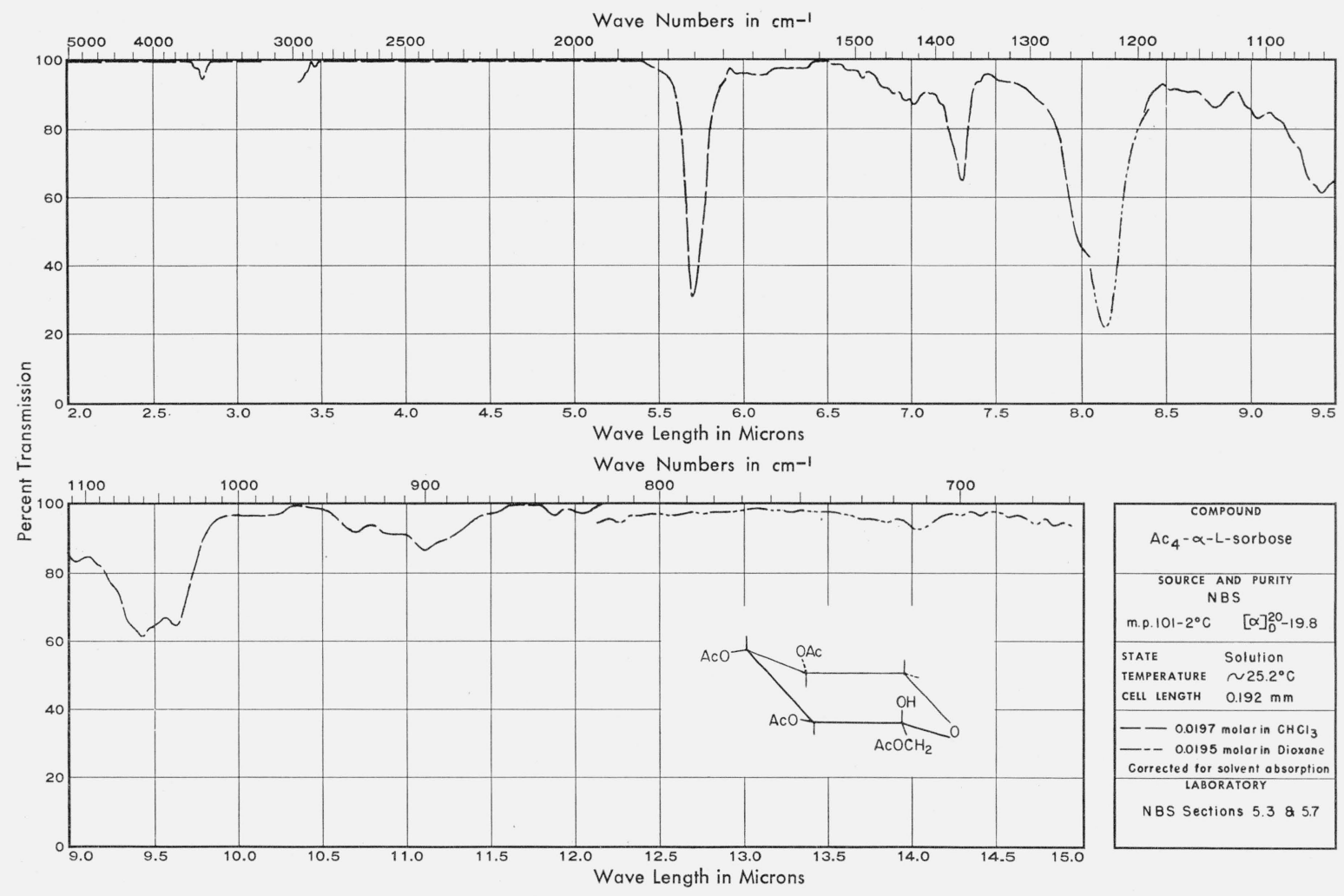

Figure 36.

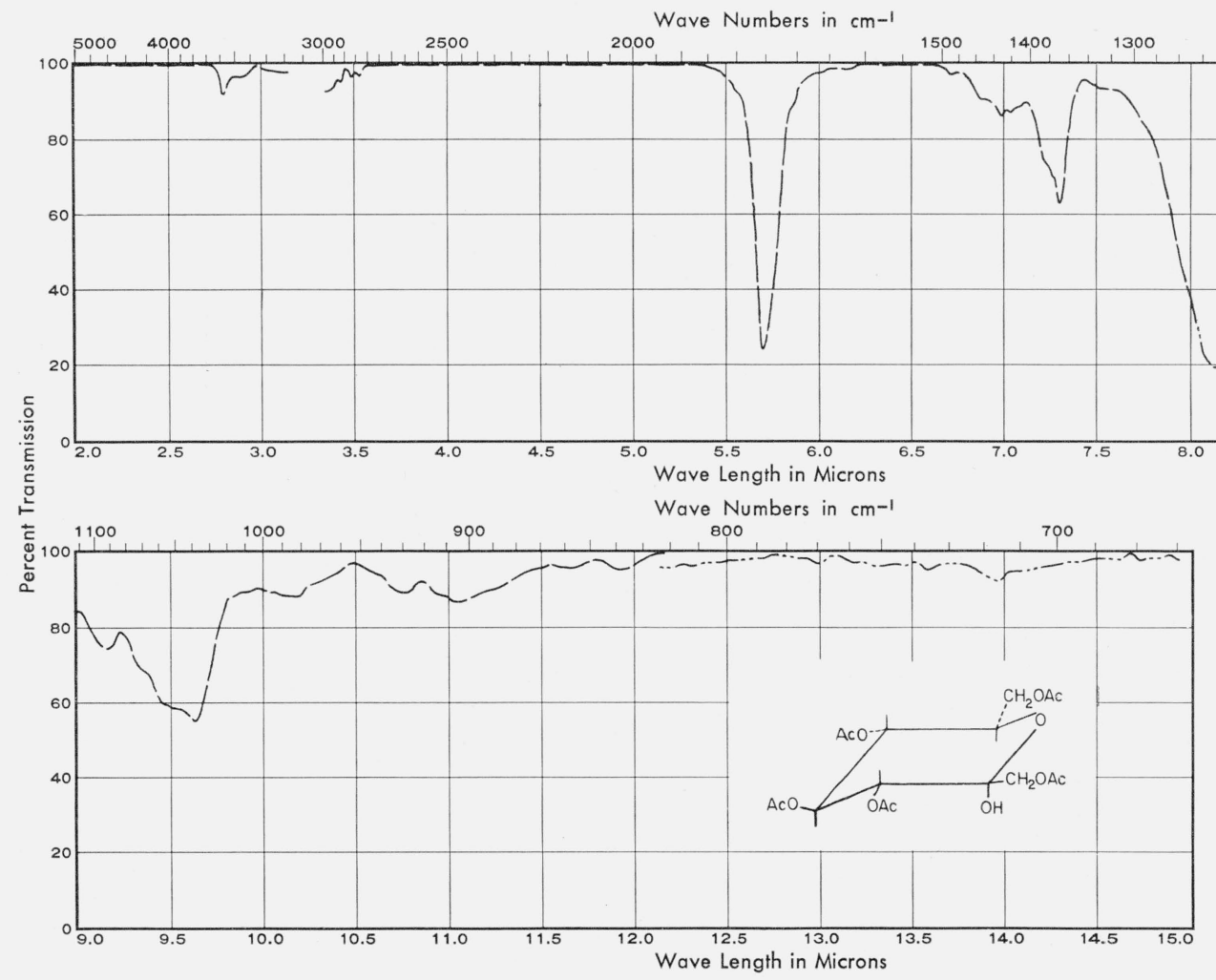

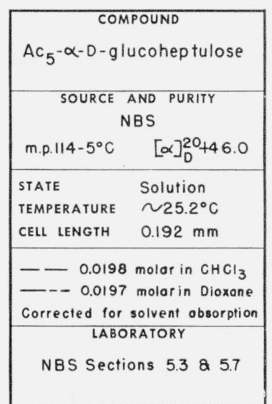

Figure 37. 




Figure 38.

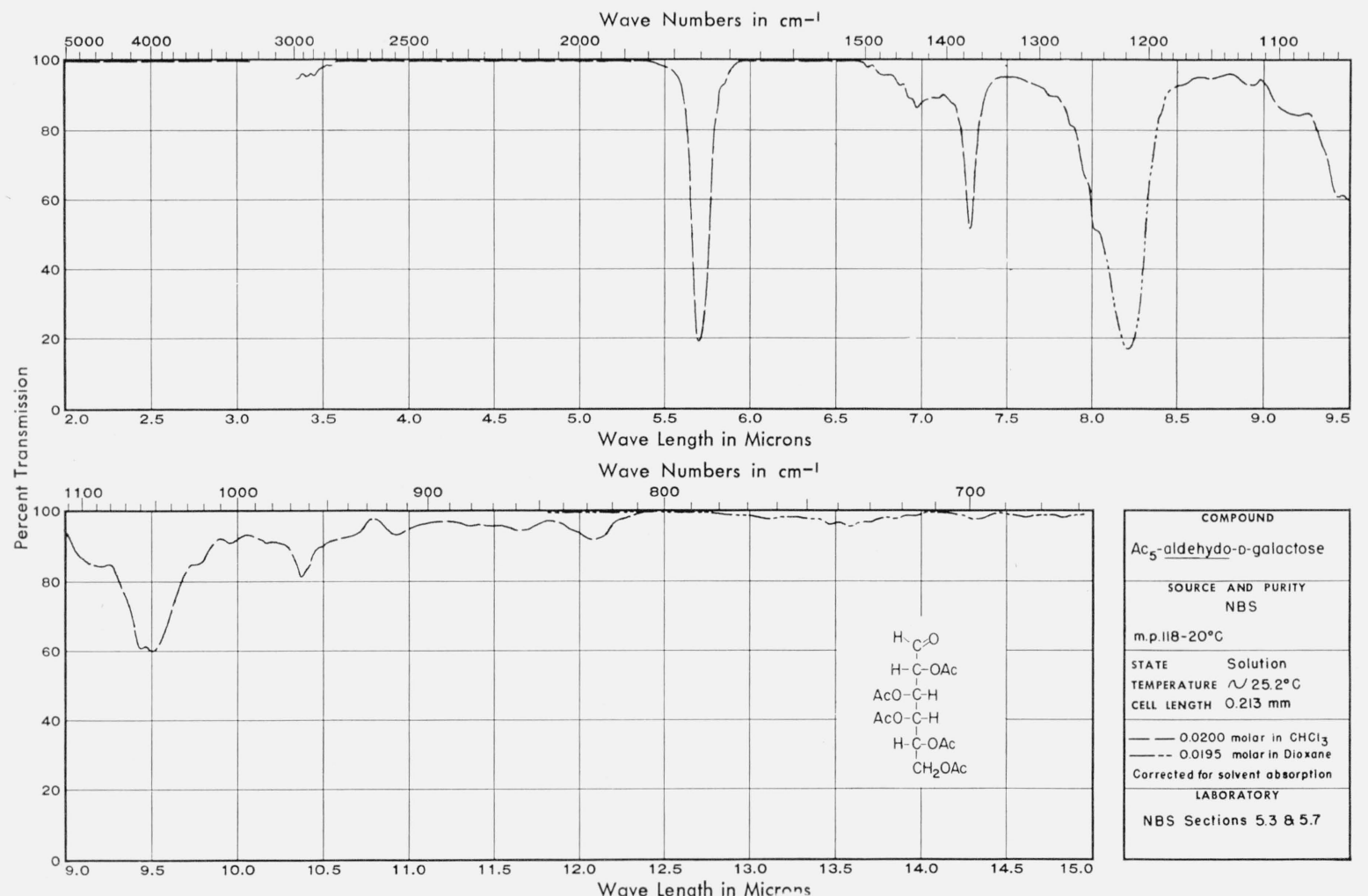

Figure 39. 


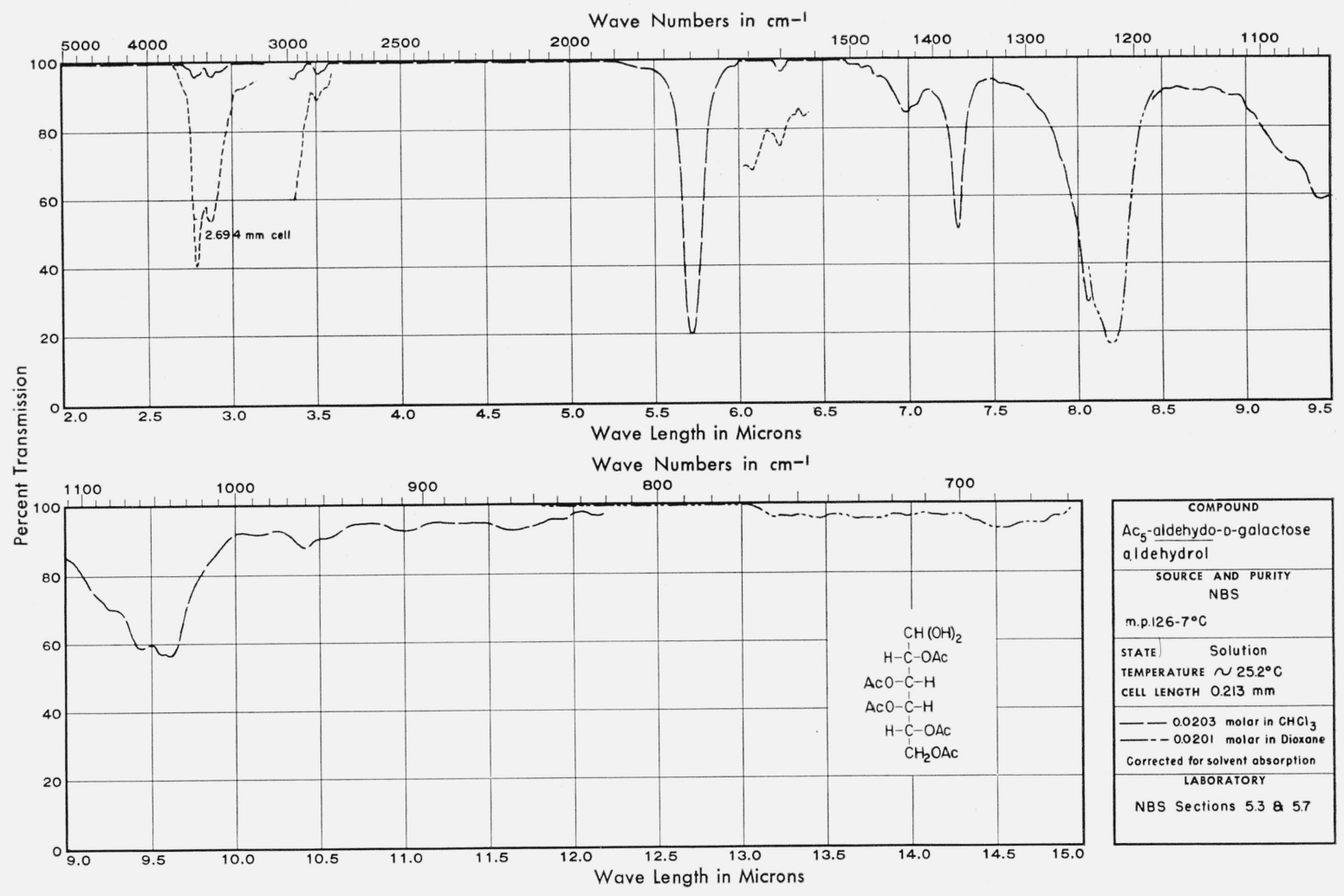

Figure 40.

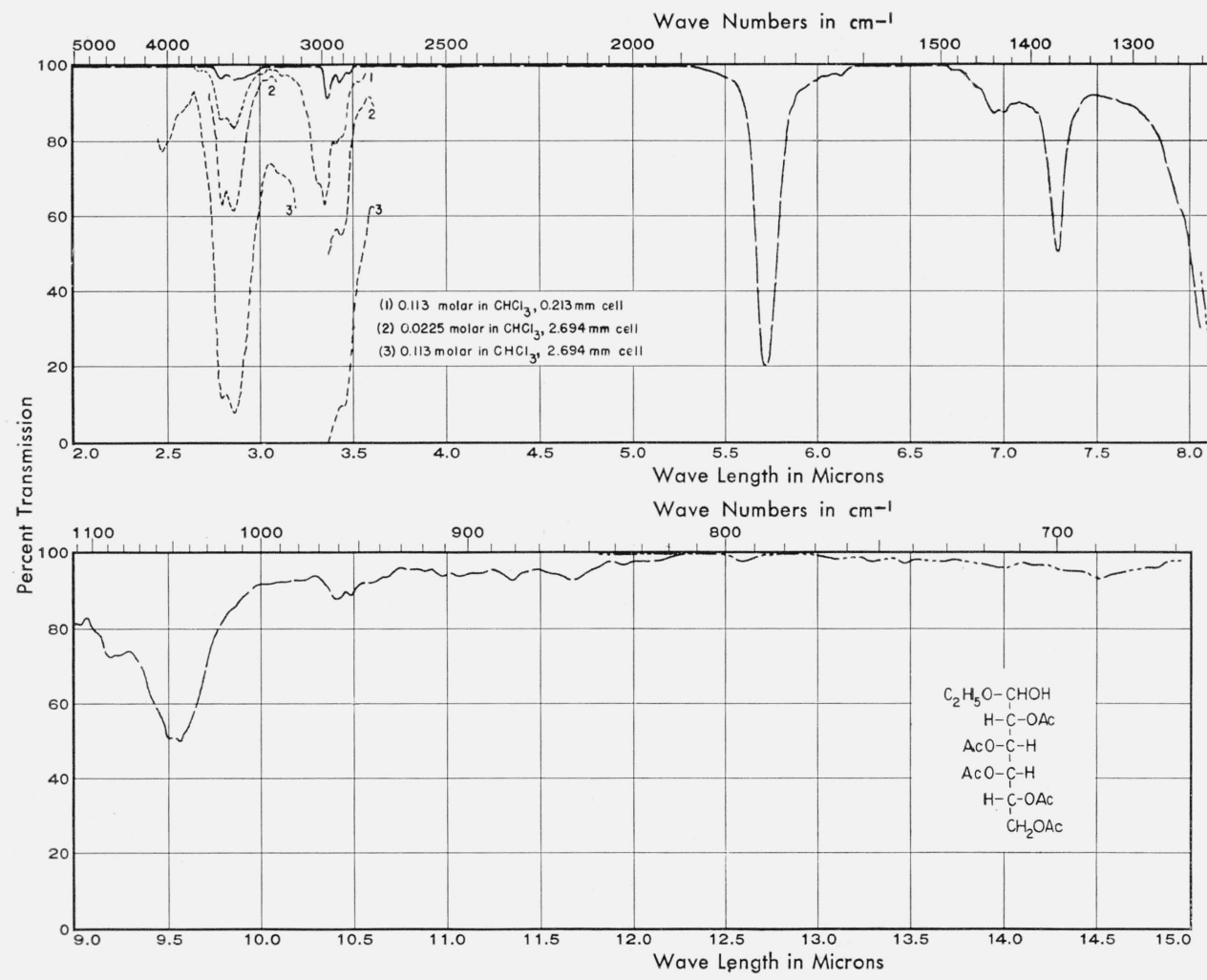

COMPOUND ethyl hemiacetal

ethyl hemiacetal
SOURCE AND PURITY NBS

m.p. $134-5^{\circ} \mathrm{C}$

State Solution

TEMPERATURE $\sim 25.2^{\circ} \mathrm{C}$

CELL LENGTH $0.213 \mathrm{~mm}$

- 0.0225 moler in $\mathrm{CHCl}_{3}$

- - 00097 moler in Dioxane Corrected for solvent absorption LABORATORY

NBS Sections $5.3 \& 57$

Figure 41. 


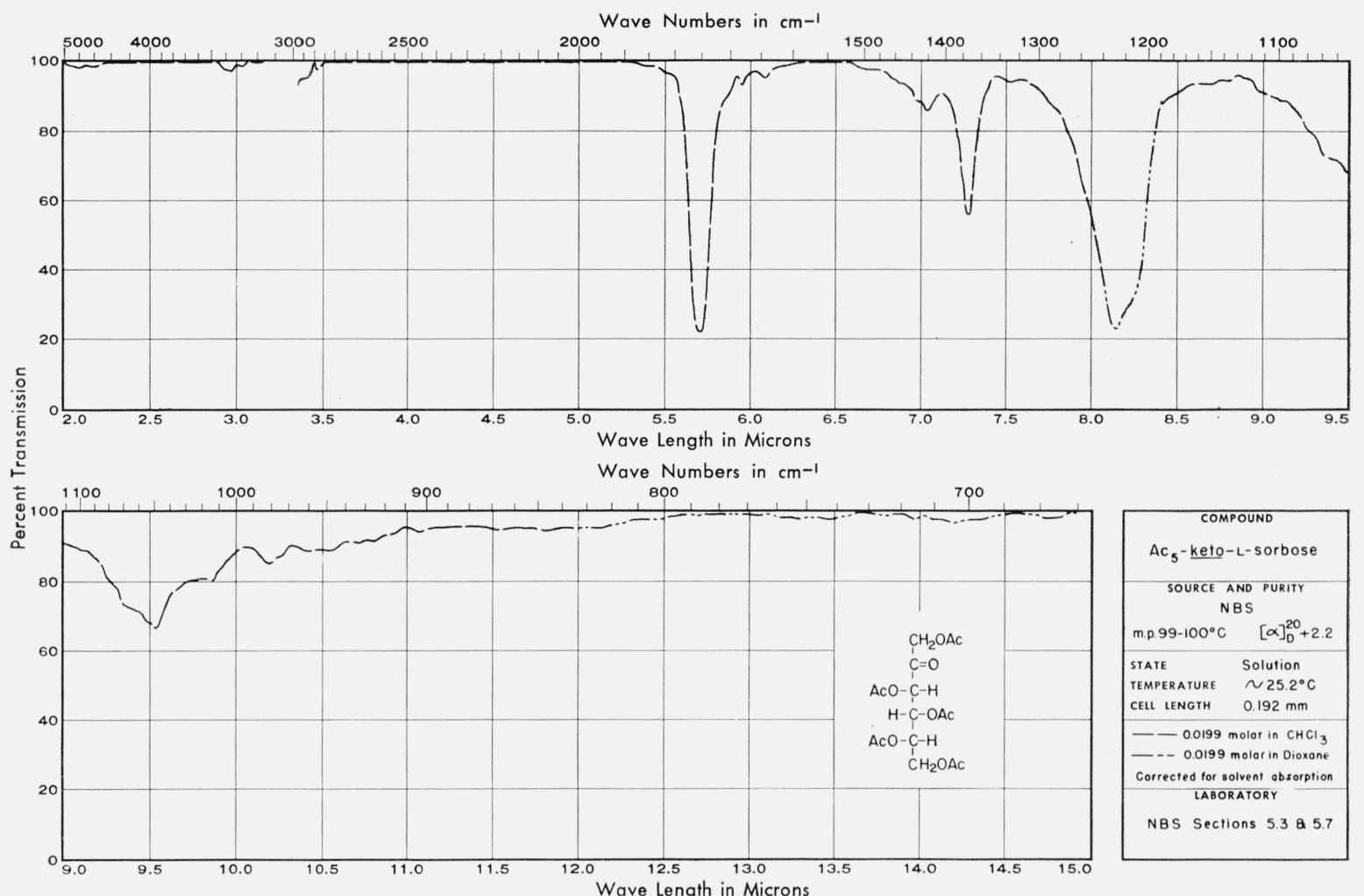

Figure 42.



COMPOUND

$\mathrm{AC}_{4}$-aldehydo-L-arabinose ethyl mercaptal

SOURCE AND PURITY NBS

m.p. $78.5-79^{\circ} \mathrm{C} \quad[\alpha]_{0}^{20}-27.9$

STATE Solution

TEMPERATURE $\sim 25.2^{\circ} \mathrm{C}$

CELL LENGTH $0.213 \mathrm{~mm}$

0.0199 molor in $\mathrm{CCl}_{4}$

- - 0.0198 molar in Dioxane Corrected for solvent obsorption LABORATORY

NBS Sections 5.3 \& 5.7

Figure 43. 




Figure 44.

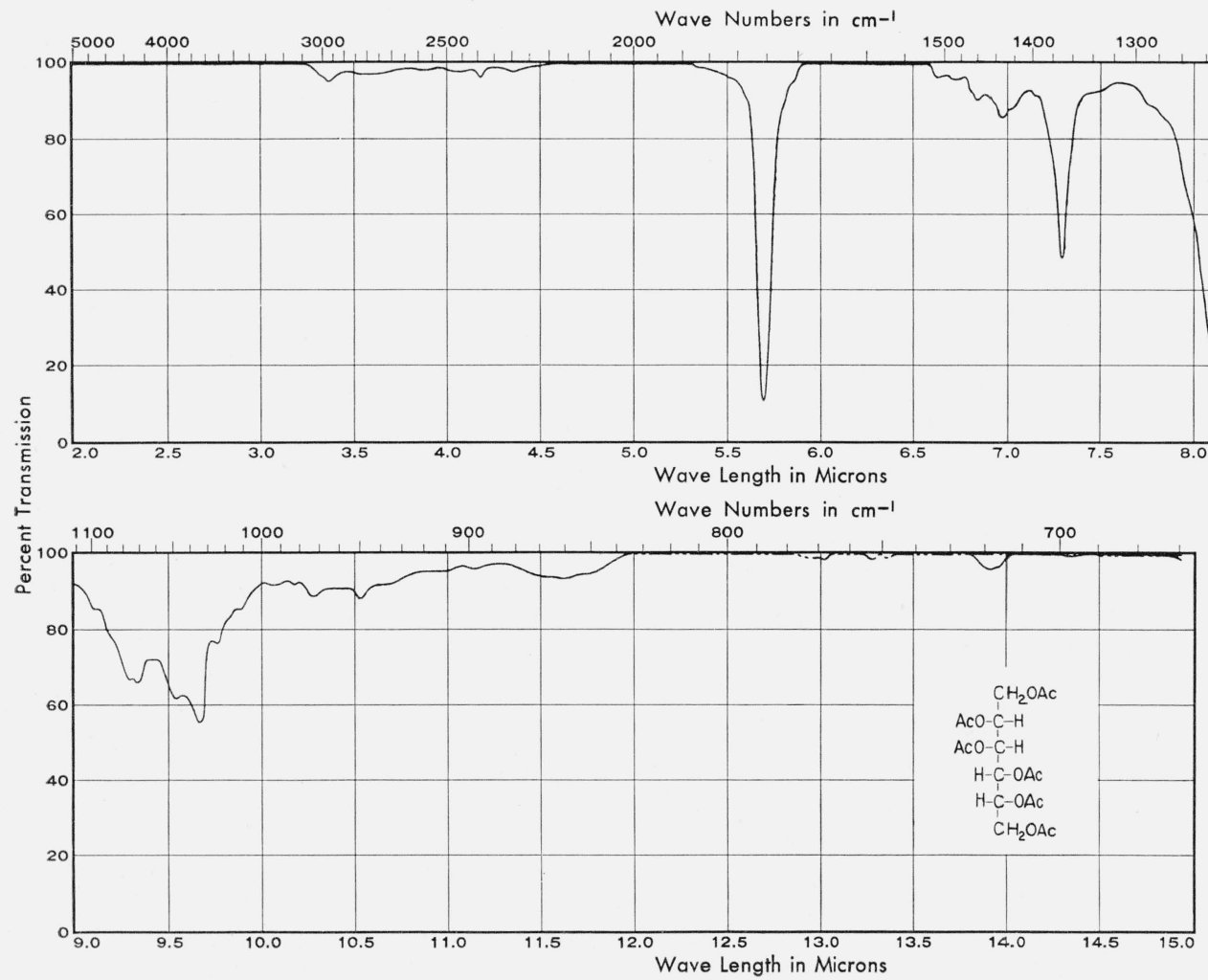

\begin{tabular}{|c|}
\hline $\begin{array}{c}\text { COMPOUND } \\
\mathrm{AC}_{6}-\mathrm{D}-\text { mannitol }\end{array}$ \\
\hline $\begin{array}{c}\text { SOURCE AND PURITY } \\
\text { NBS }\end{array}$ \\
\hline m.p.123-4. \\
\hline $\begin{array}{ll}\text { STATE } & \text { Solution } \\
\text { TEMPERATURE } & \sim 25.2^{\circ} \mathrm{C} \\
\text { CELL LENGTH } & 0.192 \mathrm{~mm}\end{array}$ \\
\hline $\begin{array}{c}-0.0196 \text { molor in } \mathrm{CCl}_{4} \\
--0.0197 \text { molor in Dioxone } \\
\text { Corrected for solvent obsorption } \\
\text { LABORATORY }\end{array}$ \\
\hline NBS Sections 5.3 \& 5.7 \\
\hline
\end{tabular}

Figure 45 . 


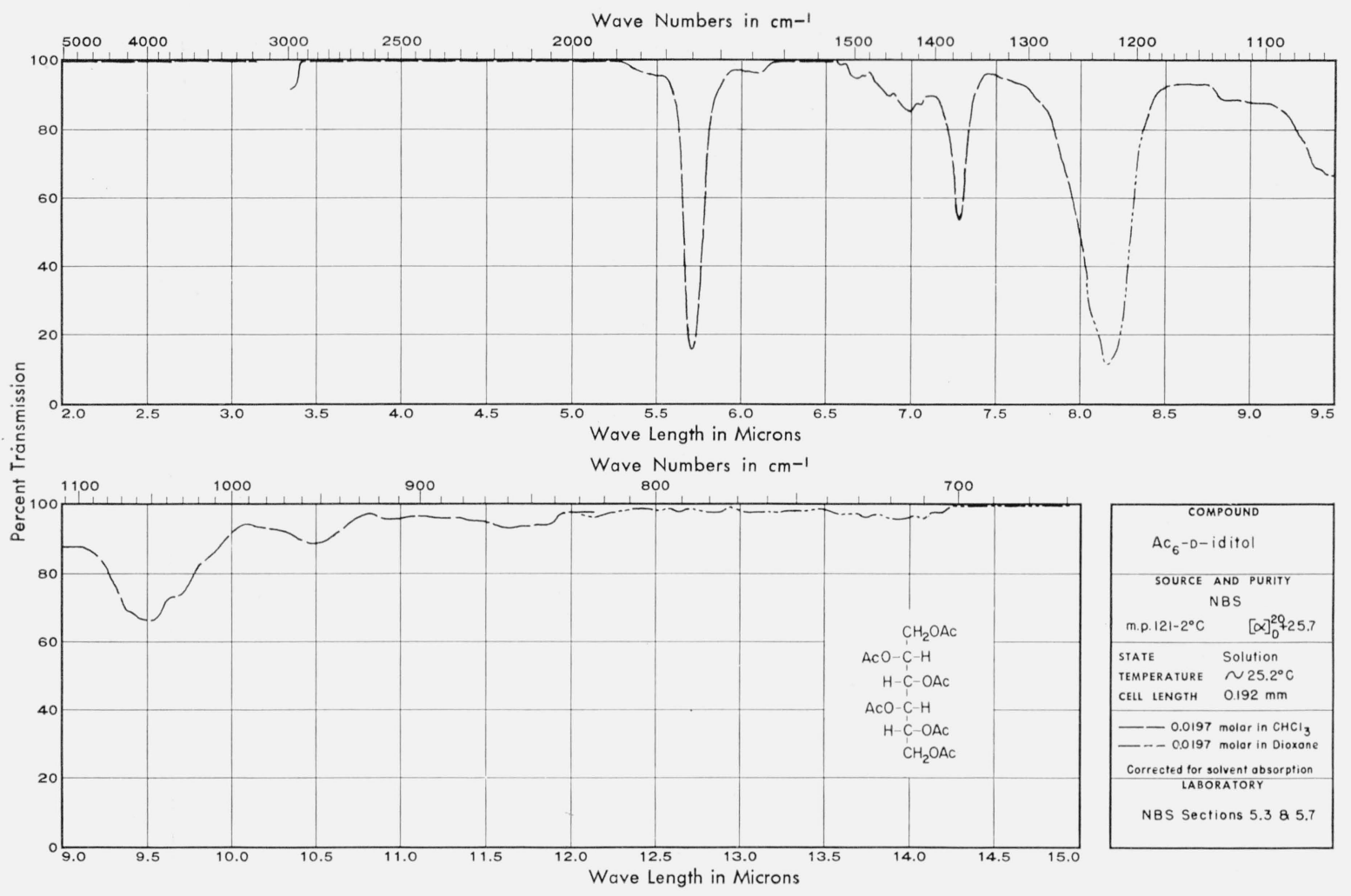

Figure 46.

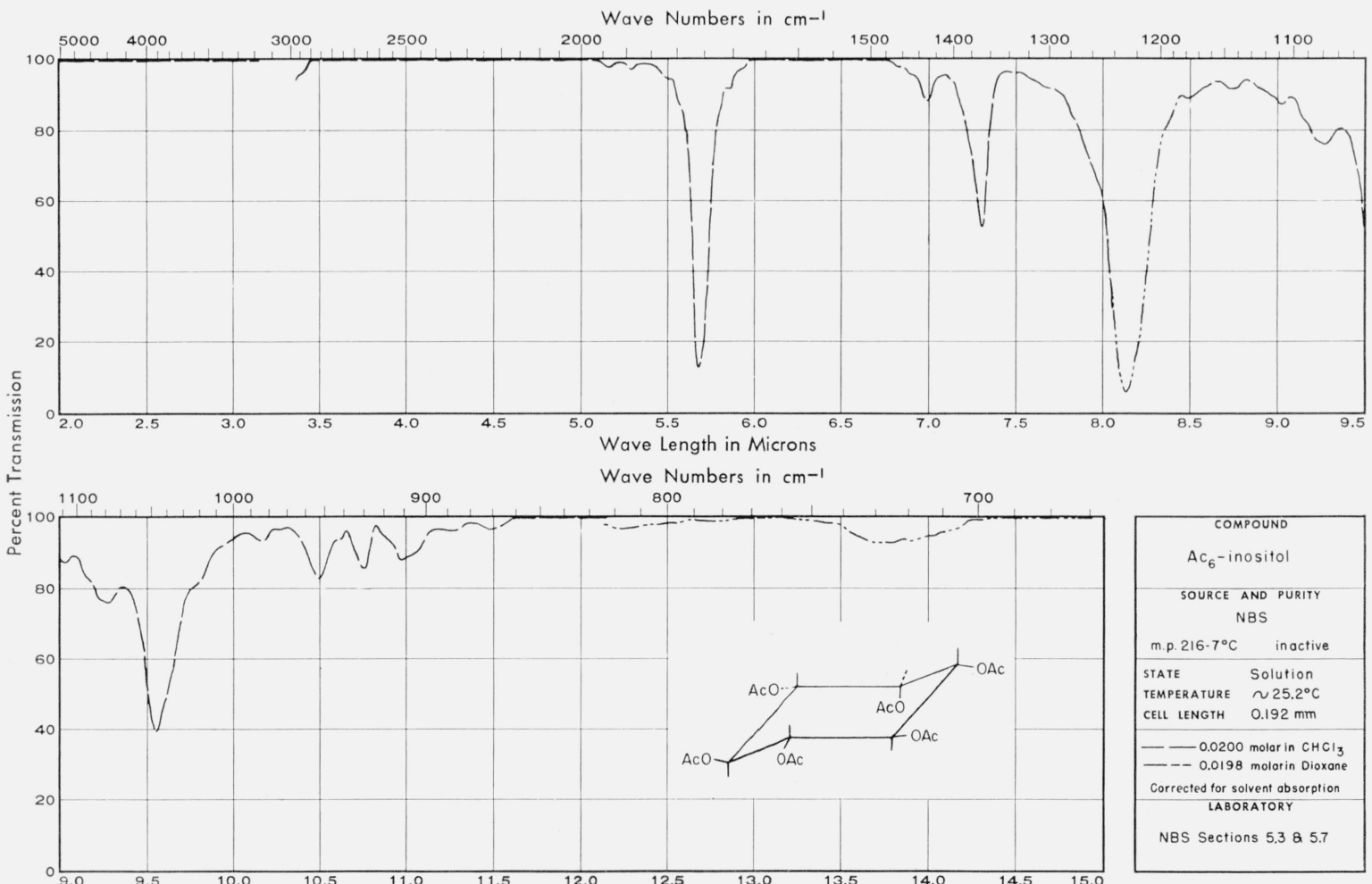

Figure 47. 


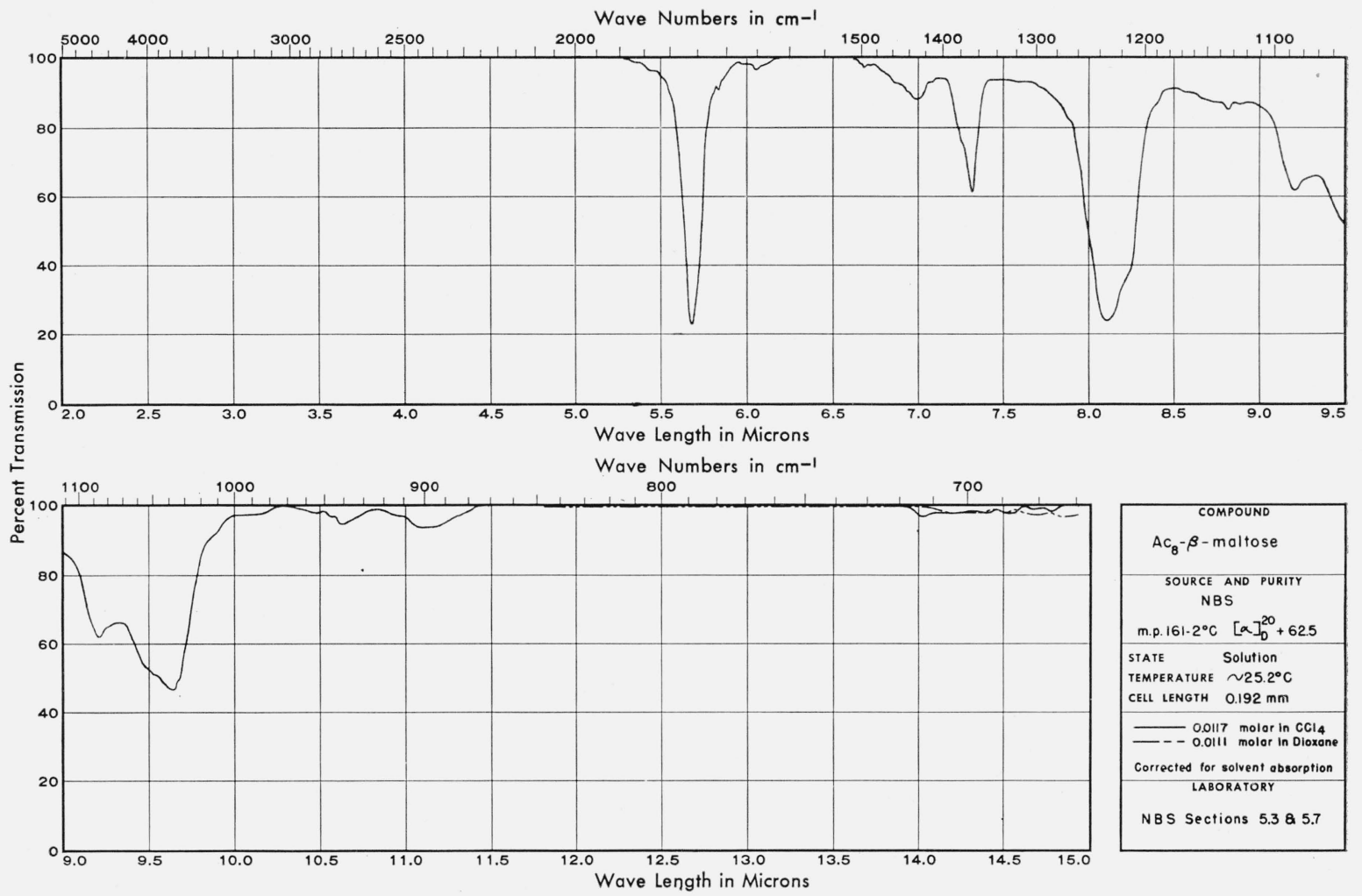

Figure 48.



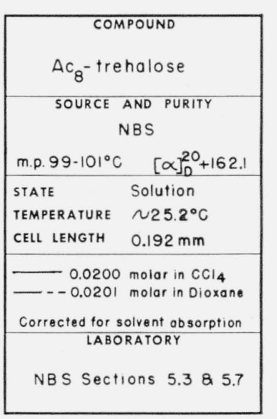

Figure 49. 


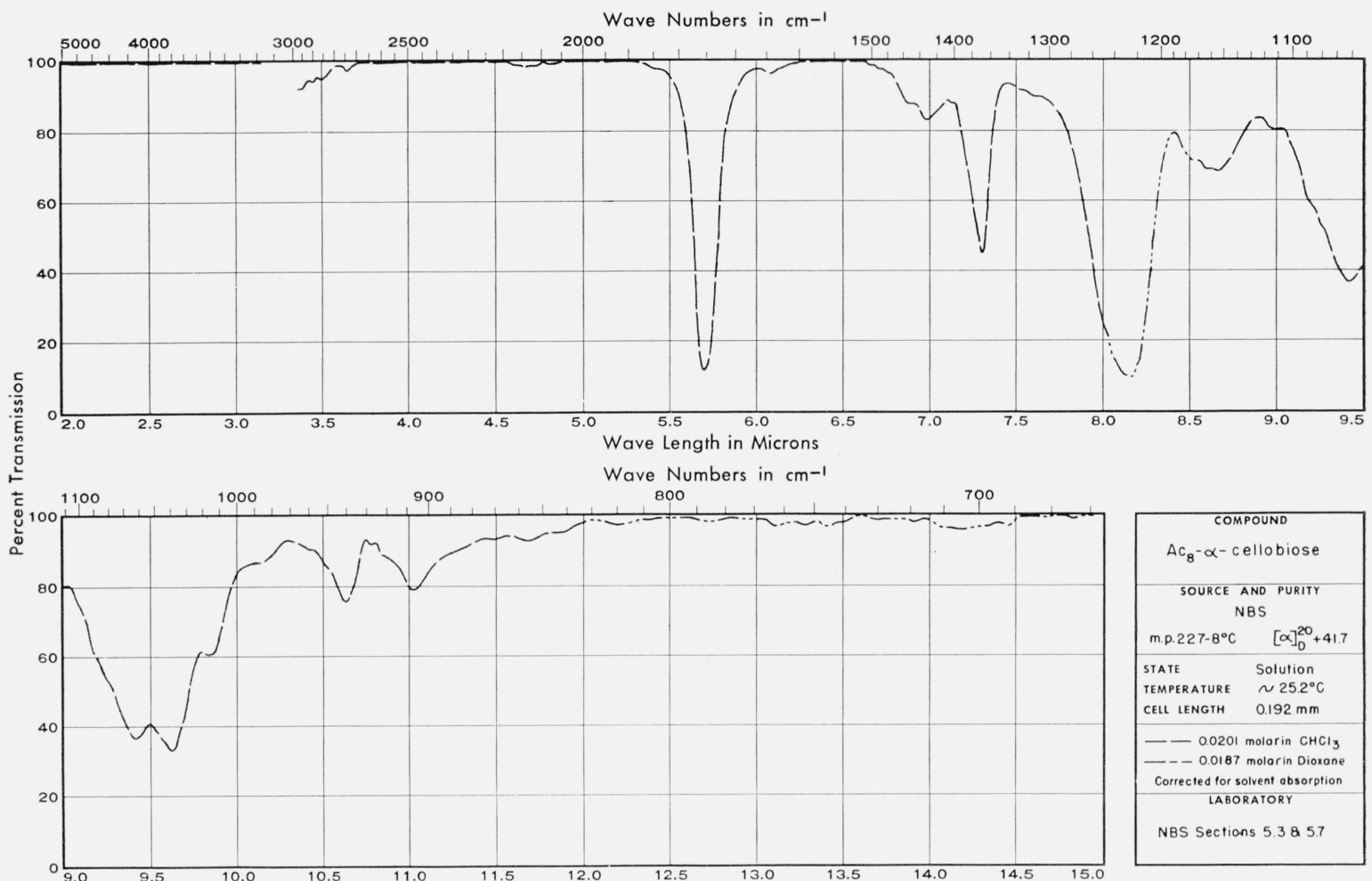

Wave Length in Microns

Figure 50.

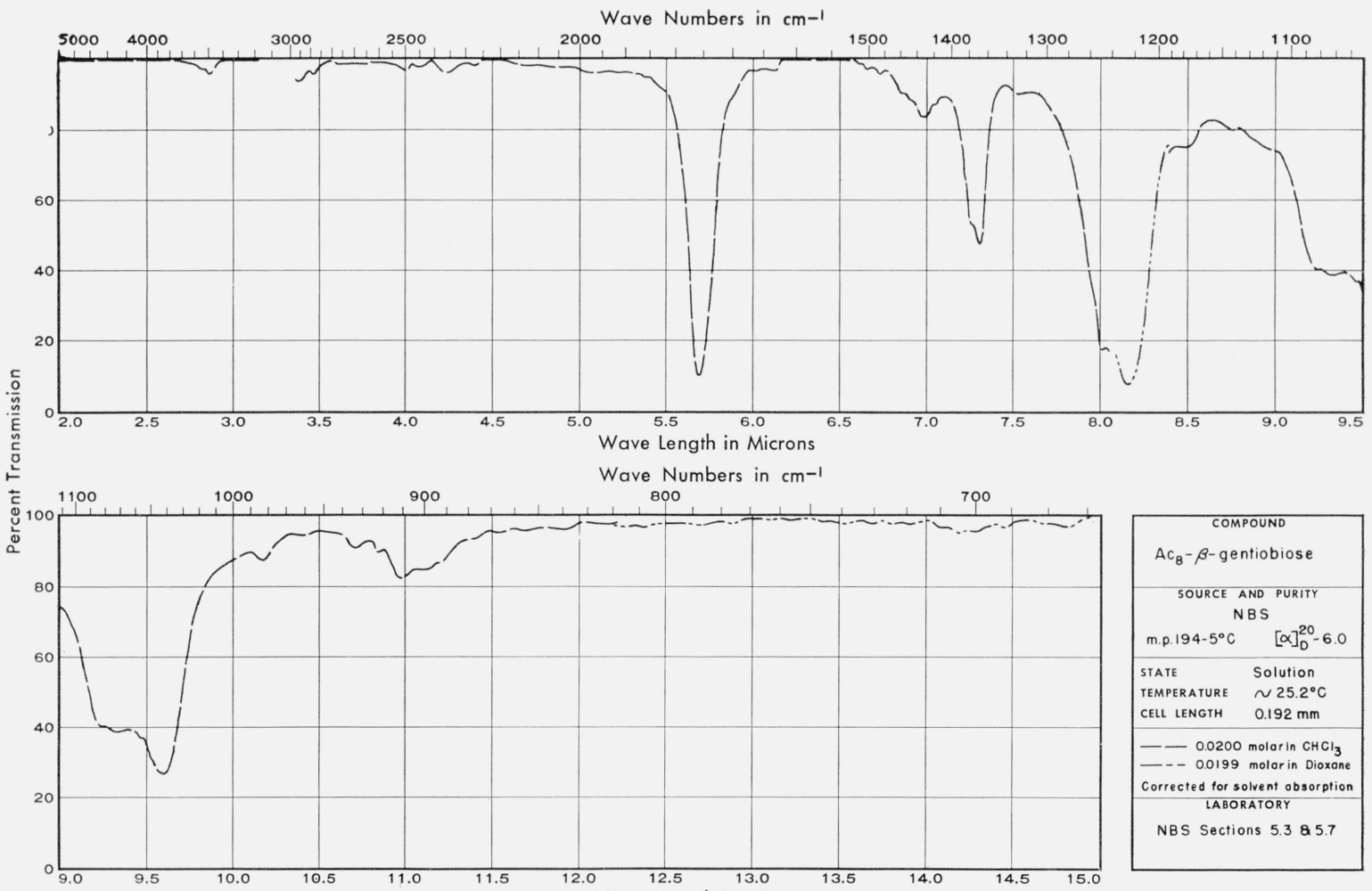

Figure 51. 


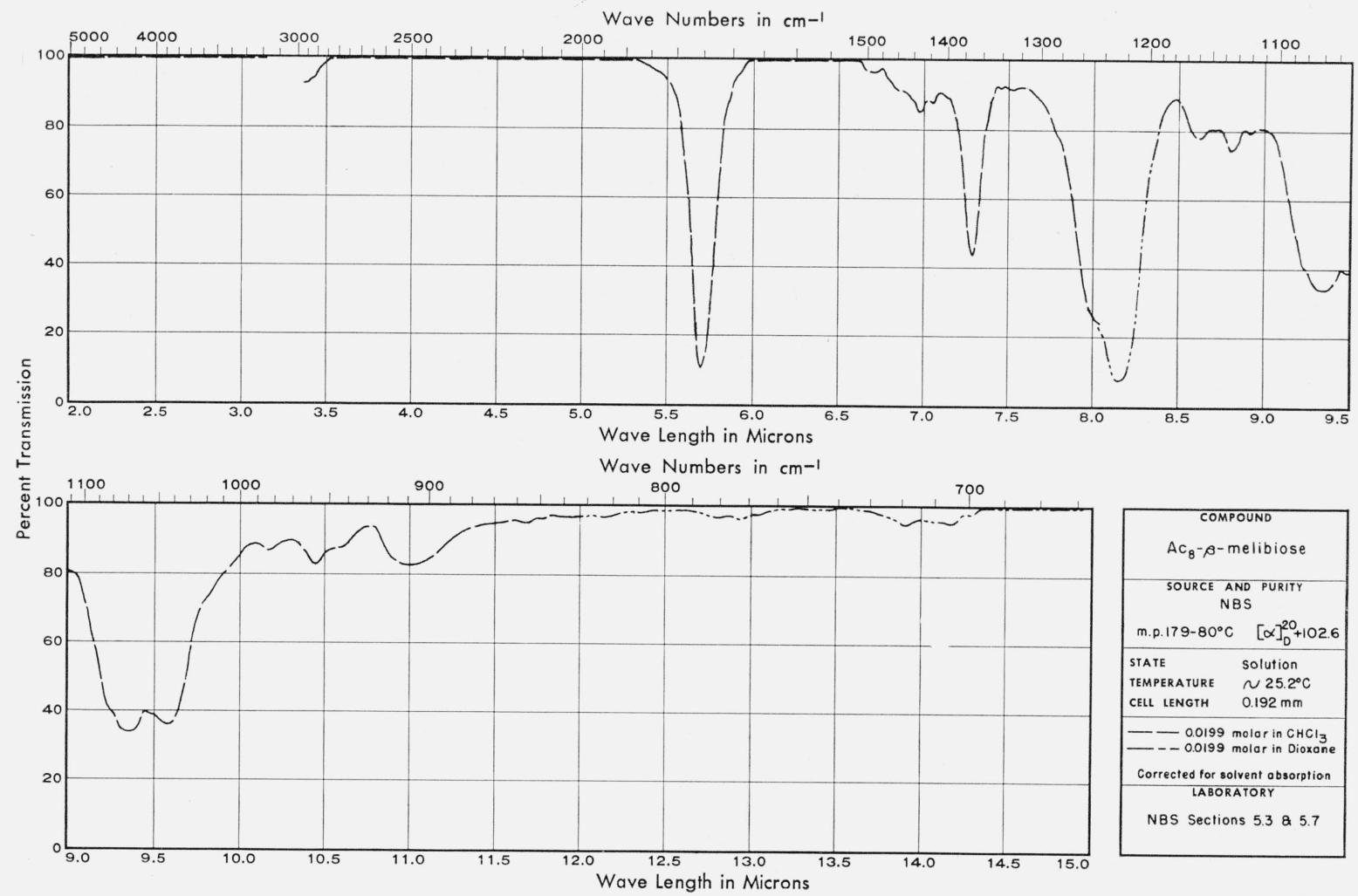

Figure 52.

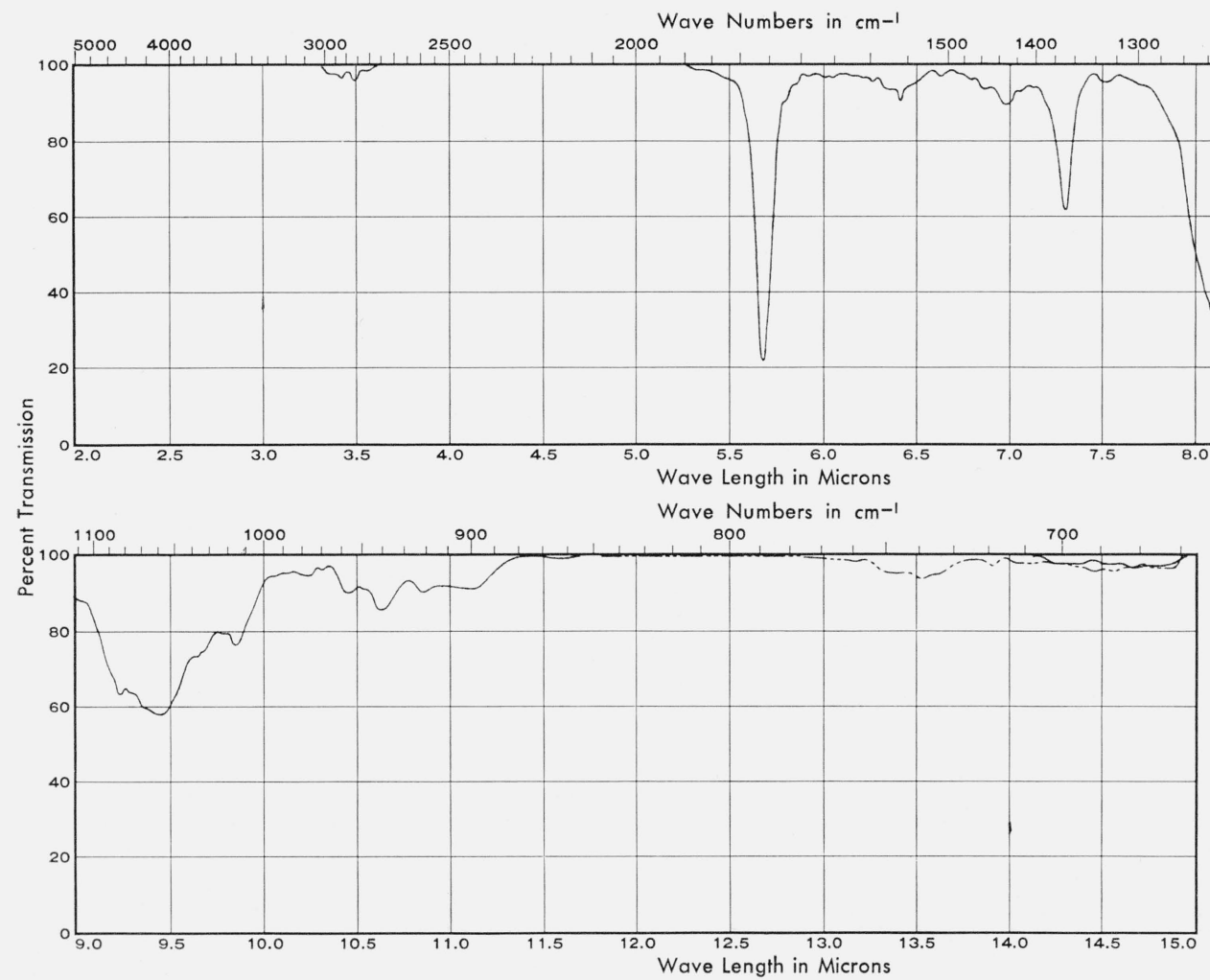

\begin{tabular}{|c|c|}
\hline \multicolumn{2}{|c|}{$\begin{array}{c}\text { COMPOUND } \\
A c_{8}-\alpha-\text { loctose }\end{array}$} \\
\hline \multicolumn{2}{|c|}{$\begin{array}{l}\text { SOURCE AND PURITY } \\
\text { NBS }\end{array}$} \\
\hline m.p. $155-6^{\circ} \mathrm{C}$ & {$[\alpha]_{0}^{20}+53.4$} \\
\hline \begin{tabular}{|l} 
STATE \\
TEMPERATURE \\
CELL LENGTH
\end{tabular} & $\begin{array}{l}\text { Solution } \\
\sim 25.2^{\circ} \mathrm{C} \\
0.192 \mathrm{~mm}\end{array}$ \\
\hline $\begin{array}{r}-0.0108 \\
--0.0171 \\
\text { corrected for s } \\
\text { LABOR }\end{array}$ & $\begin{array}{l}\text { nolarin } \mathrm{CCl}_{4} \\
\text { nolor in Dioxane } \\
\text { olvent absorption } \\
\text { ATORY }\end{array}$ \\
\hline NBS Secti & ns $5.3 \& 5.7$ \\
\hline
\end{tabular}

Figure 53. 


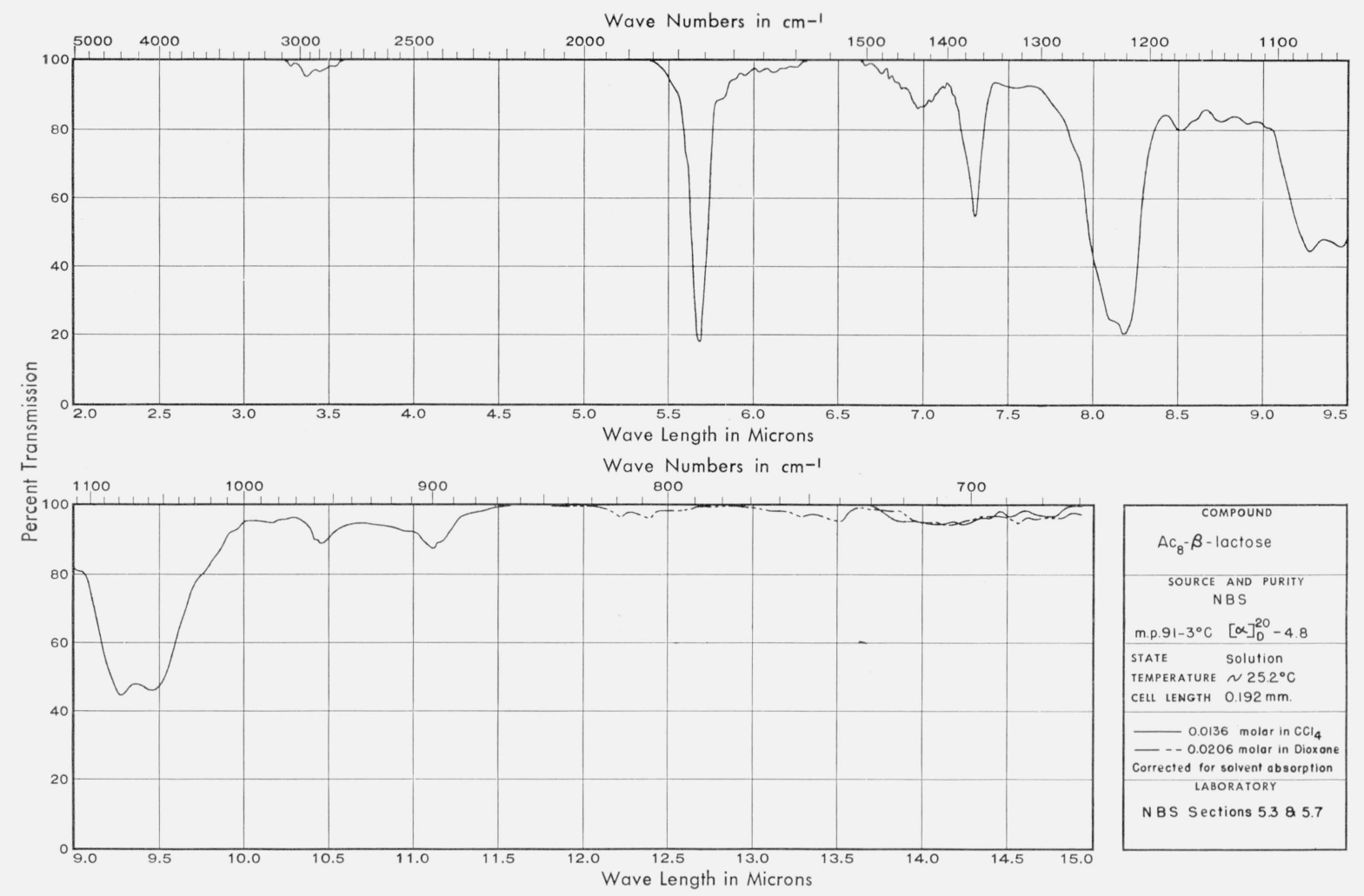

Figure 54.
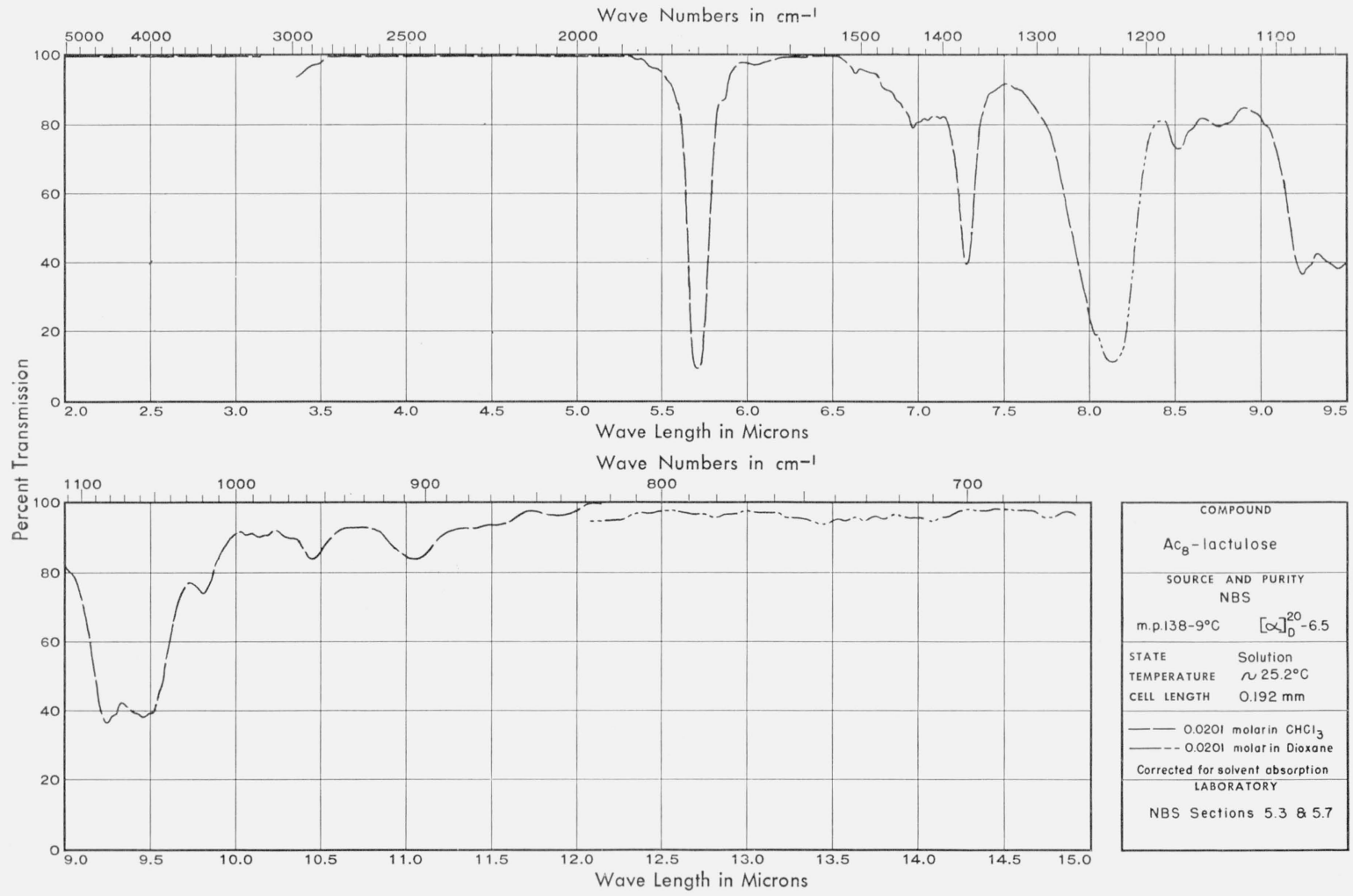

Figure 55. 


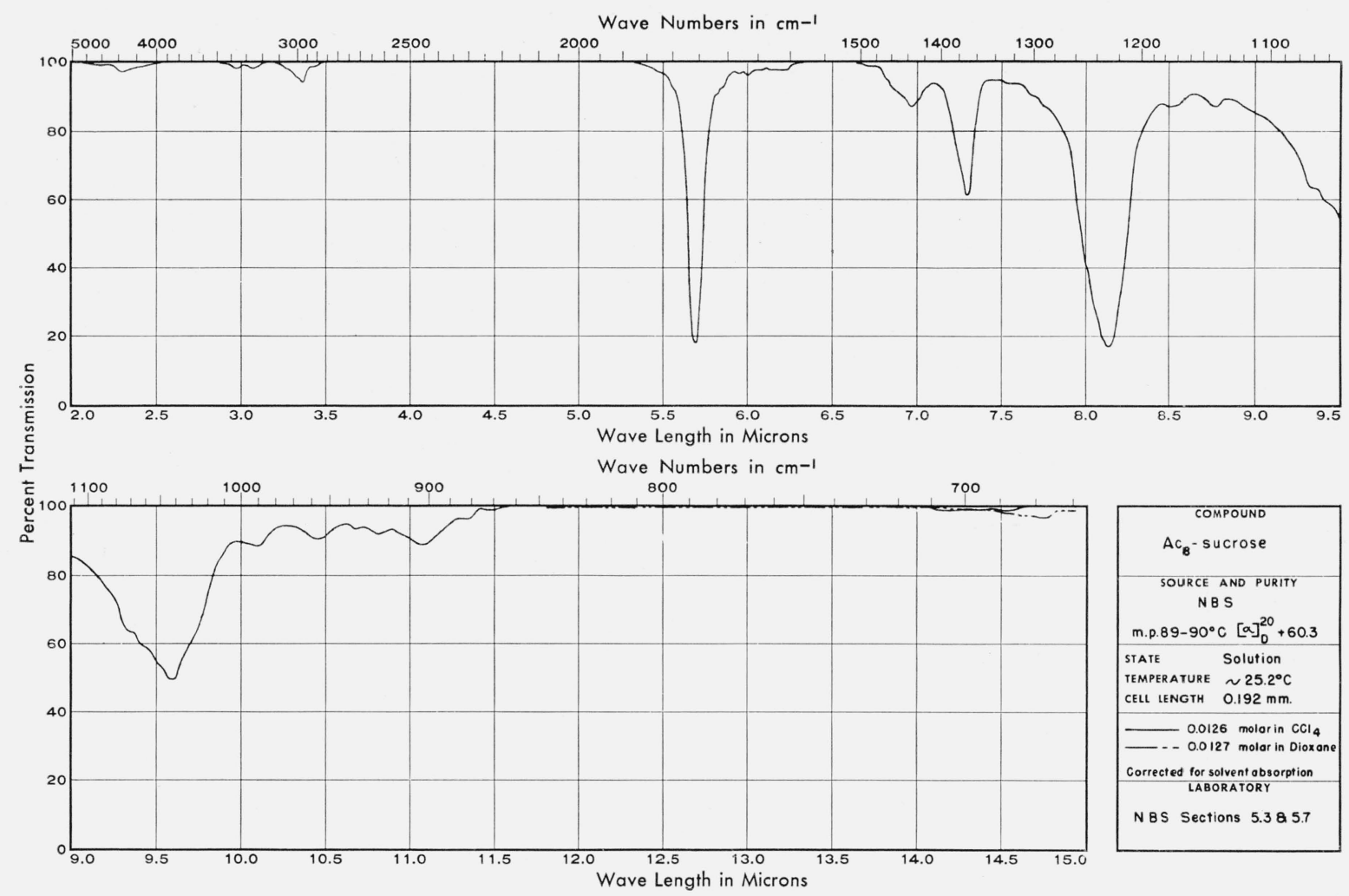

Figure 56.

Washington, December 19, 1956. 